Cochrane Database of Systematic Reviews

\title{
Benzodiazepines for the relief of breathlessness in advanced malignant and non-malignant diseases in adults (Review)
}

Simon ST, Higginson IJ, Booth S, Harding R, Weingärtner V, Bausewein C

Simon ST, Higginson IJ, Booth S, Harding R, Weingärtner V, Bausewein C.

Benzodiazepines for the relief of breathlessness in advanced malignant and non-malignant diseases in adults.

Cochrane Database of Systematic Reviews 2016, Issue 10. Art. No.: CD007354.

DOI: 10.1002/14651858.CD007354.pub3.

www.cochranelibrary.com 
TABLE OF CONTENTS

HEADER 1

ABSTRACT

PLAIN LANGUAGE SUMMARY

BACKGROUND

OBJECTIVES

METHODS

RESULTS

Figure 1.

Figure 2.

Figure 3.

Figure 4.

Figure 5.

Figure 6.

DISCUSSION

AUTHORS' CONCLUSIONS

ACKNOWLEDGEMENTS

REFERENCES

CHARACTERISTICS OF STUDIES

DATA AND ANALYSES

Analysis 1.1. Comparison 1 Overall, Outcome 1 Placebo-controlled/cross-over design.

Analysis 1.2. Comparison 1 Overall, Outcome 2 Morphine-controlled/parallel design.

Analysis 2.1. Comparison 2 Disease, Outcome 1 COPD.

Analysis 2.2. Comparison 2 Disease, Outcome 2 Cancer - placebo-controlled.

Analysis 2.3. Comparison 2 Disease, Outcome 3 Cancer - morphine-controlled.

Analysis 3.1. Comparison 3 Intervention, Outcome 1 Benzodiazepines - alprazolam.

Analysis 3.2. Comparison 3 Intervention, Outcome 2 Benzodiazepines - diazepam.

Analysis 3.3. Comparison 3 Intervention, Outcome 3 Benzodiazepines - midazolam.

Analysis 3.4. Comparison 3 Intervention, Outcome 4 Benzodiazepines - temazepam.

Analysis 3.5. Comparison 3 Intervention, Outcome 5 Benzodiazepines - ultra short-acting.

Analysis 3.6. Comparison 3 Intervention, Outcome 6 Benzodiazepines - intermediate-acting.

Analysis 3.7. Comparison 3 Intervention, Outcome 7 Benzodiazepines - long-acting.

Analysis 3.8. Comparison 3 Intervention, Outcome 8 Benzodiazepines - short duration of treatment ( $\leqq 24$ hours).

Analysis 3.9. Comparison 3 Intervention, Outcome 9 Benzodiazepines - long duration of treatment (5 to 14 days).

Analysis 3.10. Comparison 3 Intervention, Outcome 10 Benzodiazepines - morphine + midazolam-controlled.

Analysis 3.11. Comparison 3 Intervention, Outcome 11 Benzodiazepines - promethazine-controlled.

Analysis 4.1. Comparison 4 Primary outcome, Outcome 1 Breathlessness - no relief (placebo-controlled).

Analysis 4.2. Comparison 4 Primary outcome, Outcome 2 Breathlessness - no relief (morphine-controlled).

Analysis 4.3. Comparison 4 Primary outcome, Outcome 3 Breathlessness - episodic after 48 hours.

Analysis 4.4. Comparison 4 Primary outcome, Outcome 4 Breathlessness - episodic after 24 hours.

Analysis 5.1. Comparison 5 Secondary outcomes, Outcome 1 Adverse effects (placebo-controlled).

Analysis 5.2. Comparison 5 Secondary outcomes, Outcome 2 Adverse effects (morphine-controlled).

Analysis 5.3. Comparison 5 Secondary outcomes, Outcome 3 Adverse effects - clinical relevance only (morphine-controlled). ..

Analysis 5.4. Comparison 5 Secondary outcomes, Outcome 4 Adverse effects - drowsiness and somnolence only (placebocontrolled).

Analysis 5.5. Comparison 5 Secondary outcomes, Outcome 5 Adverse effects - drowsiness and somnolence only (morphinecontrolled).

Analysis 5.6. Comparison 5 Secondary outcomes, Outcome 6 Attrition (placebo-controlled).

Analysis 5.7. Comparison 5 Secondary outcomes, Outcome 7 Attrition (morphine-controlled).

Analysis 5.8. Comparison 5 Secondary outcomes, Outcome 8 Deaths (placebo-controlled). 
[Intervention Review]

\section{Benzodiazepines for the relief of breathlessness in advanced malignant and non-malignant diseases in adults}

Steffen T Simon 1,2,3, Irene J Higginson³, Sara Booth4, Richard Harding33, Vera Weingärtner², Claudia Bausewein 5

1Institute of Palliative Care (ipac), Oldenburg, Germany. 2Department of Palliative Medicine, University Hospital of Cologne, Cologne, Germany. ${ }^{3}$ Department of Palliative Care, Policy and Rehabilitation, Cicely Saunders Institute, King's College London, London, UK. ${ }^{4}$ Department of Palliative Care, Cambridge University Hospitals, Cambridge, UK. ${ }^{5}$ Department of Palliative Medicine, Munich University Hospital, LMU Munich, Munich, Germany

Contact address: Steffen T Simon, Institute of Palliative Care (ipac), Jägerstr. 64-66, Oldenburg, 26121, Germany. steffen@steffensimon.de.

Editorial group: Cochrane Pain, Palliative and Supportive Care Group.

Publication status and date: Stable (no update expected for reasons given in 'What's new'), published in Issue 10, 2016.

Citation: Simon ST, Higginson IJ, Booth S, Harding R, Weingärtner V, Bausewein C. Benzodiazepines for the relief of breathlessness in advanced malignant and non-malignant diseases in adults. Cochrane Database of Systematic Reviews 2016, Issue 10. Art. No.: CD007354. DOI: 10.1002/14651858.CD007354.pub3.

Copyright @ 2016 The Cochrane Collaboration. Published by John Wiley \& Sons, Ltd.

\section{A B S T R A C T}

\section{Background}

This is an updated version of the original Cochrane review published in Issue 1, 2010, on 'Benzodiazepines for the relief of breathlessness in advanced malignant and non-malignant diseases in adults'. Breathlessness is one of the most common symptoms experienced in the advanced stages of malignant and non-malignant disease. Benzodiazepines are widely used for the relief of breathlessness in advanced diseases and are regularly recommended in the literature. At the time of the previously published Cochrane review, there was no evidence for a beneficial effect of benzodiazepines for the relief of breathlessness in people with advanced cancer and chronic obstructive pulmonary disease (COPD).

\section{Objectives}

The primary objective of this review was to determine the efficacy of benzodiazepines for the relief of breathlessness in people with advanced disease. Secondary objectives were to determine the efficacy of different benzodiazepines, different doses of benzodiazepines, different routes of application, adverse effects of benzodiazepines, and the efficacy in different disease groups.

\section{Search methods}

This is an update of a review published in 2010. We searched 14 electronic databases up to September 2009 for the original review. We checked the reference lists of all relevant studies, key textbooks, reviews, and websites. For the update, we searched CENTRAL, MEDLINE, and EMBASE and registers of clinical trials for further ongoing or unpublished studies, up to August 2016. We contacted study investigators and experts in the field of palliative care asking for further studies, unpublished data, or study details when necessary.

\section{Selection criteria}

We included randomised controlled trials (RCTs) and controlled clinical trials (CCTs) assessing the effect of benzodiazepines compared with placebo or active control in relieving breathlessness in people with advanced stages of cancer, chronic obstructive pulmonary disease (COPD), chronic heart failure (CHF), motor neurone disease (MND), and idiopathic pulmonary fibrosis (IPF). 


\section{Data collection and analysis}

Two review authors independently assessed identified titles and abstracts. Three review authors independently performed assessment of all potentially relevant studies (full text), data extraction, and assessment of methodological quality. We carried out meta-analysis where appropriate.

\section{Main results}

Overall, we identified eight studies for inclusion: seven in the previous review and an additional study for this update. We also identified two studies awaiting classification in this update. The studies were small (a maximum number of 101 participants) and comprised data from a total of 214 participants with advanced cancer or COPD, which we analysed. There was only one study of low risk of bias. Most of the studies had an unclear risk of bias due to lack of information on random sequence generation, concealment, and attrition. Analysis of all studies did not show a beneficial effect of benzodiazepines for the relief of breathlessness (the primary outcome) in people with advanced cancer and COPD (8 studies, 214 participants) compared to placebo, midazolam, morphine, or promethazine. Furthermore, we observed no statistically significant effect in the prevention of episodic breathlessness (breakthrough dyspnoea) in people with cancer (after 48 hours: risk ratio of 0.76 (95\% Cl 0.53 to 1.09; 2 studies, 108 participants)) compared to morphine. Sensitivity analyses demonstrated no statistically significant differences regarding type of benzodiazepine, dose, route and frequency of delivery, duration of treatment, or type of control. Benzodiazepines caused statistically significantly more adverse events, particularly drowsiness and somnolence, when compared to placebo (risk difference 0.74 (95\% Cl 0.37, 1.11); 3 studies, 38 participants). In contrast, two studies reported that morphine caused more adverse events than midazolam (RD - 0.18 ( $95 \% \mathrm{Cl}-0.31,-0.04) ; 194$ participants).

\section{Authors' conclusions}

Since the last version of this review, we have identified one new study for inclusion, but the conclusions remain unchanged. There is no evidence for or against benzodiazepines for the relief of breathlessness in people with advanced cancer and COPD. Benzodiazepines caused more drowsiness as an adverse effect compared to placebo, but less compared to morphine. Benzodiazepines may be considered as a second- or third-line treatment, when opioids and non-pharmacological measures have failed to control breathlessness. There is a need for well-conducted and adequately powered studies.

\section{PLAIN LANGUAGE SUMMARY}

\section{Benzodiazepines for the relief of breathlessness in advanced diseases in adults}

\section{Background}

Breathlessness is a common and distressing symptom in advanced cancer and other diseases at the end of life. Treating breathlessness sufficiently remains very difficult. Benzodiazepines are a group of sedating medicines (drugs), including lorazepam, clorazepate, diazepam, alprazolam, and temazepam, that are used mainly for sleep disturbance and anxiety, but are widely used for the relief of breathlessness.

\section{Key results}

In this updated systematic review we aimed to determine whether benzodiazepines relieved breathlessness in adults with advanced disease. In August 2016, we found eight studies.

Benzodiazepines caused more side effects such as drowsiness or somnolence when compared to placebo but caused less side effects when compared to morphine. Our review therefore supports the use of benzodiazepines only if other first-line treatments, such as opioids and non-drug treatments, have failed. However, there is still an urgent need for more studies in this field to find better ways to relieve this burdensome symptom in people with advanced diseases.

We concluded in summary that there is no evidence that benzodiazepines relieve breathlessness in adults with advanced disease. 


\section{B A C K G R O U N D}

This review is an update of a previously published review in the Cochrane Database of Systematic Reviews, Issue 1, 2010, on 'Benzodiazepines for the relief of breathlessness in advanced malignant and non-malignant diseases in adults'.

\section{Description of the condition}

The American Thoracic Society defines breathlessness as "a subjective experience of breathing discomfort that consists of qualitatively distinct sensations that vary in intensity. The experience derives from interactions among multiple physiological, psychological, social, and environmental factors, and may induce secondary physiological and behavioral responses" (Parshall 2012). This multidimensional concept of breathlessness as 'total breathlessness' is comparable with the concepts of 'total pain' or 'total suffering' (Booth 2006). The term 'breathlessness' is used interchangeably with dyspnoea, shortness of breath, breathing difficulty, and laboured breathing. Breathlessness is defined as refractory when it persists despite optimal treatment of the underlying condition (Dorman 2009), and can manifest as continuous breathlessness or episodic breathlessness (Simon 2012; Simon 2014).

Breathlessness is one of the most common symptoms in the last year of life (Higginson 2004). In advanced diseases, it is highly prevalent in chronic obstructive pulmonary disease (COPD) $56 \%$ to $98 \%$ ), chronic heart failure (CHF) (18\% to $88 \%)$, and cancer (16\% to $77 \%$ ) (Moens 2014). It is a distressing symptom for the patient, but also for the caregivers (Nordgren 2003). The frequency and severity of breathlessness increases during the course of the disease until death (Currow 2010; Seow 2011). Furthermore, breathlessness may be related to anxiety and depression (Neuman 2006), thus treatment of anxiety and depression may reduce this symptom. However, the contribution, the causal relationship, and the direction of influence are still unclear (Booth 2008).

Different diseases cause breathlessness, such as primary and secondary cancer, COPD, CHF, motor neurone disease (MND), and cryptogenic fibrosing alveolitis/idiopathic pulmonary fibrosis (IPF). The advanced stage of each disease must be defined separately because of the different disease trajectories. The pathophysiology of breathlessness depends mainly on the underlying cause. It includes, for example, airway obstruction, reduction of lung or gas exchange capacity, muscle weakness, degeneration of neurons, or reduction of blood diffusing capacity. The pathological pathway is complex and beyond a sole reduction of $\mathrm{PO}_{2}$ (partial pressure of oxygen) or increase of $\mathrm{PCO}_{2}$ (partial pressure of carbon dioxide) (Manning 1995). The medulla in the brain stem, the motor and sensory cortex, peripheral and central chemoreceptors, and mechanoreceptors in the airways and chest wall are the main sites of action responsible for the perception of breathlessness (Booth 2008). There are different explanations of how different parts interact and induce the sensation of breathlessness, such as corollary discharge, afferent-reafferent dissociation, and receptor reaction. The corollary discharge describes the hypothesis that a sensory 'copy' of the motor output is sent from the motor cortex to the sensory cortex and imparts a conscious awareness of respiratory effort, and is the most widely accepted hypothesis (Beach 2006).
After treatment of the underlying cause, symptom management of breathlessness includes non-pharmacological and pharmacological interventions. A recent Cochrane Review on nonpharmacological interventions for the relief of breathlessness in advanced disease showed effectiveness of neuro-electrical muscle stimulation, chest wall vibration, walking aids, and breathing training (Bausewein 2008). A recent review on the use of oxygen highlights that there is a statistically and clinically significant benefit for both ambulatory and long-term oxygen in COPD, but no consistent evidence for their use in cancer (Cranston 2008).

Opioids are the first choice in the pharmacological management of refractory breathlessness. A Cochrane Review showed evidence for the use of oral and parenteral application of opioids, but there is currently no evidence for nebulised opioids (Jennings 2001; Parshall 2012). However, most of the studies were underpowered, and there is a need for further well-designed studies to investigate the effectiveness in different diseases, applications, and doses. Besides opioids, there are other drugs for the palliation of breathlessness, such as steroids (for lymphangitis carcinomatosa), inhaled local anaesthetics, or more sedating drugs such as benzodiazepines, phenothiazines, buspirone, or chlorpromazine, with variable evidence in symptom control (Davis 2005; Parshall 2012).

\section{Description of the intervention}

Benzodiazepines are frequently used in the management of breathlessness in advanced diseases and are regularly recommended in textbooks for palliative medicine or clinical guidelines (Booth 2006; Bruera 2006). The most common drugs are diazepam, midazolam, alprazolam, and lorazepam. However, there are more than 40 different benzodiazepines (Hardman 2005).

\section{How the intervention might work}

It is increasingly evident that breathlessness interacts with mental health, for example anxiety and depression and anxiety or panic can trigger or worsen breathlessness (Booth 2008; Davis 1997). Benzodiazepines are anxiolytics, which have sedating effects and are intended to relieve anxiety and might therefore have palliating effects for breathlessness.

Benzodiazepines belong to the group of hypnotics and sedatives. Their core chemical structure is a fusion of the benzene and the diazepine ring with various modifications that are responsible for the different compounds of the drug. The interaction of benzodiazepines with specific subunits of GABA (gamma-aminobutyric acid) receptors is responsible for their mechanism of action. The central and main effects of benzodiazepines are sedative-hypnotic, muscle-relaxant, anxiolytic, and anticonvulsant. Side effects include impairment of mental and motor function, light-headedness, and nausea (Hardman 2005). Physical dependence is a huge problem in longterm use of benzodiazepines. There is no effect on respiration (for example depression of respiration) in normal doses, and only a slight depression of ventilation in higher doses (Hardman 2005). The main therapeutic uses are insomnia, anxiety disorders, acute epilepsy, alcohol withdrawal, and anaesthetic premedication (Hardman 2005). The group of non-benzodiazepines (for example zolpidem) act on the same receptors with similar effects, but have a different chemical structure. We have not included these in this review as they do not belong to the benzodiazepine group. 


\section{Why it is important to do this review}

Despite the frequent use of benzodiazepines for the relief of breathlessness in palliative care, the evidence for their efficacy is still unclear.

\section{O B JECTIVES}

The primary objective of this review was to determine the efficacy of benzodiazepines for the relief of breathlessness in people with advanced disease.

Secondary objectives were to determine the efficacy of different benzodiazepines, different doses of benzodiazepines, different routes of application, adverse effects of benzodiazepines, and the efficacy in different disease groups.

\section{METHODS}

\section{Criteria for considering studies for this review}

Types of studies

- Randomised controlled trials (RCTs). We defined 'randomised' as studies described by the authors as 'randomised' anywhere in the manuscript.

- Controlled clinical trials (CCTs).

While writing the protocol, we expected a limited number of studies and therefore decided also to include controlled trials, giving special consideration to the higher risk of bias in these trials in the analysis.

\section{Types of participants}

Adult participants described as suffering from either breathlessness, dyspnoea, shortness of breath, difficult breathing, or laboured breathing due to advanced malignant and nonmalignant diseases.

The advanced stages of diseases included the following.

- Cancer: advanced local or metastatic disease.

- COPD: stage III (severe) or IV (very severe) according to the Global Initiative for Obstructive Lung Disease (GOLD) classification. This includes people with airflow limitation of FEV $1<50 \%$, FEV1/FVC $<0.7$ (FEV1: forced expiratory volume in one second; FVC: forced vital capacity) and symptoms such as more severe breathlessness, reduced exercise capacity, and repeated exacerbations (GOLD 2007).

- CHF: stage III or IV of the New York Heart Association (NYHA) classification including symptoms such as breathlessness or palpitation and an increasing limitation of exercise capacity and discomfort at rest.

- MND: all participants suffering from breathlessness.

- IPF: all participants suffering from breathlessness as the most prominent and disabling symptom.

We excluded studies including participants with acute or chronic asthma, pneumonia, or other potentially curable diseases. Participants included in the studies could be in any care setting (for example hospital or home care).

We included studies evaluating participants on oxygen as long as oxygen was used in both the intervention and the control arm.

\section{Types of interventions}

The use of benzodiazepines (at any dose, any frequency (also single dose), any duration, and through any route) for the relief of breathlessness compared with placebo or active control. We included all drugs that belong to the pharmacological group of benzodiazepines (Hardman 2005).

\section{Types of outcome measures}

\section{Primary outcomes}

Primary outcomes included subjective measurements of breathlessness on validated and reliable scales such as:

- uni-dimensional scales (e.g. visual analogue scales (VAS), numeric rating scales (NRS), categorical scales, modified Borg scales); or

- multidimensional scales (e.g. St. George's Respiratory Questionnaire (SGRQ), Chronic Respiratory Disease Questionnaire (CRQ)).

We included studies that measured breathlessness as a primary or secondary outcome, and also studies evaluating breathlessness at rest or on exercise.

\section{Secondary outcomes}

Secondary outcomes included:

1. measurement of anxiety;

2. measurement of depression;

3. adverse effects of benzodiazepines;

4. functional exercise capacity (e.g. walking tests);

5. measurement of quality of life; and

6. attrition.

\section{Search methods for identification of studies}

We ran the search for the original review on 12 September 2009 and ran a subsequent search on 23 August 2016.

\section{Electronic searches}

For the original review, we identified studies from a search of the following 14 databases:

- the Cochrane Pain, Palliative and Supportive Care Trials Register (12 September 2009);

- the Cochrane Central Register of Controlled Trials (CENTRAL) in the Cochrane Library (2009, Issue 3) (12 September 2009);

- the Cochrane Database of Systematic Reviews (CDSR) in the Cochrane Library (12 September 2009);

- Database of Abstracts of Reviews of Effects (DARE) (12 September 2009);

- MEDLINE (1950 to 12 September 2009);

- EMBASE (1980 to 12 September 2009);

- CINAHL (1980 to 12 September 2009);

- PsycINFO (1806 to 12 September 2009);

- American College of Physicians (ACP) Journal Club (12 September 2009);

- Health Technology Assessment (HTA) Database (12 September 2009); 
- NHS Economic Evaluation Database (NHSEED) (12 September 2009);

- Database of Halley Stewart Library (St. Christopher's Hospice) (12 September 2009);

- International Pharmaceutical Abstracts (1970 to 12 September 2009); and

- lowa Drug Information System (IDIS) (1966 to 12 September 2009).

For the update, we searched:

- CENTRAL Issue 72016 (the Cochrane Library) (searched 2009 to 2016);

- MEDLINE \& Medline in Process (OVID) (Sept 2009 to 23 August 2016);

- EMBASE (OVID) (September 2009 to 23 August 2016).

We decided not to search the other databases searched for the original review as they did not yield any useful records.

We searched the following study registers or meta registers of clinical trials for ongoing or unpublished studies for the update:

- ClinicalTrials.gov (08 July 2016);

- metaRegister of Controlled trials (mRCT) - active registers (08 July 2016);

- WHO International Clinical Trials Registry Platform (08 July 2016).

We again contacted study investigators and experts in the field of palliative care to ask for further studies, unpublished data, or study details when necessary.

Please see Appendix 1 for the search strategies applied in the original review. Appendix 2 shows the search strategies applied in this update, with minor changes in lines 3 and 5 (in line 3 to ensure that both British and US spellings of labour/labor were picked up; in line 5 to ensure that both of the phrases 'shortness of breath' and 'short of breath' were included).

\section{Searching other resources}

\section{Handsearching}

We checked the reference lists of all relevant studies, key textbooks, and key websites for further relevant studies. We checked the reference lists of several reviews on the subject (Abernethy 2008; Allen 1984; Altose 1985; Bausewein 2008; Booth 2008; Davis 1997; De Conno 1991; Lanken 2008; Manning 2000; Ripamonti 1999; Rocker 2007; Runo 2001; Thomas 2002; Tobin 1990; Viola 2008; Williams 2006).

We handsearched the reference lists of the following 16 textbooks: Goodman and Gilman's The Pharmacological Basis of Therapeutics; Oxford Textbook of Palliative Medicine; Textbook of Palliative Medicine; Textbook of Palliative Nursing; Palliative Medicine; Management of Advanced Disease;Palliative Care Formulary 3; Oxford Handbook of Palliative Care; Palliative Medicine - a CaseBased Manual; Principles and Practice of Palliative Care and Supportive Oncology; Dyspnoea in Advanced Disease; Dyspnoea Heart Failure and Palliative Care; Supportive Care in Respiratory Disease; Textbook of Respiratory Medicine; and Palliative Care in Neurology.
In addition, we searched seven websites to identify relevant data: www.benzo.org.uk; www.book.palliative.info; www.caresearch.com.au; www.controlled-trials.com; www.patient.co.uk.

We undertook no further handsearches for this review update.

\section{Personal contact}

We contacted the following authors of main studies and investigators who are known to be carrying out research in this area for further studies and unpublished data for the original review: Amy Abernethy, Sam Ahmedzai, Eduardo Bruera, Leandro Cerchietti, Jessica Corner, David Currow, Carol Davies, Deborah Dudgeon, Wesley Ely, Tim Harrison, Michio Hosaka, Miriam Johnson, Alfredo Navigante, Andrew Wilcock, and Ashley Woodcock. In addition, we asked all members of the Association of Palliative Medicine (UK) and all users of the bulletin board of www.palliativedrugs.com in a circular letter for additional studies or unpublished data. For the update, we contacted the above mentioned experts again and also asked the following newly identified study investigators for further information on their studies: Scott Bolesta, Eliza S. Daubert, Diana E. Hart, Neil K Hiliard, Fiona Horwood, Clare Randall, and Gerben Stege.

\section{Language}

There was no language restriction in the selection of studies.

\section{Data collection and analysis}

\section{Selection of studies}

Two review authors (STS, CB in the original review; VW, STS in the update) independently assessed the relevant titles and abstracts identified. Disagreement was resolved by consensus and with a third review author (IJH in the original review; $C B$ in the update). Three review authors (STS, CB, SB in the original review; VW, STS, CB in the update) independently assessed the full text of all potentially relevant studies, and disagreement at this stage was again resolved by consensus and with a fourth review author (IJH).

\section{Data extraction and management}

Three review authors (STS, CB, SB) independently extracted data from each appropriate study in the original review; two review authors (STS, VW) did this for the update. We specifically designed an extraction form for collection of relevant data consisting of:

Study ID and publication details, including:

- study aim.

Study design and methods, including:

- randomisation procedure;

- allocation concealment;

- details of blinding;

- number and time of follow-ups;

- handling of missing data; and

- details of analysis.

Participant characteristics, including: 
- demographics;

- diagnosis;

- performance status;

- number and description of participants in the intervention and control groups; and

- setting.

Intervention, including:

- the drug and its characteristics (e.g. half-life);

- route of administration;

- dose;

- frequency of application;

- duration of therapy; and

- description of placebo.

Primary outcomes, including:

- measurement of breathlessness; and

- change in level of breathlessness.

Secondary outcomes, including:

- adverse effects of benzodiazepines;

- functional exercise capacity;

- dose modification;

- number and reason of withdrawals/attrition;

- measurement of anxiety;

- measurement of depression;

- measurement of quality of life; and

- arterial blood gas measurements.

Additional information, including:

- participant comments on intervention.

Methodological quality, including:

- Risk of bias table (according to Cochrane standard);

- Edwards Method Score (11 items as described below).

We contacted authors of studies to provide unpublished data for the meta-analysis where required.

\section{Assessment of risk of bias in included studies}

Three review authors (STS, CB, SB in the original review; STS, VW in the update) independently assessed all selected studies for methodological quality. We used two measures of methodological quality. Firstly, we assessed the quality of studies using the Review Manager (RevMan) 'Risk of bias' table, categorising them as 'low risk', 'high risk', or 'unclear risk' according to the Cochrane Handbook for Systematic Reviews of Interventions (Higgins 2011; RevMan 2008; RevMan 2014). Secondly, we graded the quality of studies according to the Edwards Method Score (Edwards 2001; Edwards 2003). This checklist of methodological quality contains 11 items that assess the primary research quality of the studies and its published description. The following items were assessed and scored zero, one, or two for adequacy: definition of aims; sample formation; description of inclusion and exclusion criteria; description of participant characteristics; power calculation; objectivity of outcome measures used; adequacy of follow-up; adequacy of analysis (intention-to-treat (ITT)); adjustment for baseline differences between groups; appropriate unit of allocation to groups; and randomisation method. We then constructed a total method score $(\max 22)$ and rated the overall quality of the studies as follows: low (12 and under), medium (13 to 14), high (15 and over) (Edwards, personal communication). We integrated the results of the quality assessment in data analysis, as well as in meta-analysis (cumulative meta-analysis only in highquality studies).

\section{Measures of treatment effect}

We used primary and secondary outcomes in the meta-analysis when appropriate and possible. The primary outcome measures (breathlessness) were either in the form of continuous or ordinal data. We treated all ordinal data as continuous data because the scales used were long enough (following the recommendation of the Cochrane Handbook, Higgins 2011). In the meta-analysis, we treated studies with cross-over design in the same way as studies with a parallel design if there was no indication of a carry-over effect (following the advice of the Cochrane Handbook and after discussion with the statistician of the Cochrane Review Group) (Higgins 2011). We judged the potential existence of a carry-over effect on a theoretical basis after analysis of the study (for example drug persistency in the body into the next period). We estimated the effect by comparing the post-treatment measurements of the intervention and the control groups. We calculated the standardised mean differences (SMD) for continuous data with a $95 \%$ confidence interval $(\mathrm{CI})$ to show the size of the effect of interventions. Due to the diversity of measurement tools for breathlessness, we used SMD to measure the intervention effect in standardised units. A negative SMD was defined as a beneficial effect of the intervention. We calculated the risk ratio (RR) for dichotomous data to estimate the relative risk. We used risk difference when there was no event in one of the groups (for example for adverse effects or attrition), because the estimation of $\mathrm{RR}$ is not possible in this case. For all data we considered a $\mathrm{P}$ value of less than 0.05 as statistically significant.

\section{Unit of analysis issues}

We combined cross-over trials and studies with a parallel design in the meta-analysis and treated the cross-over studies as parallel design. We did this after a critical analysis of all studies, review of the literature (Elbourne 2002; Higgins 2011), discussion with a statistician, and the following judgements:

1. the cross-over design was suitable for the targeted research questions;

2. none of the cross-over studies showed evidence of a carry-over effect;

3. dropouts were excluded from analysis;

4. there was no evidence for a period effect. This approach can produce a unit-of-analysis error.

\section{Dealing with missing data}

When means and standard deviations (SD) were missing, we did not impute or estimate them for meta-analysis, because none of the suggested imputations in the Cochrane Handbook for Systematic Reviews of Interventions were reliable (after consultation with the statistician of the Cochrane Review Group) (Higgins 2011). We 
therefore contacted the authors for additional data (means and $\mathrm{SD}$ ). If they could not provide means or SD, we asked for the original data and calculated means and SD from these data. Data were only retrieved from graphs if exact numbers could be determined. With this procedure, we were able to retrieve all relevant data.

\section{Assessment of heterogeneity}

We anticipated clinical heterogeneity because of the differences in diagnostic groups, participants' disease, types of benzodiazepines, doses, duration of treatment, and route of delivery. We measured the impact of statistical heterogeneity (of effects) by quantifying inconsistency using the $\mathrm{I}^{2}$ statistic and based its interpretation on the recommendations given in the Cochrane Handbook (Higgins 2011).

\section{Assessment of reporting biases}

We assessed selective outcome reporting but did not assess further forms of reporting bias (no further assessment than those included in the 'Risk of bias' tool).

\section{Data synthesis}

We combined studies using RevMan (Version 5.0 for the original review, Version 5.3 for the update) (RevMan 2008; RevMan 2014). We attempted to obtain all relevant data from each paper.
We performed a meta-analysis including all appropriate studies. We excluded studies from the meta-analysis if the methodological quality of the study was low (Edwards Method Score 12 and lower). We used a random-effects model because clinical heterogeneity was present. We used the fixed-effect model only for the presentation of single studies or for studies with adequate homogeneity.

\section{Subgroup analysis and investigation of heterogeneity}

See section Assessment of heterogeneity.

\section{Sensitivity analysis}

We undertook sensitivity analysis to look for influences of different variables (for example participants, interventions, outcomes, and study design). We also performed sensitivity analysis taking into account methodological quality and the robustness of results.

\section{RESULTS}

\section{Description of studies}

We have illustrated the study selection process for the update of this review in Figure 1. 
Figure 1. Study flow diagram.

7 studies included in
previous version of the
review

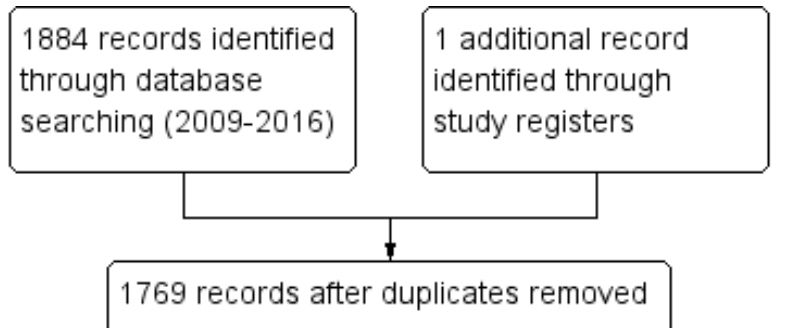

1769 records after duplicates removed

1749 records excluded with reasons:

anaesthesia-related study: 26

children/animals: 110

different design (excl. reviews): 997

different disease: 193

different intervention: 88

non-pharmacological interventions: 10

different outcome: 1

palliative sedation: 42

pharmacokinetic study: 4

reviews: 278

17 full-text articles and 1 study register records excluded with reasons:

5 non-controlled, retrospective or

observational design

4 reviews

2 guidelines

2 editorials

1 different outcome

2 study failed to recruit any participants

19 full-text articles and 1 study register record assessed for eligibility and

2 awaiting classification 
Figure 1. (Continued)

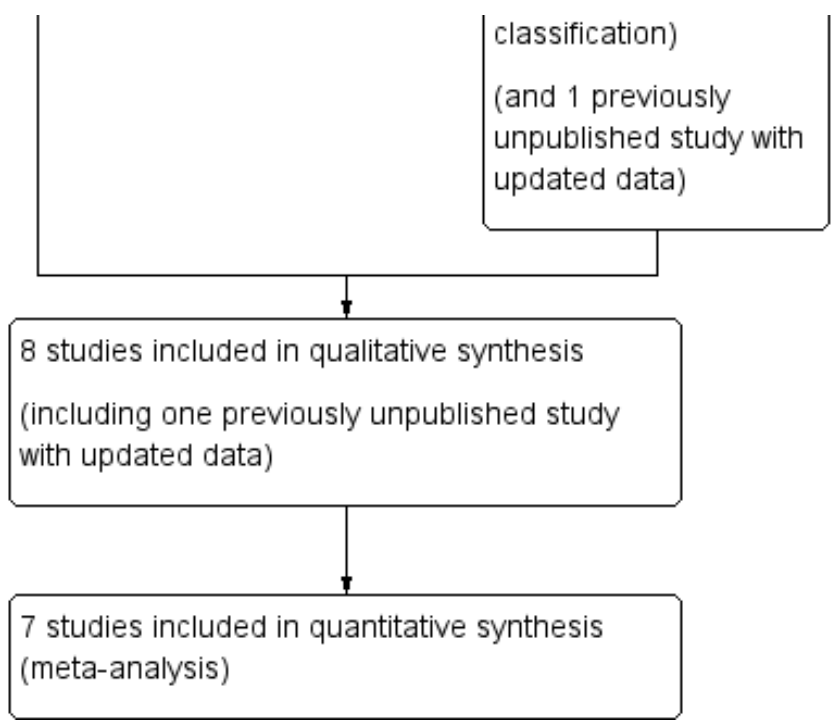

\section{Results of the search}

For the update, we included eight studies in total (Eimer 1985, Harrison (unpublished), Man 1986, Navigante 2006, Navigante 2010 (updated data which was an unpublished study in the earlier review), Shivaram 1989, Stege 2010 (this study was awaiting assessment in the earlier review), Woodcock 1981). In addition in this update, we included two study for awaiting classification (Hart 2012, Hardy 2016).

For the earlier review, we identified a total of 1309 references through the search of 14 databases. We excluded 207 duplicates. We studied the titles and abstracts of each of the 1102 articles and selected relevant articles if they met the inclusion criteria. In the earlier review, we sorted the 1071 excluded articles into the following exclusion groups: different disease (241 articles), different drug (223), reviews (242), anaesthesia-related study (111), psychology-related study (61), pharmacokinetic study (45), different design (38), palliative/terminal sedation (37), nonpharmacological interventions (14), and other (for example children) (59). We retrieved 31 articles for more detailed evaluation in the original review. In the earlier review, we identified 48 additional references from the reference lists of the original 31 articles by handsearching and the auxiliary function 'Related Articles' in Science Direct (www.sciencedirect.com). The search of 59 reviews, 16 textbooks, and seven websites did not yield any new articles. For the earlier review, we studied a total of 79 articles in more detail after obtaining the full text. Of these 79 articles, seven studies met our inclusion criteria and were included in the earlier review, and one study was awaiting classification (Stege 2010). We excluded a total of 74 articles for the earlier review. In addition, after sending a letter to all members of the Association of Palliative Medicine (UK) and after personal contact with several investigators (see above) at time of the original review, we were able to identify three new and unpublished studies (Harrison (unpublished), Navigante 2010, Stege 2010). We received data from two out of the three unpublished studies which we could include in the earlier review (Harrison (unpublished), Navigante 2010). The author of the third study could not send the data before submission and was set for "awaiting classification" of the earlier review (Stege 2010).

For the update of the review, we identified 1884 records: 32 articles in CENTRAL, 92 in MEDLINE, and 1760 in EMBASE. We also identified one potentially relevant clinical study report in trial registries. After de-duplication, there were 1769 articles for assessment. After screening titles and abstracts and exclusion of 1749 studies (see Figure 1 for reasons of exclusion) we obtained full copies of 19 published studies and one study from trial registries. Of these 20 records, we excluded 17 studies and the record from trial registries (this was a pilot study which failed to recruit any participants and was therefore excluded (NCT01687751, personal communication with Neil Hilliard, June 2015)). One of the excluded records was a study protocol only, and the study was cancelled early before any participants were included (Daubert 2014; personal communication with Eliza Daubert and Scott Bolesta in June 2015). Two additional studies were considered for awaiting classification. One out of these two studies was published only as a conference abstract and we received no data until the time of submission of the review (see Characteristics of studies awaiting classification) (Hart 2012). The second study was published just before the submission of this review and the data will be considered at the next update (conclusion of this study supports the conclusion of the review) (see Characteristics of studies awaiting classification) (Hardy 2016). Finally for the update, we added one new study to the seven studies of the original review (Stege 2010 - this study was unpublished and awaited assessment in the earlier review). In addition, we updated data of one previously unpublished but previously included study (Navigante 2010).

\section{Included studies}

\section{See Characteristics of included studies.}

Eimer 1985: a double-blind, placebo-controlled, cross-over RCT tested clorazepate in five non-anxious participants with severe COPD in a hospital setting to determine whether relieving breathlessness could be achieved. The study started with three arms $(7.5 \mathrm{mg} /$ day and $22.5 \mathrm{mg} /$ day oral clorazepate compared to placebo), but the high-dose arm (22.5 mg) was excluded from analysis after 3 out of 5 participants dropped out due to intolerable adverse effects. The duration of treatment was two weeks with a one-week wash-out period. Breathlessness was assessed weekly 
with a Breathlessness Grade from 1 (little breathlessness) to 6 (extreme breathlessness). Secondary outcomes were anxiety, depression, adverse effects, a 12-minute walking test, and attrition.

Harrison (unpublished): the effectiveness of lorazepam in the relief of breathlessness was tested in a randomised, doubleblind, placebo-controlled, cross-over study of 26 participants with advanced cancer in an in- and outpatient setting (single-centre). Seventeen participants completed the study and were included in the analysis. The study tested lorazepam $0.5 \mathrm{mg}$ twice daily orally over five days with a two-day wash-out period. A visual analogue scale (VAS) (0 to 100) was used to measure breathlessness as primary outcome (responding to three questions: 1 . breathlessness in general over the last 24 hours (summary); 2. breathlessness at its best over the last 24 hours; and 3. breathlessness at its worst over the last 24 hours). Secondary outcomes were anxiety and depression (measured on the Hospital Anxiety and Depression Scale (HADS)) and adverse effects after the treatment.

Man 1986: a double-blind, placebo-controlled, cross-over RCT of 29 participants with advanced but clinically stable COPD in an outpatient setting assessed the efficacy and safety of alprazolam in relieving breathlessness. The analysis included 24 participants, and five participants dropped out. The study compared the effect of alprazolam $1.0 \mathrm{mg} /$ day orally to placebo before and after one week of treatment (with a one-week wash-out period after cross-over). Breathlessness was measured either by Grade of Dyspnoea with 5 (breathlessness at rest) to 2 (able to keep up with people of similar age on level, but not on hills and stairs) to 1 (other than 2 to 5), as well as with a Dyspnoea Scoring (VAS 0 to 10) at rest and during exercise (bicycle ergometer). The study measured adverse effects, attrition, and a 12-minute walking test as additional outcomes.

Navigante 2006: a single-blind RCT with a parallel design assessed the role of midazolam in the alleviation of severe breathlessness during the last week of life of 101 participants with advanced cancer. The investigators conducted a three-arm trial in a hospital setting comparing morphine only (10 mg/day), midazolam only (20 mg/day), and the combination of morphine plus midazolam (10 plus $20 \mathrm{mg} /$ day), with a treatment duration of 48 hours and subcutaneous administration. The dose was adjusted if the participant was not morphine naive $(+25 \%$ on top of daily subcutaneous equivalent dose of morphine). Rescue medication was provided with $5 \mathrm{mg}$ midazolam in the morphine group and $2.5 \mathrm{mg}$ morphine in the midazolam and midazolam plus morphine group. Breathlessness was the primary outcome, assessed in four different ways:

1. Breathlessness intensity with the modified Borg scale (0 to 10$)$ before the intervention and 24 and 48 hours after intervention;

2. Percentage of participants with breathlessness relief (yes/no) after 24 and 48 hours and no breathlessness relief after 48 hours;

3. Numbers of episodes of breathlessness ('breakthrough dyspnoea' = numbers of rescue medication) per participant after 24 and 48 hours; and

4. Percentage of participants with episodic breathlessness after 24 and 48 hours.

Other outcomes were adverse effects (total of clinical relevance and different adverse effects in grading 1 to 3 ), anxiety, and attrition.
Navigante 2010: a single-blind RCT with a parallel design was undertaken with 63 participants with advanced cancer and breathlessness in a single-centre outpatient clinic (two participants dropped out after randomisation). The aim was to assess the efficacy of oral midazolam for the relief of breathlessness in comparison to oral morphine. A fast titration phase (FTP) was used to determine the effective dose (effect of at least 50\% reduction of breathlessness) for the follow-up phase (FUP) starting with midazolam $2 \mathrm{mg}$ every four hours (excluding sleeping time) and morphine $3 \mathrm{mg}$ every four hours (excluding sleeping time) with incremental steps of $25 \%$ of the preceding dose every 30 minutes. The duration of treatment in the FUP was five days with daily assessment of the primary endpoint breathlessness intensity (numeric rating scale (NRS), 0 to 10) and the secondary outcomes number of episodes of breathlessness per day, descriptors the participant used for breathlessness, and the number of adverse effects. The study reported dose reduction, therapeutic failure, and additional procedures (for example antibiotics).

Shivaram 1989: a double-blind, randomised, placebo-controlled, cross-over study of 12 participants with advanced COPD with anxiety (non-psychiatric stage) in an unknown setting (probably hospital) assessed the effect of alprazolam to relieve breathlessness. Four participants dropped out and were excluded, leaving eight participants for analysis. The study compared the effect of oral alprazolam $0.75 \mathrm{mg} /$ day to placebo at baseline and after two weeks of treatment (with two days wash-out). Breathlessness was measured on a modified Borg scale (0 to 10). No other outcomes except adverse effects were assessed.

Stege 2010: a double-blind, randomised, placebo-controlled, crossover study of 17 participants with COPD (Global Initiative for Obstructive Lung Disease (GOLD) stages 3 or 4 ) with insomnia in an outpatient centre of a respiratory medicine hospital department. The aim of the study was to assess whether temazepam ( $10 \mathrm{mg}$ daily over one week) influences indices of breathing and gas exchanges during sleep; the effect on dyspnoea sensation (assessed with 10point VAS) and other outcomes were secondary objectives. Three participants dropped out, leaving 14 participants for analysis.

Woodcock 1981: a double-blind, placebo-controlled, cross-over RCT of 18 participants with severe COPD compared the effect of oral diazepam ( $25 \mathrm{mg} /$ day) and promethazine $(125 \mathrm{mg} /$ day) on breathlessness. Three participants dropped out, leaving 15 participants for analysis. Breathlessness was the main outcome, assessed as 'daily dyspnoea' by VAS ( 0 to 10 ) and 'dyspnoea grade' 5 (breathlessness at rest) to 2 (able to keep up with people of similar age on level, but not on hills and stairs) to 1 (other than 2 to 5), after each intervention in an outpatient setting with a two-week treatment duration (no wash-out period). The study assessed adverse effects, dose modification, anxiety, depression, a 12-minute walking test, treadmill, and ergometer measurement.

\section{Study design}

All studies were RCTs (Eimer 1985; Harrison (unpublished); Man 1986; Navigante 2006; Navigante 2010; Shivaram 1989; Woodcock 1981). Besides Navigante 2006 and Navigante 2010, who used a single-blind, parallel, and morphine-controlled design, all other studies were double-blind, cross-over, and placebo-controlled (Eimer 1985; Harrison (unpublished); Man 1986; Shivaram 1989; Stege 2010; Woodcock 1981). 


\section{Sample size}

In general, the sample size was small (between five and 29 participants), except for two studies of Navigante and colleagues (Navigante 2006 with 101 participants and Navigante 2010 with 63 participants). One study finished data collection without dropouts (Eimer 1985). Five studies had between three and nine dropouts (dropout/N: 9/26, 5/29, 4/12, 3/17, 3/18) (Harrison (unpublished); Man 1986; Shivaram 1989; Stege 2010; Woodcock 1981); one study lost two of 63 participants (Navigante 2010); and one study lost 31 participants due to death during the study (Navigante 2006), which were always excluded from the analysis. Four studies provided a power calculation (Harrison (unpublished); Navigante 2010; Shivaram 1989; Stege 2010), and three of them reached an appropriate number of participants (Navigante 2010; Shivaram 1989; Stege 2010). None of the studies presented an intention-totreat analysis. A total of 214 participants were analysed, including 33 participants of the third intervention arm of the paralleldesigned study from Navigante 2006.

\section{Participants}

Three studies included participants with cancer (Harrison (unpublished); Navigante 2006; Navigante 2010), and five studies included participants with advanced COPD (Eimer 1985; Man 1986; Shivaram 1989; Stege 2010; Woodcock 1981).

\section{Outcomes}

Breathlessness intensity was measured mainly on a VAS/NRS (Harrison (unpublished); Man 1986; Navigante 2010; Stege 2010; Woodcock 1981), a modified Borg scale (Navigante 2006; Shivaram 1989), and a Dyspnoea Grade 1 to 6 scale or 1 to 5 scale (Eimer 1985; Man 1986; Woodcock 1981). The majority of studies measured breathlessness at rest (Eimer 1985; Harrison (unpublished); Navigante 2006; Navigante 2010; Shivaram 1989); only three studies also assessed breathlessness on exercise (Eimer 1985; Man 1986; Woodcock 1981). Two studies assessed episodic breathlessness (Navigante 2006; Navigante 2010), and one study did not further specify breathlessness (Stege 2010). Other outcomes were anxiety (Harrison (unpublished); Navigante 2006; Woodcock 1981), depression (Harrison (unpublished); Woodcock 1981), adverse effects (all), walking tests (Eimer 1985; Man 1986; Woodcock 1981), and attrition (all).

\section{Intervention}

Two studies tested alprazolam, one with $1.0 \mathrm{mg} /$ day (Man 1986), and one with $0.75 \mathrm{mg} /$ day (Shivaram 1989). One study tested 25 $\mathrm{mg}$ /day diazepam within a three-arm design with $125 \mathrm{mg}$ /day promethazine compared to placebo (Woodcock 1981). Navigante 2006 applied midazolam $20 \mathrm{mg} /$ day only and in combination with morphine $10 \mathrm{mg} /$ day compared to morphine $10 \mathrm{mg} /$ day only within a three-arm design. Navigante 2010 studied oral midazolam $8 \mathrm{mg} /$ day versus morphine $12 \mathrm{mg} /$ day (both starting doses). Harrison (unpublished) examined lorazepam $1 \mathrm{mg} /$ day. Eimer 1985 tested two different doses of clorazepate, 7.5 and $22.5 \mathrm{mg} / \mathrm{day}$, compared to placebo; however, due to intolerable adverse effects, the $22.5 \mathrm{mg}$ arm was excluded from analysis. Stege 2010 examined the effect of temazepam $10 \mathrm{mg} /$ day orally. The treatment durations ranged between 48 hours, in Navigante 2006, and two weeks, in Eimer 1985, Shivaram 1989, and Woodcock 1981.

\section{Excluded studies}

See Characteristics of excluded studies.

We excluded 90 out of 97 full-text publications because they did not meet the inclusion criteria (30 'no subjective measurement of breathlessness'; 24 'reviews'; 15 'different drugs'; six 'different disease/healthy participant'; three 'combination of drugs'; six 'different study design', two 'guidelines', two 'editorials', and two studies 'failed in recruiting any participants'. We excluded a substantial number of studies because of a lack of subjective measurement of breathlessness, mainly older studies from the 1970 s and 1980s that studied benzodiazepines in relation to spirometry, functional tests, or blood tests. Among them is the most cited paper in this area (Mitchell-Heggs 1980a), which we had to exclude because of a lack of subjective measurement of breathlessness. Although the authors mentioned breathlessness as an outcome, we could determine no subjective measure, either in the text, tables, or graphs. Other reasons for excluding this study were the lack of systematic or standardised design and absence of control group. Four excluded studies used benzodiazepines only in combination with other drugs (Clemens 2011; Lichterfeld 1967; Navigante 1997; Navigante 2003), thus a separate assessment of the drug effect was not possible. Three excluded studies assessed breathlessness in healthy people (comparing diazepam, promethazine, and placebo) (Jones 1985; Stark 1981a; Stark 1981b). One study compared diazepam versus flupenthixol in people with psychosomatic disorders (breathlessness was only one of 12 associated symptoms and was not the primary outcome) (Jokinen 1984). Although we expected to find a substantial number of observational studies, there were only a few thematically relevant non-controlled or retrospective studies, which we had to exclude. Among them was the case report from Greene 1989, a non-controlled phase II study (Allcroft 2013), the abovementioned non-controlled study on the combined use of opioids and benzodiazepines (Clemens 2011), a retrospective study on the management of dyspnoea in hospitalised palliative-care patients (Gomutbutra 2013), and a prospective observational study on the patterns of benzodiazepine use among older adults with COPD in Canada (Vozoris 2013). We excluded the study Hosaka 1996 because four of the 22 participants did not meet our inclusion criteria regarding the underlying disease (asthma, tuberculosis), and the level of airways obstruction was above our inclusion criteria (mean FEV1 63\% and FEV1/FVC 1.06), indicating that the disease stage was not as advanced as required for this review. This non-randomised, placebo-controlled, double-blind, cross-over trial studied the use of diazepam 10 to $12 \mathrm{mg} /$ day over four weeks in 22 people with chronic respiratory insufficiency (mainly COPD and fibrosis) who received home oxygen therapy. The study, which was published in Japanese (abstract in English), showed a statistically significant improvement in breathlessness at rest in the diazepam group and a statistically non-significant worsening in the placebo group, but the levels of breathlessness at baseline were different between the groups.

In the search for the update, we excluded the potentially relevant studies of Daubert 2014 and NCT01687751 (identified through register search), because no participants could be recruited in these trials and no future results are expected (personal communication with Neil Hilliard, Eliza Daubert and Scott Bolesta in June 2015). 


\section{Studies awaiting classification}

In the update, we identified one potentially relevant study with the database search (Hart 2012), and one potentially relevant study in the clinical trial registries (Hardy 2016) (see Characteristics of studies awaiting classification).

Hardy 2016 is a randomised, placebo-controlled, cross-over trial testing the hypothesis that intranasal midazolam is superior to placebo for the palliation of dyspnoea in people with optimally treated life-limiting disease. A sample size of 200 participants was planned but the study was terminated after interim analysis of 75 participants showing no difference between intervention arms. The primary outcome was breathlessness intensity at $15 \mathrm{~min}$ compared to baseline. There was no difference at any time points in breathlessness scores between arms. This study concludes that intranasal midazolam had no clinical benefit over intranasal placebo for the control of breathlessness.

The aim of the randomised, double-blind, double-dummy, placebo-controlled pilot study of Hart 2012 was to compare the efficacy of intranasal midazolam with that of oral lorazepam tablets in relieving dyspnoea in people with severe respiratory disease. The study included 30 participants, and the findings showed a "worthwhile improvement in symptom control of dyspnoea and quality of life" (Hart 2012). Unfortunately, this study was only published as a conference abstract, and we did not receive data from the authors at time of the submission (personal contact with Dr. Hart in August 2016).

\section{Risk of bias in included studies}

See Characteristics of included studies, the corresponding 'Risk of bias' tables, Figure 2, and Figure 3. 
Figure 2. Methodological quality summary: review authors' judgements about each methodological quality item for each included study.

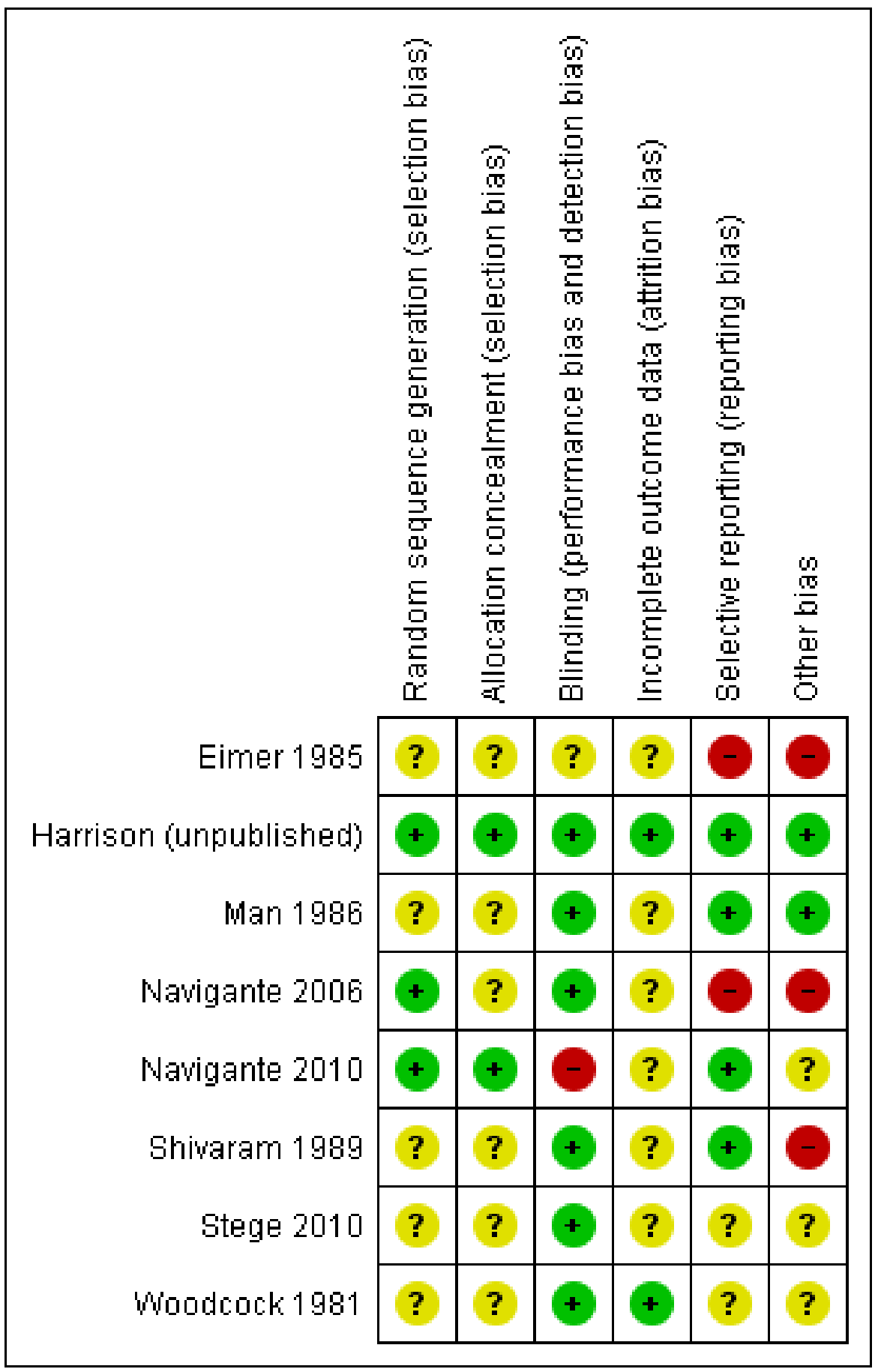


Figure 3. Risk of bias graph: review authors' judgements about each risk of bias item presented as percentages across all included studies.

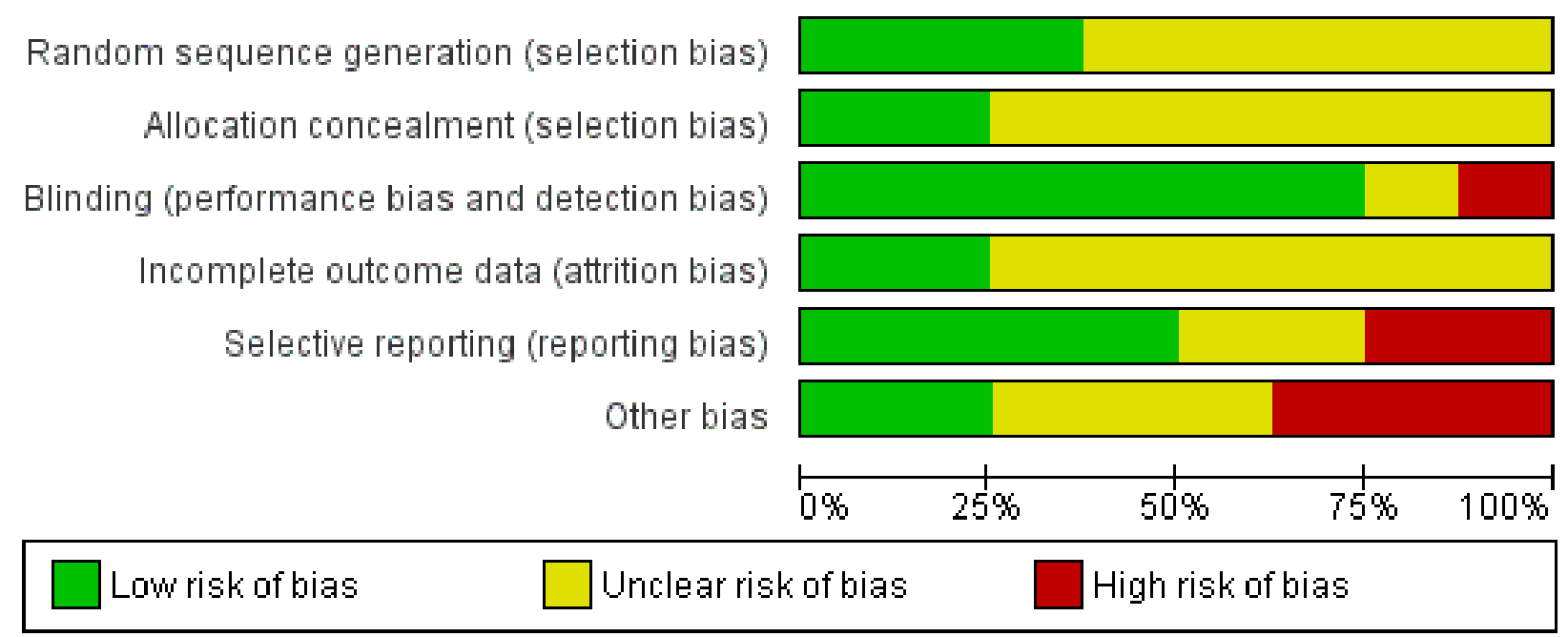

In the update, seven studies, Harrison (unpublished), Man 1986, Navigante 2006, Navigante 2010, Shivaram 1989, Stege 2010, and Woodcock 1981, showed high quality on the Edwards Method Score (Edwards 2001; Edwards 2003). Only one study had a high risk of bias due to lack of presented data and information and inappropriate presentation of data in figures (Eimer 1985). We therefore did not include this study in the meta-analysis.

\section{Allocation}

All studies were RCTs. Four studies did not mention the denominator population that was screened for participation (Man 1986; Navigante 2010; Shivaram 1989; Woodcock 1981). There was a substantial gender imbalance due to more males than females participating in most studies (exact total numbers are not countable because of a different presentation of data for gender of randomised or analysed participants); only Navigante 2006 included more females than males. One study did not mention the gender distribution (Navigante 2010).

\section{Blinding}

Two studies were single-blinded (Navigante 2006; Navigante 2010); one study did not define blinding appropriately, but was stated to be double-blind (Eimer 1985); and the rest used a double-blind design.

\section{Incomplete outcome data}

Seven studies with dropouts excluded them from the analysis (Harrison (unpublished); Man 1986; Navigante 2006; Navigante 2010; Shivaram 1989; Stege 2010; Woodcock 1981). None of the studies mentioned missing data or the handling of missing data.

\section{Selective reporting}

Woodcock 1981 stated that there was no effect of diazepam in the relief of breathlessness. However, a beneficial effect could be seen for diazepam, although it was not statistically significant $(P=0.06)$. Stege 2010 stated that no respiratory adverse events had occurred, however there was no information on other than respiratory adverse events.

\section{Other potential sources of bias}

Seven studies were published in indexed, peer-reviewed journals (Eimer 1985; Man 1986; Navigante 2006; Navigante 2010 Shivaram 1989; Stege 2010; Woodcock 1981), and one study was unpublished (Harrison (unpublished)). The author of the unpublished study sent us all the original data at time of the original review and was very helpful and supportive (Harrison (unpublished)). One study did not mention a wash-out period between intervention and control phases (cross-over design) (Woodcock 1981). However, sensitivity analysis showed no difference regarding the results compared to studies including a wash-out period. Navigante 2006 used the comparative drug (midazolam plus morphine) for rescue medication. Since this combination of midazolam and morphine could have been used in all three treatment arms, a confident comparison or distinction between midazolam and morphine was not possible. Navigante 2010 allowed the use of treatments with potential impact on breathlessness besides the intervention and the control in the study (for example antibiotics, aspiration of pleural effusion, radiotherapy).

\section{Effects of interventions}

We included eight studies (eight RCTs; six cross-over and two parallel designs; five COPD and three cancer studies) in the review with a total of 214 participants analysed (COPD, $N=66$; cancer, $\mathrm{N}=148$ ). We have summarised the main findings of each of the studies below (see also the Characteristics of included studies tables). We carried out the meta-analysis separately for placebocontrolled studies, Harrison (unpublished), Man 1986, Shivaram 1989, Stege 2010, and Woodcock 1981, and morphine-controlled studies (Navigante 2006; Navigante 2010).

\section{Benzodiazepines for breathlessness in chronic obstructive pulmonary disease (COPD)}

\section{Eimer 1985}

Five participants with advanced COPD were examined in a randomised, cross-over trial. Breathlessness was measured at rest and after a 12-minute walking test, after two weeks of 
treatment with clorazepate $7.5 \mathrm{mg} /$ day compared to placebo. All participants completed the study. The change scores from baseline to postintervention showed no statistically significant difference between the intervention and the control group. The results were presented only in a figure without exact data, which was difficult to interpret.

\section{Man 1986}

Twenty-nine participants with advanced COPD were randomised in a cross-over design to alprazolam $1.0 \mathrm{mg} /$ day or placebo over one week, but only 24 participants completed the study (five dropouts were excluded from analysis). There was no statistically significant effect of alprazolam versus placebo compared to baseline in the relief of breathlessness at rest and on exercise. Furthermore, no difference between the intervention and the control group was observed after treatment.

\section{Shivaram 1989}

Twelve participants with advanced COPD were randomised (crossover), of which only eight participants completed the study (four dropouts were excluded from analysis). There was no improvement of breathlessness at rest with alprazolam $0.75 \mathrm{mg} /$ day compared to baseline after two weeks, but there was an improvement with placebo (not statistically significant). Furthermore, no difference was observed after treatment between the intervention and the control group.

\section{Stege 2010}

Seventeen participants with advanced COPD who experienced insomnia were randomised (cross-over), of which 14 were analysed, excluding three dropouts. There was no difference of breathlessness intensity with temazepam $10 \mathrm{mg} /$ day for one week compared to placebo.

\section{Woodcock 1981}

Eighteen participants with advanced COPD were randomised in a cross-over design to determine the effect of diazepam $25 \mathrm{mg} /$ day in the relief of breathlessness compared to placebo and promethazine $125 \mathrm{mg} /$ day (third arm). There were three dropouts, and 15 participants completed the study and were included in the analysis. Diazepam produced a statistically non-significant effect in the relief of breathlessness at rest compared to placebo after two weeks. There was also no difference in breathlessness on exercise compared to placebo.

\section{Meta-analysis and summary}

We included four out of five cross-over studies (see Risk of bias in included studies) with a total of 61 participants with COPD (122 observations) in the meta-analysis (Man 1986; Shivaram 1989; Stege 2010; Woodcock 1981) (Analysis 2.1), comparing posttreatment measures between intervention and control groups. We observed no statistically significant effect of alprazolam, diazepam, or temazepam with a standardised mean difference (SMD) estimated as -0.12 ( $95 \%$ confidence interval (CI) -0.52 to 0.29 ). The overall heterogeneity of effects was low $\left(I^{2}=18 \%\right)$.

Overall, the analysis (five studies) and meta-analysis (four studies) with 66 and 61 participants, respectively, showed no statistically significant effect of four different benzodiazepines (clorazepate, diazepam, alprazolam, temazepam) in the relief of breathlessness in people with advanced COPD. One study showed a slight but statistically non-significant advantage of diazepam compared to placebo (Woodcock 1981).

\section{Benzodiazepines for breathlessness in cancer}

Harrison (unpublished)

Twenty-six participants with advanced cancer were randomised (cross-over), but only 17 participants completed the study and were included in the analysis. Lorazepam $1.0 \mathrm{mg}$ /day had no statistically significant effect on breathlessness at rest compared to baseline and to placebo after five days of treatment. The result was similar for the overall level of breathlessness, breathlessness at its best, and breathlessness at its worst.

\section{Navigante 2006}

One hundred and one participants with terminal cancer were randomised in a three-arm study with a parallel design that compared midazolam $20 \mathrm{mg} /$ day, morphine $10 \mathrm{mg} /$ day, and midazolam $20 \mathrm{mg} /$ day plus morphine $10 \mathrm{mg} /$ day after 24 and 48 hours of treatment (plus rescue doses). Thirty-one participants died during the study after receiving the treatment (no difference between the study groups). Each treatment arm showed a statistically significant reduction of breathlessness compared to baseline, but without any difference when comparing the three arms after 48 hours. After 24 hours, morphine only and the combination of both drugs were slightly better than midazolam only. The highest percentage of participants who experienced a relief of breathlessness (92\%) was in the midazolam plus morphine group after 24 hours; the lowest percentage was in the midazolam-only group (46\%). The midazolam group reported the highest percentage of participants with persistent and uncontrolled breathlessness after 48 hours (26\%), the midazolam plus morphine group the lowest.

For meta-analysis, we used the assessment after 48 hours unless stated otherwise.

\section{Navigante 2010}

Sixty-three participants with advanced cancer were randomised in a parallel design to compare midazolam $8 \mathrm{mg} /$ day and morphine 12 $\mathrm{mg} /$ day (control) over five days (starting doses with titration phase and rescue doses). Sixty-one participants completed the study, with one drop-out in each group (31 participants in the midazolam group and 30 participants in the morphine group). Both treatments showed a statistically significant reduction in breathlessness intensity after two, three, four, and five days compared to baseline. Midazolam reduced breathlessness significantly better than morphine when comparing the endpoints after all treatment days. Twenty-one participants treated with midazolam reached a $50 \%$ reduction of breathlessness after the starting dose compared to only 11 participants in the morphine group $(P=0.023)$. Therapeutic failure was observed in $20 \%$ of participants in the morphine group compared to none in the midazolam group. A dose reduction was necessary in one participant in the midazolam group and in two participants in the morphine group due to excessive somnolence.

For meta-analysis, we used the assessment after five days unless stated otherwise. 


\section{Meta-analysis and summary}

We could include all three studies of people with cancer in the meta-analysis, but analysed the placebo-controlled and morphine-controlled studies separately. The placebo-controlled study found no statistically significant effect with a SMD of -0.06 $(95 \% \mathrm{Cl}-0.73$ to 0.62$)$ (Harrison (unpublished)) (Analysis 2.2). Pooling of the two morphine-controlled studies also showed no statistically significant effect, with a SMD of $-0.68(95 \% \mathrm{Cl}-2.21$ to 0.84 ) (Navigante 2006; Navigante 2010) (Analysis 2.3). One study demonstrated a statistically significant effect of midazolam compared to morphine (Navigante 2010), but this result was contrary to a similar study by the same research group where the morphine group showed a slightly better improvement of breathlessness than the midazolam group (Navigante 2006). We found no difference when comparing midazolam with midazolam plus morphine (third study arm in Navigante 2006).

Overall, we found no statistically significant effect. Due to the high level of heterogeneity in the designs of the three studies (control group, study design, stage of disease, benzodiazepine, dose, and route of application), the meta-analyses of all three studies should be interpreted with caution. There are conflicting results in the comparison of midazolam to morphine based on two studies from the same research group.

\section{Benzodiazepines for the prevention of episodic breathlessness} in cancer

\section{Navigante 2006}

The proportion of participants with episodic breathlessness was lower in the midazolam plus morphine group (21.2/24.0\%) than in the morphine and midazolam groups after 24 and 48 hours, and highest in the midazolam group (36.4/38.5\%). The median number of episodes of breathlessness per participant after 24 and 48 hours was higher in the morphine-only group (two episodes) than in the midazolam-only and midazolam plus morphine groups (one episode).

\section{Navigante 2010}

The proportion of participants with episodic breathlessness was lower in the midazolam group compared to the morphine group and reached a statistically significant level of $P=0.035$ at three days, $\mathrm{P}=0.034$ at four days, and $\mathrm{P}<0.001$ at five days of treatment.

\section{Meta-analysis and summary}

We could include both studies that examined episodic breathlessness in the meta-analysis, comparing midazolam with morphine in 116 and 108 participants with cancer, respectively, after 24 and 48 hours (Navigante 2006; Navigante 2010). For the second study (Navigante 2010), we calculated the effect after 48 hours using the measurement at the third day when asked about episodic breathlessness on the day before (that is 48 hours). Overall, we found no statistically significant effect after 48 hours with a risk ratio of $0.76(95 \% \mathrm{Cl} 0.53$ to $1.09 ; 108$ participants) (Analysis 4.3).

Although one study demonstrated a statistically significant positive effect with midazolam after three, four, and five days (Navigante 2010), the previous study from the same research group observed no difference between midazolam and morphine in preventing episodic breathlessness.

\section{Overall - benzodiazepines in breathlessness}

\section{Meta-analysis and summary}

We excluded one study from the meta-analysis due to a lack of methodological quality and lack of data (see Risk of bias in included studies) (Eimer 1985). Therefore, we included seven studies in the overall meta-analysis of the review update and analysed placebocontrolled and morphine-controlled studies separately. Pooling of the placebo-controlled studies showed no significant effect with a SMD of $-0.10(95 \% \mathrm{Cl}-0.42$ to 0.21$)$ (Harrison (unpublished); Man 1986; Shivaram 1989; Stege 2010; Woodcock 1981) (Analysis 1.1; Figure 4). The meta-analysis of all placebo-controlled studies included 156 observations equating to 78 participants. Pooling of the morphine-controlled studies with 107 participants also showed no statistically significant effect with a SMD of $-0.68(95 \% \mathrm{Cl}-2.21$ to 0.84) (Navigante 2006; Navigante 2010) (Analysis 1.2; Figure 5). Overall, there was no statistically significant beneficial effect of benzodiazepines in the relief of breathlessness at rest. These results must be interpreted with caution due to the presence of heterogeneity among the seven included studies regarding such components as disease group, control group, and benzodiazepine, among others.

\section{Figure 4. Forest plot of comparison: 1 Overall, outcome: 1.1 Placebo-controlled/cross-over design.}

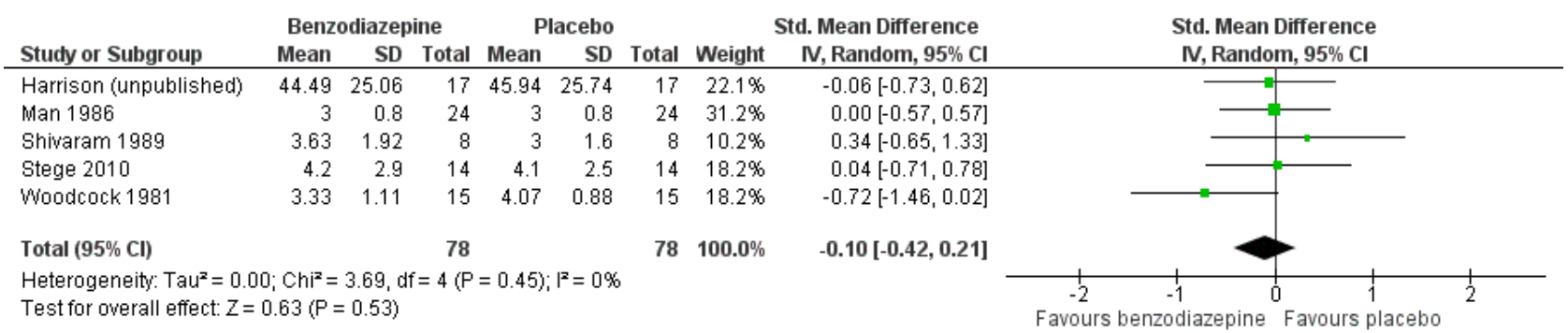


Figure 5. Forest plot of comparison: 1 Overall, outcome: 1.2 Morphine-controlled/parallel design.

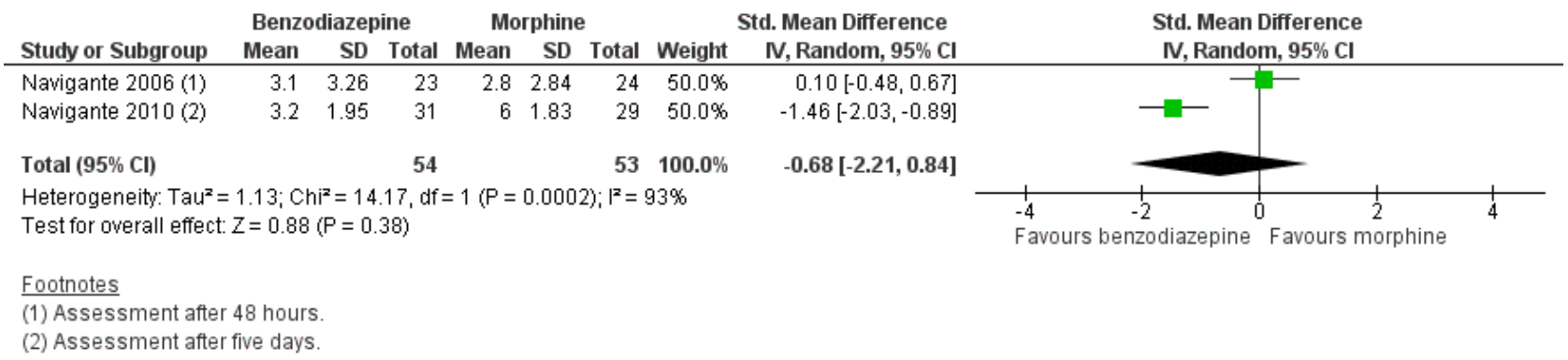

In the sensitivity analysis, a comparison to baseline of studies that presented baseline and after-treatment measures demonstrated a positive effect for benzodiazepines, but this did not reach statistical significance (data not shown). However, changes from baseline have a higher risk of confounders (for example regression to the mean) compared to after-treatment measures and should be avoided (Higgins 2011). Two studies looked at breathlessness on exercise (Man 1986; Woodcock 1981), but we could not include these in the meta-analysis due to a lack of appropriate data (data presented only in graphs).

In summary, all but one study showed no beneficial effect of benzodiazepines (Eimer 1985; Harrison (unpublished); Man 1986; Navigante 2006; Shivaram 1989; Stege 2010). Only one study showed a statistically significant effect of midazolam compared to morphine (Navigante 2010), but as mentioned above this result was in contrast to a previous study by the same research group (Navigante 2006). One study demonstrated a beneficial effect of diazepam, but this was not statistically significant (Woodcock 1981).

\section{Secondary outcomes}

\section{Anxiety}

Four out of seven studies measured anxiety with different scales (Eimer 1985; Harrison (unpublished); Navigante 2006; Woodcock 1981). Benzodiazepines did not reduce anxiety, either as a change from baseline or compared to the control group after treatment.

\section{Depression}

Three studies examining depression found no statistically significant difference between the intervention and the placebo group (Eimer 1985; Harrison (unpublished); Woodcock 1981).

\section{Adverse effects}

All studies assessed adverse effects, but Stege 2010 only reported on respiratory adverse effects (none occurred). Two studies observed no adverse effects (Eimer 1985; Shivaram 1989). Harrison (unpublished) described three adverse effects in the intervention group that lead to withdrawal compared to one case in the placebo group. Man 1986 and Woodcock 1981 observed significantly more adverse effects (mainly drowsiness) in the benzodiazepine group compared to placebo. Navigante 2006 reported more adverse effects (mainly somnolence) in the morphine group (19/45) compared to midazolam (15/45). Surprisingly, the fewest adverse effects were reported for the combination group (11/45; third arm with midazolam plus morphine). The authors defined an adverse effect as clinically relevant with Grade 2 to 4 (Grade 1 mild, 2 moderate, 3 severe, 4 life-threatening - but observed no Grade 4) and found the highest number in the morphine group (10/16) compared to midazolam (3/16) and midazolam plus morphine (3/16). These results were confirmed in the following study (Navigante 2010), which found significantly more adverse effects (mainly somnolence) in the morphine group compared to the midazolam group.

Regarding adverse effects, we observed a beneficial but not statistically significant effect in the control group when studies used placebo as a control (Analysis 5.1, Figure 6). Studies comparing midazolam with morphine showed a statistically significant favourable effect for midazolam (Analysis 5.2). Drowsiness and somnolence were mainly reported with a statistically significant difference between intervention and control group when placebo was used as a control (benzodiazepines caused more drowsiness or somnolence) (Analysis 5.4).

\section{Figure 6. Forest plot of comparison: 5 Secondary outcomes, outcome: 5.1 Adverse effects (placebo-controlled).}

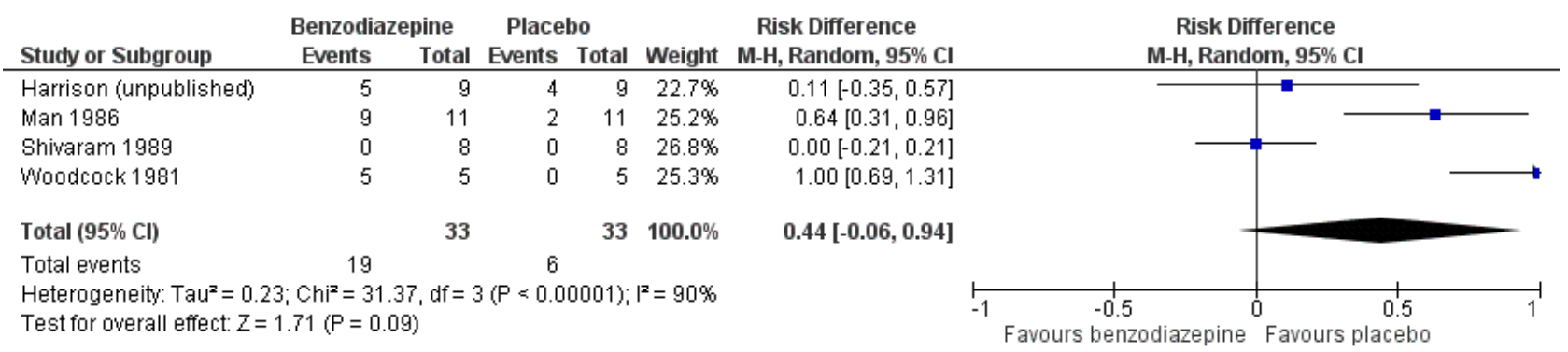




\section{Exercise tolerance}

Only three out of seven studies looked at breathlessness on exercise. Eimer 1985 used a 12-minute walking distance test and Man 1986 used a 12-minute walking distance test and bicycle exercise. They did not find any difference between benzodiazepines and placebo regarding exercise tolerance. However, Woodcock 1981 demonstrated a significant impairment in walking distance after 12 minutes in the intervention group compared to placebo, and a non-significant decline in time to exhaustion on treadmill and workload on bicycle ergometer.

\section{Quality of life}

None of the included studies studied quality of life.

\section{Attrition}

Regarding attrition, there was no difference between the intervention and control groups, either for the placebo-controlled studies or the morphine-controlled studies. Only one study reported results in favour of the intervention group, with four dropouts in the placebo group mainly due to increasing breathlessness and drowsiness (Shivaram 1989). One study had no attrition, either in the intervention or in the control group (Eimer 1985). One study reported three dropouts: one participant was excluded from the intervention group due to an exacerbation of COPD during the study, one participant was excluded due to obstructive sleep apnoea-hypopnoea syndrome after baseline polysomnography, and one withdrew due to burden of the measurements in the control group (Stege 2010). One study reported five dropouts (Man 1986); one dropout was assigned to the placebo group (unknown adverse effect), and the other four dropouts were missing appointments without assignment to one group. The Harrison (unpublished) study reported twice as many dropouts in the placebo group (six) as in the intervention group (three). Alternatively, Woodcock 1981 counted twice as many dropouts in the intervention group (two) as in the placebo group (one). The reason for attrition was mainly drowsiness, which occurred in the intervention group in both studies. Both dropouts in Navigante 2010 were missing follow-ups. Navigante 2006 had a very high attrition rate, and all dropouts were due to death (31 deaths in all three study arms with a total of 101 participants), but without a difference when comparing the three arms. We could find no difference between intervention and control group regarding deaths in all studies (Analysis 5.8; Analysis 5.9).

\section{Others}

\section{Blood gases}

Only one study reported a slightly but almost statistically significant difference $(P=0.05)$ in blood gases between alprazolam and placebo $\left(\mathrm{PaO}_{2}\right.$ at rest higher and $\mathrm{PaCO}_{2}$ after exercise lower with placebo) (Man 1986). All other studies that measured oxygen saturation, $\mathrm{PaO}_{2}$, or $\mathrm{PaCO}_{2}$ found no significant change from baseline or between intervention and control group (Eimer 1985; Navigante 2006; Navigante 2010; Shivaram 1989; Stege 2010; Woodcock 1981).

\section{Spirometric tests}

Only one study found a slightly but almost statistically significant difference $(P=0.05)$ in spirometric tests with higher levels for FEV1 (forced expiratory volume in one second), TLC (total lung capacity), and FRC (functional residual capacity) in the placebo group (Man 1986). Three other studies measured the functional lung capacity, but did not find any significant change from baseline or between intervention and control group (Eimer 1985; Shivaram 1989; Woodcock 1981).

\section{DISCUSSION}

\section{Summary of main results}

Benzodiazepines are widely used drugs in the treatment of breathlessness, but very few studies have evaluated their effectiveness. On the basis of eight RCTs including 214 participants, we conclude that there is no evidence for a beneficial effect of benzodiazepines for the relief of breathlessness at rest in people with advanced cancer or chronic obstructive pulmonary disease (COPD). However, this conclusion is based on a small number of studies with a limited number of participants, heterogeneity among included studies, and some inconsistency across the studies. Furthermore, we could observe no statistically significant effect in the prevention of episodic breathlessness in people with cancer. Sensitivity analysis demonstrated no statistically significant differences regarding the type of benzodiazepine, dose, route and frequency of delivery, duration of treatment, or type of control.

\section{Overall completeness and applicability of evidence}

The study from Navigante 2010 is the only RCT that showed a statistically significant beneficial effect, although it used morphine as a control. This result is surprising, as morphine has been shown to be effective in the relief of breathlessness (Jennings 2001). Furthermore, a study from the same research group of people with terminal cancer two years earlier demonstrated a contrary result, with an advantage of morphine over midazolam, and best results for the combination of the two drugs (Navigante 2006). However, the results of the earlier study must be interpreted with caution as there were some methodological difficulties: the authors studied people with terminal cancer and observed a very high attrition rate due to death (31/101); and they allowed rescue medication during the study, therefore all three treatment arms might have included both drugs and a valid differentiation of the effect was not possible without uncertainty (Navigante 2006). Further studies are needed to examine the comparison between morphine and midazolam and to verify the results of Navigante 2010.

Episodic breathlessness was only studied in people with cancer, and the focus was on preventing breakthrough dyspnoea (no evaluation of the effect on relief of episodic breathlessness) (Navigante 2006; Navigante 2010). The extent of the beneficial preventative effect of midazolam compared to morphine was larger after 48 hours than after 24 hours, but statistically non-significant at both times. RCTs assessing the treatment (not prevention) of episodic breathlessness with benzodiazepines are still missing.

Most studies observed adverse effects. Drowsiness and somnolence were mainly reported with a significantly higher occurrence in the benzodiazepine group when a placebo was the control. In contrast to the other studies, Shivaram 1989 reported attrition only in the placebo group, due to increasing breathlessness and drowsiness. We excluded these three cases from analysis. It could be argued that the occurrence of increasing breathlessness only in the placebo group favours the intervention group in the relief of breathlessness, and this might have changed 
their conclusion. Shivaram 1989 argued that this could be a suggestive effect, as participants were told that the treatment might cause increasing breathlessness. However, as only 12 participants were included, it is not possible to judge if this is a random effect.

There was no difference between the intervention and control groups in respect to attrition and deaths, either for the placebocontrolled studies or for the morphine-controlled studies. However, the reporting of dropouts in cross-over studies was not always sufficient to assess when the dropout occurred (first or second period of the study), in order to calculate the attrition (Eimer 1985; Harrison (unpublished); Man 1986; Shivaram 1989; Stege 2010; Woodcock 1981). Given the small numbers of dropouts, the potential miscalculation is likely to be small for the present cross-over studies. However, attrition must still be interpreted with caution. Navigante 2006 observed a high attrition rate due to deaths (31/101) without any difference between the three study arms. As mentioned before, all three treatment arms allowed a combination of midazolam and morphine, therefore the high death rate could not been attributed to a single drug. The authors argued that most of the deaths were caused by the underlying advanced disease. As they studied people with terminal cancer and a life expectancy of less than a week, this seems likely. However a relation between treatment and death could not be excluded entirely because of the relatively high doses of midazolam. There is some evidence from a large cohort study that benzodiazepines alone might increase mortality, but concurrent benzodiazepines and opioids do not (Ekstrom 2014).

Different types of benzodiazepines were tested as well as different doses, long- and short-acting drugs, and different durations of treatment and modes of administration. However, we could find no differences when conducting sensitivity analysis regarding all these criteria. Furthermore, different comparators were used: five studies used placebo (Harrison (unpublished); Man 1986; Shivaram 1989; Stege 2010; Woodcock 1981), and two studies used morphine as a control treatment (Navigante 2006; Navigante 2010). We therefore conducted separate meta-analyses for each group with the same control treatment.

The measurement tools for examining breathlessness in all but one study were validated and frequently used (Eimer 1985).

\section{Quality of the evidence}

Overall, this review analysed 214 participants in eight studies, including 33 participants of the third intervention arm of the parallel-designed study from Navigante 2006. However, the number of participants in each single study was small (between five and 35 in each comparison group). We intended to evaluate the effect of benzodiazepines in five different disease groups (cancer, COPD, chronic heart failure, motor neurone disease, and idiopathic pulmonary fibrosis), but could only identify studies of people with COPD and cancer. Studies of the other patient groups are also needed. One study identified in the review update included people with different life-limiting diseases (see Hardy 2016 in Characteristics of studies awaiting classification section).

We judged seven out of eight studies to be of high quality on the Edwards Method Score (15 or more on the scale) (Edwards 2003). To minimise the risk of bias, we excluded one study from the meta-analysis due to low methodological quality (high risk of bias) based on both the Edwards Method Score and the Cochrane 'Risk of bias' tool (Eimer 1985). However, the single-blinding process in two studies (Navigante 2006; Navigante 2010), and the exclusion of dropouts from analysis, increased the risk of bias in all studies. The 'Risk of bias' tool also revealed that most studies were at unclear risk regarding allocation concealment and potential attrition bias (see "Risk of bias in included studies") (Figure 3). The Edwards Method Score has previously been used successfully for judging the quality of non-pharmacological interventions (for example communication sessions and treatments of breathlessness) (Bausewein 2008; Edwards 2003). Our experience of using the Edwards Method Score to assess the quality of a pharmacological intervention in this review was good, however the tool seems to overestimate the quality of studies compared to the Cochrane 'Risk of bias' tool.

\section{Potential biases in the review process}

We combined cross-over trials and studies with a parallel design in the meta-analysis and treated the cross-over studies as parallel design. We did this after a critical analysis of all studies, review of the literature (Elbourne 2002; Higgins 2011), discussion with a statistician, and the following judgements:

1. the cross-over design was suitable for the targeted research questions;

2. none of the cross-over studies showed evidence of a carry-over effect;

3. dropouts were excluded from analysis;

4. there was no evidence for a period effect. This approach can produce a unit-of-analysis error.

However, this error leads to a conservative analysis and underweighs the cross-over studies (Higgins 2011). Most cross-over studies did not show an effect of benzodiazepines in the relief of breathlessness. This conservative analysis therefore supports our conclusion. In addition, sensitivity analysis showed no difference when analysing the cross-over studies separately (Figure 4).

Two studies presented only median scores for post-treatment measures because of skewed data (Navigante 2006; Navigante 2010). The mean and standard deviation (SD) was needed to include these studies in the meta-analysis. Instead of calculating the mean and SD from the median and range, we followed the advice of the statistician of the Cochrane Pain, Palliative and Supportive Care Review Group and obtained the mean and SD from the raw data provided by the author. With this approach we were able to include these studies in the meta-analysis.

Although we used a broad search strategy, we could have missed some unpublished data, such as PhD or Masters theses. However, we identified two unpublished studies through circular mails and personal contact with authors in the original review (Harrison (unpublished); Navigante 2010) (see Characteristics of ongoing studies).

\section{Agreements and disagreements with other studies or reviews}

Three excluded studies assessed breathlessness in healthy participants and could not find a beneficial effect of diazepam (Jones 1985; Stark 1981a; Stark 1981b). The trial from Hosaka 1996 was the only study excluded because the participants were 
at non-advanced disease stage (chronic respiratory insufficiency but lung function tests above our inclusion criteria). This study was also the only non-RCT study, but with a high risk of bias. A statistically significant improvement in the relief of breathlessness was seen in the intervention group in change from baseline. However, baseline data between intervention and control groups were different. Other methodological problems in this study (no wash-out phase, breathlessness not primary outcome, sample of participants included a few people with potentially curable disease) necessitate careful interpretation of results. Apart from this trial, we identified no study that looked at people with a non-advanced disease stage. Furthermore, we included only RCTs in order to reduce the risk of bias, but expected some uncontrolled trials in this area. Surprisingly, we could only find one uncontrolled study (Greene 1989). This case study reported a beneficial effect of alprazolam in one participant. One excluded study was a singlesite, open-label pilot study of clonazepam together with sustainedrelease morphine with 10 participants who completed the study showed promising results (safety, feasibility) in order to justify a definitive phase III study (Allcroft 2013).

After little research activity in this field, with a few studies in the 1980s and no studies during the 1990s, the set-up of four trials during the last conduction of this review possibly offers hope for further studies, which are urgently needed.

\section{AUTHORS' CONCLUSIONS}

\section{Implications for practice}

For the update of this review, we identified one additional study for inclusion, but the conclusions remain unchanged.

- There is no evidence for a beneficial effect of benzodiazepines in the relief of breathlessness in people with advanced cancer and COPD. There is a non-significant beneficial effect, but the overall effect size is small. Benzodiazepines caused more drowsiness as an adverse effect compared to placebo but less compared to morphine. These results justify considering benzodiazepines as second- or third-line treatment, when opioids and non-pharmacological measures have failed to control breathlessness. Although we included a few low- to highquality studies in this review, there is still a further need for wellconducted and adequately powered studies in this field.

- There is currently not enough evidence to support the use of benzodiazepines in the prevention of episodic breathlessness in people with cancer. There are no data from controlled trials for the treatment of episodic breathlessness with benzodiazepines.

- There are no differences regarding the type of benzodiazepine, dose, mode and frequency of administration, and duration of treatment.

\section{Implications for research}

Although we included a few high-quality studies in this review, there is still a further need for more well-conducted and larger studies in this field. Further research should pay attention to the following issues.

- Larger studies with more participants to reach a statistically sound conclusion are required.

- More attention should be paid to the reporting of methodological details of randomised controlled trials because this is essential for interpretation of the results.

- Studies in chronic heart failure (CHF), motor neurone disease (MND), idiopathic pulmonary fibrosis (IPF), and other lifethreatening diseases with breathlessness (e.g. advanced renal failure) are needed.

- Treatment of episodic breathlessness with benzodiazepines has not yet been studied in controlled trials.

- Benzodiazepines in the relief of breathlessness with panic attacks might be worth studying.

\section{ACKNOWLEDGEMENTS}

We are grateful to John Plummer (statistician of the Cochrane Review Group) for his very helpful comments and discussions regarding statistical methods and analysis. We are also grateful to Dr Yoshie Shizusawa, who helped with the extraction of data from the Japanese paper. Many thanks to Dr Fliss Murtagh for comments on an earlier draft of this review. We thank Joanne Abbott from the Cochrane Pain, Palliative and Supportive Care Review Group for her great support with the literature searches for the update.

The following peer referees contributed feedback to initial drafts of the review: Fiona Cramp, Ollie Minton, and Paul Perkins.

Cochrane Review Group funding acknowledgement: The National Institute for Health Research (NIHR) is the largest single funder of the Cochrane PaPaS Group. Disclaimer: The views and opinions expressed therein are those of the authors and do not necessarily reflect those of the NIHR, National Health Service (NHS) or the Department of Health. 


\section{RE F E R E N C E S}

\section{References to studies included in this review}

\section{Eimer 1985 \{published data only\}}

Eimer M, Cable T, Gal P, Rothenberg LA, McCue JD. Effects of clorazepate on breathlessness and exercise tolerance in patients with chronic airflow obstruction. Journal of Family Practice 1985;21:359-62.

\section{Harrison (unpublished) \{unpublished data only\}} Harrison TJR. A comparison of the effectiveness of oral lorazepam and placebo in relieving breathlessness associated with advanced cancer. (MSc thesis, 2004).

\section{Man 1986 \{published data only\}}

Man GCW, Hsu K, Sproule BJ. Effect of alprazolam on exercise and dyspnea in patients with chronic obstructive pulmonary disease. Chest 1986;90:832-6.

\section{Navigante 2006 \{published data only\}}

Navigante AH, Cerchietti LC, Castro MA, Lutteral MA, Cabalar ME. Midazolam as adjunct therapy to morphine in the alleviation of severe dyspnea perception in patients with advanced cancer. Journal of Pain and Symptom Management 2006;31:38-47.

\section{Navigante 2010 \{published and unpublished data\}}

Navigante AH, Castro MA, Cerchietti LC. Morphine versus midazolam as upfront therapy to control dyspnea perception in cancer patients while its underlying cause is sought or treated. Journal of Pain and Symptom Management 2010;39(5):820-30.

\section{Shivaram 1989 \{published data only\}}

Shivaram U, Cash M, Finch P. Effects of alprazolam on gas exchange, breathing pattern, and lung function in COPD patients with anxiety. Respiratory Care 1989;34:196-200.

\section{Stege 2010 \{published data only\}}

Stege G, Heijdra YF, van den Elshout FJ, van de Ven MJ, de Bruijn PJ, van Sorge AA, et al. Temazepam $10 \mathrm{mg}$ does not affect breathing and gas exchange in patients with severe normocapnic COPD. Respiratory Medicine 2010;104(4):518-24.

\section{Woodcock 1981 \{published data only\}}

Woodcock AA, Gross ER, Geddes DM. Drug treatment of breathlessness: contrasting effects of diazepam and promethazine in pink puffers. British Medical Journal 1981:283:343-6.

\section{References to studies excluded from this review}

Allcroft 2013 \{published data only\}

Allcroft P, Margitanovic V, Greene A, Agar MR, Clark K, Abernethy AP, et al. The role of benzodiazepines in breathlessness: a single site, open label pilot of sustained release morphine together with clonazepam. Journal of Palliative Medicine 2013;16(7):741-4. [PUBMED: 23597092]

\section{Allen 1984 \{published data only\}}

Allen SC. Treatment of dyspnoea: the role of drugs. Drugs of Today 1984;8:397-403.
Anonymous 1980a \{published data only\}

Anonymous (Lancet). Diazepam and breathlessness. Lancet 1980;2:242-3

Anonymous 1980b \{published data only\}

Anonymous (British Medical Journal). Centrally acting drugs in chronic airways obstruction. British Medical Journal 1980;281:1232-3.

Appel 1989 \{published data only\}

Appel M, Bron HN, Hooymans PM, Janknegt R. Efficacy of flumazenil in COPD patient with therapeutic diazepam levels. The Lancet 1989;1:392.

\section{Argyropoulou 1993 \{published data only\}}

Argyropoulou P, Patakas D, Koukou A, Vasiliadis P, Georgopoulos D. Buspirone effect on breathlessness and exercise performance in patients with chronic obstructive pulmonary disease. Respiration 1993;60:216-20.

Bar-Or 1982 \{published data only\}

Bar-Or D, Marx JA, Good J. Breathlessness, alcohol, and opiates. The New England Journal of Medicine 1982;306(22):1363-4.

\section{Beaupre 1988 \{published data only\}}

Beaupre A, Soucy R, Phillips R, Bourgouin J. Respiratory center output following zopiclone or diazepam administration in patients with pulmonary disease. Respiration 1988;54(4):235-40.

Borson 1992 \{published data only\}

Borson S, McDonald GJ, Gayle T, Deffebach M, Lakshminarayan S, VanTuinen C. Improvement in mood, physical symptoms, and function with nortriptyline for depression in patients with chronic obstructive pulmonary disease. Psychosomatics 1992;33(2):190-201.

\section{Bottomley 1990 \{published data only\}}

Bottomley DM, Hanks GW. Subcutaneous midazolam infusion in palliative care. Journal of Pain and Symptom Management 1990;5:259-61.

\section{Boyden 2015 \{published data only\}}

Boyden JY, Connor SR, Otolorin L, Nathan SD, Fine PG, Davis MS, et al. Nebulized medications for the treatment of dyspnea: $A$ literature review. Journal of Aerosol Medicine and Pulmonary Drug Delivery 2015; Vol. 28, issue 1:1-19. [1941-2711]

\section{Catchlove 1971a \{published data only\}}

Catchlove RF, Kafer ER. The effects of diazepam on the ventilatory response to carbon dioxide and on steady-state gas exchange. Anesthesiology 1971;34(1):9-13.

\section{Catchlove 1971b \{published data only\}}

Catchlove RF, Kafer ER. The effects of diazepam on respiration in patients with obstructive pulmonary disease. Anesthesiology 1971;34(1):14-8. 
Cherny 2014 \{published data only\}

Cherny NI. ESMO clinical practice guidelines for the management of refractory symptoms at the end of life and the use of palliative sedation. Annals of Oncology 2014; Vol. 25:iii143-52. [0923-7534]

\section{Clark 1971 \{published data only\}}

Clark TJH. Respiratory depression caused by nitrazepam in patients with respiratory failure. The Lancet 1971;2:737-8.

\section{Clemens 2011 \{published data only\}}

Clemens KE, Klaschik E. Dyspnoea associated with anxiety - symptomatic therapy with opioids in combination with lorazepam and its effect on ventilation in palliative care patients. Supportive Care in Cancer 2011; Vol. 19, issue 12:2027-33. [1433-7339]

\section{Cohn 1992 \{published data only\}}

Cohn MA, Morris DD, Juan D. Effects of estazolam and flurazepam on cardiopulmonary function in patients with chronic obstructive pulmonary disease. Drug Safety 1992;7(2):152-8.

\section{Daubert 2014 \{published data only\}}

Daubert E, Bolesta S. Effect of lorazepam versus morphine on quality of life in hospice patients with dyspnea and anxiety. Journal of the American Pharmacists Association 2014, issue 2:e193.

\section{Denaut 1974 \{published data only\}}

Denaut M, Yernault JC, De CA. Double-blind comparison of the respiratory effects of parenteral lorazepam and diazepam in patients with chronic obstructive lung disease. Current Medical Research and Opinion 1974;2:611-5.

\section{De Sousa 1988 \{published data only\}}

De Sousa E, Jepson BA. Midazolam in terminal care. The Lancet 1988;331:67-8.

\section{Dolly 1982 \{published data only\}}

Dolly FR, Block AJ. Effect of flurazepam on sleep-disordered breathing and nocturnal oxygen desaturation in asymptomatic subjects. American Journal of Medicine 1982;73(2):239-43.

\section{Dowson 2004 \{published data only\}}

Dowson CA, Kuijer RG, Mulder RT. Anxiety and self-management behaviour in chronic obstructive pulmonary disease: what has been learned?. Chronic Respiratory Disease 2004;1(4):213-20.

\section{Ekstrom 2015 \{published data only\}}

Ekstrom MP, Abernethy AP, Currow DC. The management of chronic breathlessness in patients with advanced and terminal illness. BMJ (Online) 2015; Vol. 349, issue g7617. [0959-8146]

\section{Fonsmark 2015 \{published data only\}}

Fonsmark L, Hein L, Nibroe H, Bundgaard H, De Haas I, Iversen $\mathrm{S}$, et al. Danish national sedation strategy. Targeted therapy of discomfort associated with critical illness. Danish Society of Intensive Care Medicine (DSIT) and the Danish Society of Anesthesiology and Intensive Care Medicine (DASAIM). Danish Medical Journal 2015; Vol. 62, issue 4:1-5.

\section{Forster 1983 \{published data only\}}

Forster A, Morel D, Bachmann M, Gemperle M. Respiratory depressant effects of different doses of midazolam and lack of reversal with naloxone: a double-blind randomized study. Anesthesia Analgesia 1983;62:920-4.

Gaddie 1972 \{published data only\}

Gaddie J, Legge JS, Palmer KNV, Petrie JC, Wood RA. Effect of nitrazepam in chronic obstructive bronchitis. British Medical Journal 1972;2:688-9.

Garrett 2015 \{published data only\}

Garrett Key R. Psychiatric care of lung cancer patients. Oncology 2015; Vol. 29, issue 3. [0890-9091]

Geddes 1976 \{published data only\} Geddes DM, Rudolf M, Saunders KB. Effect of nitrazepam and flurazepam on the ventilatory response to carbon dioxide. Thorax 1976;31:548-51.

Gomutbutra 2013 \{published data only\}

Gomutbutra P, O'Riordan DL, Pantilat SZ. Management of moderate-to-severe dyspnea in hospitalized patients receiving palliative care. Journal of Pain and Symptom Management 2013; Vol. 45, issue 5:885-91. [1873-6513]

Greene 1989 \{published data only\}

Greene JG, Pucino F, Carlson JD, Storsved M. Effects of alprazolam on respiratory drive, anxiety, and dyspnea in chronic airflow obstruction: a case study. Pharmacotherapy 1989;9:34-8.

\section{Guilleminault 1993 \{published data only\}}

Guilleminault C, Clerk A, Labanowski M, Simmons J, Stoohs R. Cardiac failure and benzodiazepines. Sleep 1993;16(6):524-8.

\section{Guz 1980 \{published data only\}}

Guz A, Minty K, Adams L, Rosser R. Quantifying dyspnoea and the use of drugs to alleviate the symptom. Clinical Respiratory Physiology 1980;16:209.

Heinonen 1972 \{published data only\} Heinonen J, Muittari A. The effect of diazepam on airway resistance in asthmatics. Anaesthesia 1972;27:37-40.

\section{Hoeijer 1994 \{published data only\}}

Hoeijer U, Hedner J, Ejnell H, Grunstein R, Odelberg E, Elam M. Nitrazepam in patients with sleep apnoea: a double-blind placebo-controlled study. European Respiratory Journal 1994;7(11):2011-5.

\section{Horfarter 2006 \{published data only\}}

Horfarter B, Weixler D. Symptom control and ethics in final stages of COPD. Wiener Medizinische Wochenschrift 2006;156:275-82.

\section{Hosaka 1996 \{published data only\}}

Hosaka M, Hoshimyama Y. Effects of diazepam on quality of life in patients receiving home oxygen therapy: a double-blind, cross-over, placebo-controlled clinical trial [Japanese]. Journal of the Showa Medical Association 1996;5:522-9. 
Huttemann 1971 \{published data only\}

Huttemann U, Kunkel G, Lode H, Hass E. The influence of laevomepromazine and prometazine on respiration in healthy subjects and patients with pulmonary emphysema. Arzneimittelforschung 1971;21(10):1594-8.

Johanson 1993 \{published data only\}

Johanson GA. Midazolam in terminal care. American Journal of Hospice and Palliative Care 1993;10:13-4.

\section{Jokinen 1984 \{published data only\}}

Jokinen K. Flupenthixol versus diazepam in the treatment of psychosomatic disorders: a double-blind, multi-centre trial in general practice. Pharmatherapeutica 1984;3(9):573-81.

\section{Jolly 1996 \{published data only\}}

Jolly E, Aguirre L, Jorge E, Luna C. Acute effect of lorazepam on respiratory muscles in stable patients with chronic obstructive pulmonary disease. Medicina (B Aires) 1996;56:472-8.

\section{Jones 1985 \{published data only\}}

Jones AL, Cameron IR. The effect of promethazine and diazepam on respiratory control in breathless patients (abstract). Clinical Science 1985;69:6.

\section{Kaltsas 2014 \{published data only\}}

Kaltsas K, Anevlavis S, Bouros D. Safety of opioids and benzodiazepines in patients with breathlessness and respiratory failure associated with chronic obstructive pulmonary disease. Pneumon 2014; Vol. 27, issue 3:197-9. [1105-848X]

\section{Kann 1968 \{published data only\}}

Kann J, Jokl H. On the therapy of asthmatic dyspnea. Medizinische Klinik 1968;63(45):1814-8.

\section{Kronenberg 1975 \{published data only\}}

Kronenberg RS, Cosio MG, Stevenson JE, Drage CW. The use of oral diazepam in patients with obstructive lung disease and hypercapnia. Annals of Internal Medicine 1975;83(1):83-4.

Lakshminarayan 1976 \{published data only\}

Lakshminarayan S, Sahn SA, Hudson LD, Weil JV. Effect of diazepam on ventilatory responses. Clinical Pharmacology and Therapeutics 1976;20(2):178-83.

\section{Lareau 1999 \{published data only\}}

Lareau SC, Meek PM, Press D, Anholm JD, Roos PJ. Dyspnea in patients with chronic obstructive pulmonary disease: does dyspnea worsen longitudinally in the presence of declining lung function?. Heart \& Lung 1999;28(1):65-73.

\section{Laros 1982 \{published data only\}}

Laros CD, Bergstein PG. Relief of breathlessness in a case of progressive pulmonary fibrosis. Respiration 1982;43(6):452-7.

\section{Lichterfeld 1967 \{published data only\}}

Lichterfeld A. Controlled therapeutic comparison of antiasthmatics in out-patients in a double-blind experiment. Arzneimittel-Forschung 1967;17:1318-21.

\section{Light 1996 \{published data only\}}

Light RW, Stansbury DW, Webster JS. Effect of $30 \mathrm{mg}$ of morphine alone or with promethazine or prochlorperazine on the exercise capacity of patients with COPD. Chest 1996;109(4):975-81.

Marin 1987 \{published data only\}

Marin I, Andrieu J-M, Chretien J. Bronchopulmonary carcinoma: a medical approach to the last weeks of life; a study of 191 cases. Annales de Medecine Interne 1987;138(2):90-5.

\section{Mclver 1994 \{published data only\}}

Mclver B, Walsh D, Nelson K. The use of chlorpromazine for symptom control in dying cancer patients. Journal of Pain and Symptom Management 1994;9(5):341-5.

Mitchell-Heggs 1980a \{published data only\}

Mitchell-Heggs P, Murphy K, Minty K, Guz A, Patterson SC, Minty PS, et al. Diazepam in the treatment of dyspnoea in the 'Pink Puffer' syndrome. Quarterly Journal of Medicine 1980;49:9-20.

Mitchell-Heggs 1980b \{published data only\}

Mitchell-Heggs P, Guz A. Dyspnoea in 'pink puffers': the place of diazepam. British Journal of Diseases of the Chest 1980;74(4):418.

Mouzi 2014 \{published data only\}

Mouzi L, Ashutosh W. Anesthetic management during labor and delivery of a multiparous patient terminally ill with metastatic breast cancer. A\&A Case Reports 2014; Vol. 2, issue 4:48-9.

\section{Murciano 1990 \{published data only\}}

Murciano D, Aubier M, Palacios S, Pariente R. Comparison of zolpidem (Z), triazolam (T), and flunitrazepam (F) effects on arterial blood gases and control of breathing in patients with severe chronic obstructive pulmonary disease (COPD) (abstract). Chest 1990;97:51S-2S

\section{Murciano 1993 \{published data only\}}

Murciano D, Armengaud MH, Cramer PH, Neveux E, L'Heritier C, Pariente R, et al. Acute effects of zolpidem, triazolam and flunitrazepam on arterial blood gases and control of breathing in severe COPD. European Respiratory Journal 1993;6:625-9.

\section{Navigante 1997 \{published data only\}}

Navigante AH, Sauri A, Palazzo F, Coppola M, De CO, Kirchuk R, et al. Compared and randomized prospective trial between oxygenotherapy vs. morphine chlorhydrate + midazolam by subcutaneous route in patients with advanced cancer and dyspnea. Prensa Medica Argentina 1997;84:474-6.

\section{Navigante 2003 \{published data only\}}

Navigante AH, Cerchietti LCA, Cabalar ME. Morphine plus midazolam versus oxygen therapy on severe dyspnea management in the last week of life in hipoxemic advanced cancer patients. Medicina Paliativa 2003;10:14-9.

\section{NCT01687751 \{unpublished data only\}}

NCT01687751. Pilot study comparing treatment with dexmedetomidine to midazolam for symptom control 
in advanced cancer patients. clinicaltrials.gov/show/ NCT01687751.

\section{Nordt 1997 \{published data only\}}

Nordt SP, Clark RF. Midazolam: a review of therapeutic uses and toxicity. Journal of Emergency Medicine 1997;15(3):357-65.

\section{O'Donnell 1992 \{published data only\}}

O'Donnell DE, Webb KA. Breathlessness in patients with severe chronic airflow limitation. Physiologic correlations. Chest 1992;102(3):824-31.

\section{O'Donnell 1994 \{published data only\}}

O'Donnell DE. Breathlessness in patients with chronic airflow limitation. Mechanisms and management. Chest 1994;106(3):904-12.

\section{O'Donnell 1998 \{published data only\}}

O'Donnell DE. Dyspnea in advanced chronic obstructive pulmonary disease. Journal of Heart \& Lung Transplantation 1998;17(6):544-54.

\section{O'Neill 1985 \{published data only\}}

O'Neill PA, Morton PB, Stark RD. Chlorpromazine - a specific effect on breathlessness?. British Journal of Clinical Pharmacology 1985;19:793-7.

\section{Rao 1973 \{published data only\}}

Rao S, Sherbaniuk RW, Prasad K, Lee SJ, Sproule BJ. Cardiopulmonary effects of diazepam. Clinical Pharmacology \& Therapeutics 1973;14(2):182-9.

\section{Rapoport 1991 \{published data only\}}

Rapoport DM, Greenberg HE, Goldring RM. Differing effects of the anxiolytic agents buspirone and diazepam on control of breathing. Clinical Pharmacology and Therapeutics 1991;49:394-401.

\section{Rice 1986 \{published data only\}}

Rice KL. Treatment of dyspnea with psychotropic agents. Chest 1986;90:789-90.

\section{Rice 1987 \{published data only\}}

Rice KL, Kronenberg RS, Hedemark LL, Niewoehner DE. Effects of chronic administration of codeine and promethazine on breathlessness and exercise tolerance in patients with chronic airflow obstruction. British Journal of Disease of the Chest 1987;81(3):287-92.

\section{Rodriguez-Roisin 2014 \{published data only\}}

Rodriguez-Roisin R, Garcia-Aymerich J. Should we exercise caution with benzodiazepine use in patients with COPD?. European Respiratory Journal 2014; Vol. 44, issue 2:284-6. [0903-1936]

\section{Rose 2002 \{published data only\}}

Rose C, Wallace L, Dickson R, Ayres J, Lehman R, Searle Y. The most effective psychologically-based treatments to reduce anxiety and panic in patients with chronic obstructive pulmonary disease (COPD): a systematic review. Patient Education Counseling 2002;47(4):311-8.
Rudolf 1978 \{published data only\}

Rudolf M. Depression of central respiratory drive by nitrazepam. Thorax 1978;33:97-100.

Runo 2001 \{published data only\}

Runo JR, Ely EW. Treating dyspnea in a patient with advanced chronic obstructive pulmonary disease. Western Journal of Medicine 2001;175(3):197-201.

\section{Schultze-Werninghaus 2007 \{published data only\}}

Schultze-Werninghaus G, Steinkamp G, Gillissen A, Pfeifer M, Lorenz J, Worth $\mathrm{H}$, et al. The critically ill patient with COPD. Pneumologie 2007;61(6):410-9.

\section{Sen 1983 \{published data only\}}

Sen $D$, Jones $G$, Leggat PO. The response of the breathless patient treated with diazepam. British Journal of Clinical Practice 1983;37:232-3.

\section{Singh 1993 \{published data only\}}

Singh NP, Despars JA, Stansbury DW, Avalos K, Light RW. Effects of buspirone on anxiety levels and exercise tolerance in patients with chronic airflow obstruction and mild anxiety. Chest 1993;103(3):800-4.

Smith 2015 \{published data only\}

Smith TJ. Symptom management in the older adult. 2015 Update. Clinics in Geriatric Medicine 2015; Vol. 31, issue 2:155-75. [0749-0690]

\section{Stark 1981a \{published data only\}}

Stark RD, Gambles SA. Does diazepam reduce breathlessness in healthy subjects? (abstract). British Journal of Clinical Pharmacology 1982;13:600.

Stark 1981b \{published data only\}

Stark RD, Gambles SA, Lewis JA. Methods to assess breathlessness in healthy subjects: a critical evaluation and application to analyse the acute effects of diazepam and promethazine on breathlessness induced by exercise or by exposure to raised levels of carbon dioxide. Clinical Science 1981;61:429-39.

\section{Stark 1983 \{published data only\}}

Stark RD, O'Neill PA. Dihydrocodeine for breathlessness in pink puffers. British Journal of Medicine 1983;286:1280-1.

Stark 1988 \{published data only\}

Stark RD. Dyspnoea: Assessment and pharmacological manipulation. European Respiratory Journal 1988;1(3):280-7.

Steens 1993 \{published data only\}

Steens RD, Pouliot Z, Millar TW, Kryger MH, George CF. Effects of zolpidem and triazolam on sleep and respiration in mild to moderate chronic obstructive pulmonary disease. Sleep 1993;16:318-26.

\section{Tenorio 2012 \{published data only\}}

Tenorio Carmona B, Ramirez Rodriguez G, Rangel Selvera OA, Ales Siles I, Sanchez Del Corral Usaola F, Ruiperez Cantera I. Associated symptoms to terminality in elderly patient and 
the necessity of subcutaneous application at the home care assistance. European Geriatric Medicine 2012; Vol. 3:S47. [1878-7649]

\section{Timms 1988 \{published data only\}}

Timms RM, Dawson A, Hajdukovic RM, Mitler MM. Effect of triazolam on sleep and arterial oxygen saturation in patients with chronic obstructive pulmonary disease. Archives of Internal Medicine 1988;148:2159-63.

Vozoris 2013 \{published data only\}

Vozoris NT, Fischer HD, Wang X, Anderson GM, Bell CM, Gershon AS, et al. Benzodiazepine use among older adults with chronic obstructive pulmonary disease: a populationbased cohort study. Drugs \& Aging 2013; Vol. 30, issue 3:183-92. [1170-229X]

Walsh 1993 \{published data only\}

Walsh D. Dyspnoea in advanced cancer. The Lancet 1993;342:450-1.

\section{Wanrooij 2005 \{published data only\}}

Wanrooij B, Koelewijn M. Dyspnea relief in the palliative phase. Huisarts en Wetenschap 2005;48(5):239-45.

\section{Wiedemann 1995 \{published data only\}}

Wiedemann K, Diestelhorst C. The effect of sedation on pulmonary function. Anaesthetist 1995;44:588-93.

\section{Wilson 1954 \{published data only\}}

Wilson RH, Hoseth W, Dempsey ME. Respiratory acidosis. I. Effects of decreasing respiratory minute volume in patients with severe chronic pulmonary emphysema, with specific reference to oxygen, morphine and barbiturates. American Journal of Medicine 1954;17(4):464-70.

\section{Woodcock 1981a \{published data only\}}

Woodcock AA, Gross ER, Gellert A, Shah S, Johnson M, Geddes DM. Effects of dihydrocodeine, alcohol, and caffeine on breathlessness and exercise tolerance in patients with chronic obstructive lung disease and normal blood gases. The New England Journal of Medicine 1981;305(27):1611-6.

Woodcock 1981b \{published data only\} Woodcock AA, Gross ER, Geddes DM. Oxygen relieves breathlessness in "pink puffers". The Lancet 1981;317(8226):907-9.

\section{References to studies awaiting assessment}

\section{Hardy 2016 \{published data only\}}

Hardy J, Randall C, Pinkerton E, Flatley C, Gibbons K, Allan S. A randomised, double-blind controlled trial of intranasal midazolam for the palliation of dyspnoea in patients with life-limiting disease. Support Care Cancer 2016;24:3069. [DOI: 10.1007/s00520-016-3125-2]

Hart 2012 \{published data only (unpublished sought but not used)\} Hart DE, Corna NE, Horwood F, Maingay G. Randomised control trial of intranasal midazolam or oral lorazepam for the relief of dyspnoea in severe respiratory disease [Abstract]. American Journal of Respiratory and Critical Care Medicine 2012;185:A2953.

\section{Additional references \\ Abernethy 2008}

Abernethy AP, Uronis HE, Wheeler JL, Currow DC. Pharmacological management of breathlessness in advanced disease. Progress in Palliative Care 2008;16(1):15-20.

\section{Altose 1985}

Altose MD. Assessment and management of breathlessness. Chest 1985;88:77S-83S.

\section{Bausewein 2008}

Bausewein C, Booth S, Gysels M, Higginson IJ. Nonpharmacological interventions for breathlessness in advanced stages of malignant and non-malignant diseases. Cochrane Database of Systematic Reviews 2008, Issue 2. [DOI: 10.1002/14651858.CD005623.pub2]

\section{Beach 2006}

Beach D, Schwartzstein RM. The genesis of breathlessness what do we understand?. In: Booth S, Dudgeon D editor(s). Dyspnoea in Advanced Disease - a Guide to Clinical Management. 1st Edition. Oxford: Oxford University Press, 2006:1-18.

\section{Booth 2006}

Booth S, Dudgeon D, editors. Dyspnoea in Advanced Disease - a Guide to Clinical Management. 1st Edition. Oxford: Oxford University Press, 2006.

\section{Booth 2008}

Booth S, Moosavi SH, Higginson IJ. The etiology and management of intractable breathlessness in patients with advanced cancer: a systematic review of pharmacological therapy. Nature Clinical Practice Oncology 2008;5:90-100.

\section{Bruera 2006}

Bruera E, Higginson IJ, Robb SD, von Gunten CF. Textbook of Palliative Medicine. 1st Edition. London: Hodder Arnold, 2006.

\section{Cranston 2008}

Cranston JM, Crockett A, Currow D. Oxygen therapy for dyspnoea in adults. Cochrane Database of Systematic Reviews 2008, Issue 3. [DOI: 10.1002/14651858.CD004769.pub2]

\section{Currow 2010}

Currow DC, Smith J, Davidson PM, Newton PJ, Agar MR, Abernethy AP. Do the trajectories of dyspnea differ in prevalence and intensity by diagnosis at the end of life? A consecutive cohort study. Journal of Pain and Symptom Management 2010;39(4):680-90.

\section{Davis 1997}

Davis CL. ABC of palliative care. BMJ 1997;315(7113):931-4. 


\section{Davis 2005}

Davis C. Drug therapies. In: Ahmedzai SH, Muers MF editor(s). Supportive Care in Respiratory Disease. 1st Edition. Oxford: Oxford University Press, 2005:147-63.

\section{De Conno 1991}

De Conno F, Spoldi E, Caraceni A, Ventafridda V. Does pharmacological treatment affect the sensation of breathlessness in terminal cancer patients?. Palliative Medicine 1991;5:237-43

\section{Dorman 2009}

Dorman S, Jolley C, Abernethy A, Currow D, Johnson M, Farquhar M, et al. Researching breathlessness in palliative care: consensus statement of the National Cancer Research Institute Palliative Care Breathlessness Subgroup. Palliative Medicine 2009;23(3):213-27.

\section{Edwards 2001}

Edwards A, Elwyn G, Covey J, Matthews E, Pill R. Presenting risk information - a review of the effects of "framing" and other manipulations on patient outcomes. Journal of Health Communication 2001;6(1):61-82. [PUBMED: 11317424]

\section{Edwards 2003}

Edwards A, Unigwe S, Elwyn G, Hood K. Personalised risk communication for informed decision making about entering screening programs. Cochrane Database of Systematic Reviews 2003, Issue 4. [DOI: 10.1002/14651858.CD001865.pub2]

\section{Ekstrom 2014}

Ekstrom MP, Bornefalk-Hermansson A, Abernethy AP, Currow DC. Safety of benzodiazepines and opioids in very severe respiratory disease: national prospective study. BMJ 2014;348:g445.

\section{Elbourne 2002}

Elbourne DR, Altman DG, Higgins JPT, Curtin F, Worthington HV, Vail A. Meta-analyses involving cross-over trials: methodological issues. International Journal of Epidemiology 2002;31:140-9.

\section{GOLD 2007}

Global Initiative for Chronic Obstructive Lung Disease (GOLD). Global strategy for the diagnosis, management and prevention of COPD (2007). http://www.goldcopd.org (accessed 31 January 2008).

\section{Hardman 2005}

Hardman JG, Limbird LE. Goodman \& Gilman's The Pharmacological Basis of Therapeutics. 11th Edition. New York: McGraw-Hill, 2005.

\section{Higgins 2011}

Higgins JPT, Green S (editors). Cochrane Handbook for Systematic Reviews of Interventions, The Cochrane Collaboration. Available from www.cochrane-handbook.org Version 5.1.0 [updated March 2011].

\section{Higginson 2004}

Higginson IJ, Addington-Hall J. The epidemiology of death and symptoms. In: Doyle D, Hanks G, Cherny N, Calman K editor(s).
Oxford Textbook of Palliative Medicine. 3rd Edition. Oxford: Oxford University Press, 2004:14-24.

\section{Jennings 2001}

Jennings AL, Davies AN, Higgins JP, Broadley K. Opioids for the palliation of breathlessness in terminal illness. Cochrane Database of Systematic Reviews 2001, Issue 4. [DOI: 10.1002/14651858.CD002066]

\section{Lanken 2008}

Lanken PN, Terry PB, Delisser HM, Fahy BF, Hansen-Flaschen J, Heffner JE, et al. An official American Thoracic Society clinical policy statement: palliative care for patients with respiratory diseases and critical illnesses. Journal of Respiratory and Critical Care Medicine 2008;177(8):912-27.

\section{Manning 1995}

Manning HL, Schwartzstein RM. Pathophysiology of dyspnea. The New England Journal of Medicine 1995;333:1547-53.

\section{Manning 2000}

Manning HL. Dyspnea treatment. Respiratory Care 2000;45(11):1342-50.

\section{Moens 2014}

Moens K, Higginson IJ, Harding R. Are there differences in the prevalence of palliative care-related problems in people living with advanced cancer and eight non-cancer conditions? A systematic review. Journal of Pain and Symptom Management 2014; Vol. 48, issue 4:660-77. [PUBMED: 24801658]

\section{Neuman 2006}

Neuman A, Gunnbjornsdottir M, Tunsater A, Nystrom L, Franklin KA, Norrman E, et al. Dyspnea in relation to symptoms of anxiety and depression: a prospective population study. Respiratory Medicine 2006;100:1843-9.

\section{Nordgren 2003}

Nordgren L, Sorensen S. Symptoms experienced in the last six months of life in patients with end-stage heart failure. European Journal of Cardiovascular Nursing 2003;2:213-7.

\section{Parshall 2012}

Parshall MB, Schwartzstein RM, Adams L, Banzett RB, Manning HL, Bourbeau J, et al. An Official American Thoracic Society Statement: Update on the Mechanisms, Assessment, and Management of Dyspnea. American Journal of Respiratory and Critical Care Medicine 2012;185(4):435-52.

\section{RevMan 2008 [Computer program]}

The Nordic Cochrane Centre. The Cochrane Collaboration. Review Manager (RevMan). Version 5.0. Copenhagen: The Nordic Cochrane Centre. The Cochrane Collaboration, 2008.

\section{RevMan 2014 [Computer program]}

The Nordic Cochrane Centre, The Cochrane Collaboration. Review Manager (RevMan). Version 5.3. Copenhagen: The Nordic Cochrane Centre, The Cochrane Collaboration, 2014. 


\section{Ripamonti 1999}

Ripamonti C. Management of dyspnea in advanced cancer patients. Supportive Care in Cancer 1999;7(4):233-43.

\section{Rocker 2007}

Rocker GM, Sinuff T, Horton R, Hernandez P. Advanced chronic obstructive pulmonary disease: innovative approaches to palliation. Journal of Palliative Medicine 2007;10(3):783-97.

\section{Seow 2011}

Seow H, Barbera L, Sutradhar R, Howell D, Dudgeon D, Atzema $\mathrm{C}$, et al. Trajectory of performance status and symptom scores for patients with cancer during the last six months of life. Journal of Clinical Oncology: Official Journal of the American Society of Clinical Oncology 2011;29(9):1151-8.

\section{Simon 2012}

Simon ST, Higginson IJ, Benalia H, Gysels M, Murtagh FE, Spicer J, et al. Episodic and continuous breathlessness: a new categorization of breathlessness. Journal of Pain and Symptom Management 2012;45(6):1019-29.

\section{CHARACTERISTICS OF STUDIES}

Characteristics of included studies [ordered by study ID]

\section{Simon 2014}

Simon ST, Weingärtner V, Higginson IJ, Voltz R, Bausewein C. Definition, categorization, and terminology of episodic breathlessness: consensus by an International Delphi Survey. Journal of Pain and Symptom Management 2014;47(5):828-38.

\section{Thomas 2002}

Thomas JR, Von Gunten CF. Clinical management of dyspnoea. The Lancet Oncology 2002;3(4):223-8.

\section{Tobin 1990}

Tobin MJ. Dyspnoea. Archives of Internal Medicine 1990;150:1604-13.

\section{Viola 2008}

Viola R, Kiteley C, Lloyd NS, Mackay JA, Wilson J, Wong RK, the Guideline Group. The management of dyspnea in cancer patients: a systematic review. Supportive Care Cancer 2008;16(4):329-37.

\section{Williams 2006}

Williams CM. Dyspnea. Cancer Journal 2006;12(5):365-73.

\section{Eimer 1985}

\section{Methods}

Design: RCT, cross-over, placebo-controlled

Blinding: double

Methodological quality: 10/22 (Edwards Method Score)

\begin{tabular}{|c|c|}
\hline \multirow[t]{11}{*}{ Participants } & Disease: COPD \\
\hline & Number (randomised): $\mathrm{N}=5$ \\
\hline & Setting: hospital \\
\hline & Age (years, mean): not stated (only range: 51 to 68 ) \\
\hline & Sex (male/female): 4/1 \\
\hline & Participant pool: 56 \\
\hline & Randomised: 5; study completed: 5 \\
\hline & $\begin{array}{l}\text { Withdrawals/dropouts: } 0 \text { (intervention } 2 \text { (clorazepate } 22.5 \mathrm{mg} \text { ) with } 3 \text { dropouts; } \\
\text { cluded from analysis) }\end{array}$ \\
\hline & Reason for drop-out (intervention 2): intolerable AEs (which AEs not mentioned) \\
\hline & Baseline parameters: FEV1 less than $50 \%$ \\
\hline & $\mathrm{SpO}_{2}(\mathrm{mmHg}): 65.36 ; \mathrm{SpCO}_{2}(\mathrm{mmHg}): 41.58$ \\
\hline
\end{tabular}

Interventions

Drug (dose): 1. clorazepate $(7.5 \mathrm{mg}$ ) at bedtime; 2 . clorazepate (22.5) $\mathrm{mg}$ at bedtime; 3. placebo

Delivery: oral

Duration of treatment: 2 weeks 
Eimer 1985 (Continued)

Outcomes
Breathlessness grade (1 to 6$)$

Results: no significant difference between clorazepate and placebo regarding dyspnoea and walking test (no numbers given; dyspnoea change only in graphs)

Adverse effects: none within the 5 participants in intervention 1 and placebo

$\mathrm{SpO}_{2}$ and $\mathrm{SpCO}_{2}$ : no significant change

Notes

Author conclusion: this study failed to demonstrate that placebo or clorazepate consistently relieved breathlessness in non-anxious people with severe COPD

\section{Risk of bias}

\begin{tabular}{|c|c|c|}
\hline Bias & Authors' judgement & Support for judgement \\
\hline $\begin{array}{l}\text { Random sequence genera- } \\
\text { tion (selection bias) }\end{array}$ & Unclear risk & $\begin{array}{l}\text { Method not mentioned } \\
\text { ("Patients were assigned in a randomised double-blind manner") }\end{array}$ \\
\hline $\begin{array}{l}\text { Allocation concealment } \\
\text { (selection bias) }\end{array}$ & Unclear risk & Not mentioned \\
\hline $\begin{array}{l}\text { Blinding (performance } \\
\text { bias and detection bias) } \\
\text { All outcomes }\end{array}$ & Unclear risk & Double-blinding stated in the abstract, but not mentioned further \\
\hline $\begin{array}{l}\text { Incomplete outcome data } \\
\text { (attrition bias) } \\
\text { All outcomes }\end{array}$ & Unclear risk & Not mentioned \\
\hline $\begin{array}{l}\text { Selective reporting (re- } \\
\text { porting bias) }\end{array}$ & High risk & Anxiety, depression, etc. were assessed but data not reported \\
\hline Other bias & High risk & $\begin{array}{l}\text { - Inclusion criterion "severe COPD" not explained (although the results of } \\
\text { - COPD functions did meet our inclusion criteria) } \\
\text { - No literature/validity regarding dyspnoea grading } \\
\text { - Lack of participant demographics (only gender and age range) } \\
\text { - No reasons for exclusion after screening } \\
\text { - Not clearly mentioned that "treatment" means " } 7.5 \mathrm{mg} \text { clorazepate" (con- } \\
\text { clusion made only after a statement that } 22.5 \mathrm{mg} \text { group was excluded due } \\
\text { to attrition) } \\
\text { - Results, especially for dyspnoea, poorly presented and difficult to read } \\
\text { - Data have been presented only in a graph describing "improvement" or } \\
\text { "worse" compared to baseline after first and second week of intervention or } \\
\text { - placebo } \\
\text { gumbers are only approximate, because it is difficult to read them in the }\end{array}$ \\
\hline
\end{tabular}

Harrison (unpublished)

Methods Design: RCT, cross-over, placebo-controlled

Blinding: double-blind 
Harrison (unpublished) (Continued)

Methodological quality: 18/22 (Edwards Method Score)

\begin{tabular}{|c|c|c|}
\hline \multirow[t]{8}{*}{ Participants } & \multicolumn{2}{|c|}{ Disease: advanced cancer (12/17 lung cancer) } \\
\hline & \multicolumn{2}{|c|}{ Number (randomised): $\mathrm{N}=26$} \\
\hline & \multicolumn{2}{|c|}{ Setting: outpatient and inpatient } \\
\hline & \multicolumn{2}{|c|}{ Age (years, SD): 67.2 (8.3) } \\
\hline & \multicolumn{2}{|l|}{ Sex (male/female): $16 / 1$} \\
\hline & \multicolumn{2}{|l|}{ Participant pool: 54} \\
\hline & \multicolumn{2}{|c|}{ Randomised: 26 ; study completed: 17} \\
\hline & \multicolumn{2}{|c|}{$\begin{array}{l}\text { Withdrawals/dropouts: } 9 \text { ( } 4 \text { drowsiness, } 1 \text { deterioration, } 1 \text { dysphagia, } 2 \text { death, } 1 \text { unclear) (excluded } \\
\text { from analysis) }\end{array}$} \\
\hline \multirow[t]{3}{*}{ Interventions } & \multicolumn{2}{|c|}{ Drug (dose): lorazepam ( $0.5 \mathrm{mg}$ twice daily = $1 \mathrm{mg}$ per day) } \\
\hline & \multicolumn{2}{|l|}{ Delivery: oral } \\
\hline & \multicolumn{2}{|c|}{ Duration of treatment: 5 days ( 2 days wash-out) } \\
\hline \multirow[t]{4}{*}{ Outcomes } & \multicolumn{2}{|c|}{ Dyspnoea VAS 0 to 100 ("How much trouble has your breathing caused you over the last 24 hours?") } \\
\hline & \multicolumn{2}{|c|}{$\begin{array}{l}\text { Results (mean): baseline to } 5 \text { days after intervention: } 1 \text {. lorazepam } 49.18 \text { to } 44.49 ; 2 \text {. placebo } 48.06 \text { to } \\
45.94\end{array}$} \\
\hline & \multicolumn{2}{|c|}{ Adverse effects (number of AEs/number with withdrawals): 1 . lorazepam: 5/3; 2 placebo: 4/1 } \\
\hline & \multicolumn{2}{|c|}{ No change or differences in anxiety and depression (HADS) } \\
\hline Notes & \multicolumn{2}{|c|}{$\begin{array}{l}\text { Author conclusion: there were no differences between lorazepam and placebo in relieving breathless- } \\
\text { ness }\end{array}$} \\
\hline \multicolumn{3}{|l|}{ Risk of bias } \\
\hline Bias & Authors' judgement & Support for judgement \\
\hline $\begin{array}{l}\text { Random sequence genera- } \\
\text { tion (selection bias) }\end{array}$ & Low risk & "...was randomly determined by computer prior to the study commencement" \\
\hline $\begin{array}{l}\text { Allocation concealment } \\
\text { (selection bias) }\end{array}$ & Low risk & "A randomisation list was kept by the pharmacy" \\
\hline $\begin{array}{l}\text { Blinding (performance } \\
\text { bias and detection bias) } \\
\text { All outcomes }\end{array}$ & Low risk & Study was blinded \\
\hline $\begin{array}{l}\text { Incomplete outcome data } \\
\text { (attrition bias) }\end{array}$ & Low risk & All data were presented \\
\hline All outcomes & & The study author sent the raw data in addition \\
\hline $\begin{array}{l}\text { Selective reporting (re- } \\
\text { porting bias) }\end{array}$ & Low risk & Study protocol is available \\
\hline Other bias & Low risk & Study appeared to be free of other bias \\
\hline
\end{tabular}


Man 1986

\begin{tabular}{ll}
\hline Methods & Design: RCT, cross-over, placebo-controlled \\
Blinding: double & Methodological quality: $16 / 22$ (Edwards Method Score) \\
\hline Participants & Disease: COPD \\
& Number (randomised): $\mathrm{N}=29$ \\
& Setting: outpatient \\
& Age (years, mean): 65.4 \\
& Sex (male/female): $16 / 8$ (complete) \\
& Participant pool: not stated \\
& Randomised: $29 ;$ study completed: 24 \\
& Withdrawals/dropouts: 5 (excluded from analysis) \\
& Reason for drop-out: 1 AE (placebo), 4 missed appointments \\
& Baseline parameters: FEV1/FVC: $54 \%$ \\
& SpO 2 (mmHg): $73.4 ;$ SpCO 2 (mmHg): 32.8
\end{tabular}

Control: placebo

Delivery: oral

Duration of treatment: 1 week

Dyspnoea grade at rest (1 to 5); dyspnoea scoring at rest and exercise (VAS 0 to 10)
Results (mean, baseline to after intervention): alprazolam: 3.0 to 3.0; placebo: 3.2 to 3.0
No significant change in dyspnoea scoring during rest and exercise
Adverse effects: 11 reported (7/11 drowsiness), $9 / 11$ on alprazolam
Functional test (12-minute walking test in metres; baseline to after intervention): alprazolam: 896.5 to
$880.88 ;$ placebo: 902.17 to 931.29
The resting $\mathrm{SpO}_{2}$ was significantly higher with placebo and exercising $\mathrm{SpCO}_{2}$ was significantly lower
with placebo
at rest and during exercise

\section{Risk of bias}

\begin{tabular}{lll}
\hline Bias & Authors' judgement & Support for judgement \\
\hline $\begin{array}{l}\text { Random sequence genera- } \\
\text { tion (selection bias) }\end{array}$ & Unclear risk & "...designed as a randomized..." \\
& & Not mentioned how this was done \\
\hline
\end{tabular}




\section{Man 1986 (Continued)}

\begin{tabular}{|c|c|c|}
\hline $\begin{array}{l}\text { Allocation concealment } \\
\text { (selection bias) }\end{array}$ & Unclear risk & Not mentioned \\
\hline $\begin{array}{l}\text { Blinding (performance } \\
\text { bias and detection bias) } \\
\text { All outcomes }\end{array}$ & Low risk & $\begin{array}{l}\text { "double-blind...using alprazolam and matching placebo" } \\
\text { Labelled bottles with tablets (alprazolam-placebo-wash-out) described in de- } \\
\text { tail } \\
\text { Probably done }\end{array}$ \\
\hline $\begin{array}{l}\text { Incomplete outcome data } \\
\text { (attrition bias) } \\
\text { All outcomes }\end{array}$ & Unclear risk & $\begin{array}{l}\text { Total screened patients not mentioned } \\
\text { No intention-to-treat analysis ( } 5 / 29 \text { lost were excluded from analysis), however } \\
\text { only one with AE (placebo) }\end{array}$ \\
\hline $\begin{array}{l}\text { Selective reporting (re- } \\
\text { porting bias) }\end{array}$ & Low risk & Broad information available, good summaries, good presentation \\
\hline Other bias & Low risk & Pharmaceutical funding (company with alprazolam), although negative results \\
\hline
\end{tabular}

\section{Navigante 2006}

\begin{tabular}{|c|c|}
\hline Methods & $\begin{array}{l}\text { Design: RCT, parallel, multi-arm (3), control: morphine and morphine + midazolam } \\
\text { Blinding: single-blind (only participant blinded) } \\
\text { Methodological quality: } 17 / 22 \text { (Edwards Method Score) }\end{array}$ \\
\hline Participants & $\begin{array}{l}\text { Disease: terminal cancer (life expectancy less than a week) } \\
\text { Number (randomised): } \mathrm{N}=101 \\
\text { Setting: hospital inpatient } \\
\text { Age (years, mean): } 57.3 \\
\text { Sex (male/female): } 47 / 54 \\
\text { Participant pool: } \mathrm{n}=146 \\
\text { Randomised: } 101 \text {; study completed: } 70 \\
\text { Withdrawals/dropouts: } 31 \text { (all deaths) (excluded from analysis) }\end{array}$ \\
\hline Interventions & $\begin{array}{l}\text { Drug (dose): } 1 . \text { morphine (Mo - } 10 \mathrm{mg} / \text { day); } 2 \text {. midazolam (Mi - } 20 \mathrm{mg} / \text { day); 3. morphine + midazolam } \\
\text { (MM - Mo } 10 \mathrm{mg} / \text { day + Mi } 20 \mathrm{mg} / \text { day) } \\
\text { Rescue dose: } 1 \text {. Mi } 5 \mathrm{mg} ; 2 . \text { Mo } 2.5 \mathrm{mg} ; 3 . \text { Mo } 2.5 \mathrm{mg} \text { (this means that all } 3 \text { treatment arms could include } \\
\text { a combination of morphine and midazolam) } \\
\text { Delivery: subcutaneous } \\
\text { Duration of treatment: } 48 \text { hours }\end{array}$ \\
\hline
\end{tabular}

\section{Outcomes}

Dyspnoea intensity: modified Borg scale 0 to 10

Results presented in the paper: baseline (mean) to after intervention $(24 / 48$ hours $=$ median and $\mathrm{P}$ values): 1 . (Mo) 7.1 to $3 / 2$ ( $P=0.002 / P=0.0001) ; 2$. (Mi) 6.9 to $4 / 2$ ( $P=0.018 / P=0.004) ; 3$. (MM) 6.8 to $3 / 2$ $(\mathrm{P}=0.003 / \mathrm{P}<0.0001)$ 
(Mean and $\mathrm{Cl}$ (95\%) for 24- and 48-hour measures received from the authors (data skewed): 1. (Mo) 24 hours: 3.9 (2.8 to 5.0), 48 hours: 2.8 (1.6 to 4.0); 2. (Mi) 24 hours: 4.1 (2.8 to 5.4), 48 hours: 3.1 (1.7 to 4.5); 3. (MM) 24 hours: 3.4 (2.4 to 4.4$)$, 48 hours: 3.0 (2.0 to 4.0$)$ )

Percentages of participants with breakthrough dyspnoea (24/48 hours): 1. (Mo) 34.3\%/38\%; 2. (Mi) $36.4 \% / 38.5 \%$; 3. (MM) $21.2 \% / 24 \%$

Numbers of breakthrough episodes of dyspnoea per participant (24/48 hours): 1. (Mo) 2/2;2. (Mi) 1/1; 3. (MM) $1 / 1$

Percentages of participants with dyspnoea relief after 24 hours: 1 . (Mo) $69 \%$ (P=0.03); 2. (Mi) $46 \%$ $(\mathrm{P}=0.004)$; 3. (MM) 92\% (P-values compare to $\mathrm{MM}$ )

Percentages of participants with persistent, uncontrolled dyspnoea after 48 hours: 1. (Mo) 12.6\%; 2. (Mi) 26\% ( $\mathrm{P}=0.04$ compare to $\mathrm{MM})$; 3. (MM) 4\%

Adverse effects: the most frequently recorded $\mathrm{AE}$ was somnolence $(\mathrm{Mo}>\mathrm{MM}>\mathrm{Mi})$

Oxygen saturation (mean; baseline to after intervention; $24 / 48$ hours): 1 . (Mo) $72 \%$ to $72 \% / 70 \%$; 2 . (Mi) $73 \%$ to $70 \% / 70 \%$; 3 . (MM) $73 \%$ to $73 \% / 71.5 \%$

Anxiety: significant correlation between dyspnoea and anxiety at all times

\section{Risk of bias}

\begin{tabular}{lll}
\hline Bias & Authors' judgement & Support for judgement \\
\hline $\begin{array}{l}\text { Random sequence genera- } \\
\text { tion (selection bias) }\end{array}$ & Low risk & "...using a random number generator in 1:1:1 ratio in blocks of nine" \\
\hline $\begin{array}{l}\text { Allocation concealment } \\
\text { (selection bias) }\end{array}$ & Unclear risk & Not mentioned how it was done \\
\hline $\begin{array}{l}\text { Blinding (performance } \\
\text { bias and detection bias) }\end{array}$ & Low risk & $\begin{array}{l}\text { "Drug administrations were performed in a single-blind fashion." } \\
\text { "One potential limitation of our study is the single-blinded nature of the de- } \\
\text { sign. The treating physicians' knowledge of which schedule of drugs the pa- } \\
\text { tient received could influence their need for administering rescue medica- } \\
\text { tions. A double-blind design can avoid this, but was considered not appropri- } \\
\text { ate for our study population by the Ethics Committee at our institution. Nev- } \\
\text { ertheless, the risk for underestimation of rescue needs was minimized by a } \\
\text { double assessment of breakthrough episodes carried out by caregivers and re- } \\
\text { search physicians." }\end{array}$ \\
\hline
\end{tabular}

Incomplete outcome data Unclear risk (attrition bias)

All outcomes
45/146 excluded with statement of reasons

Attrition (deaths) clearly mentioned

Missing data not stated

Unclear if participants who experienced relief of dyspnoea was assessed on the whole number of participants or only on participants alive at the end of the study (30\% died)

Selective reporting (re- High risk
porting bias)

Unclear which other symptoms were measured (only anxiety-dyspnoea is reported). Results of ECOG and MMSE not reported.

Dyspnoea relief (only after 24 hours) and uncontrolled dyspnoea (only after 48 hours) 
Navigante 2006 (Continued)

$\begin{array}{ll}\text { Other bias } \quad \text { High risk } & \begin{array}{l}\text { Using cross-over rescue medication (midazolam for the morphine group and } \\ \text { vice versa) could produce confusion for separate analysis }\end{array}\end{array}$
vice versa) could produce confusion for separate analysis

Methods Design: RCT, parallel, control: morphine

Blinding: single-blind (only participant and caregiver blinded)

Methodological quality: 21/22 (Edwards Method Score)

\begin{tabular}{|c|c|}
\hline \multirow[t]{9}{*}{ Participants } & Disease: advanced cancer \\
\hline & Number (randomised): $\mathrm{N}=63$ \\
\hline & Setting: outpatient clinic \\
\hline & Age (years, median, intervention group $1 / 2$ ): 59/55 \\
\hline & Sex (male/female): not mentioned \\
\hline & Participant pool: not mentioned \\
\hline & Randomised: 63 ; study completed: $61^{*}$ \\
\hline & $\begin{array}{l}\text { Withdrawals/dropouts: } 2^{\star} \text { (unable or unwilling to comply with the programmed follow-up visits) (ex- } \\
\text { cluded from analysis) }\end{array}$ \\
\hline & $\begin{array}{l}\text { *Data at day } 5 \text { for the morphine group were only available for } 29 \text { participants, therefore all calculations } \\
\text { at day } 5 \text { were done with } 29 \text { participants }\end{array}$ \\
\hline \multirow[t]{3}{*}{ Interventions } & $\begin{array}{l}\text { Drug (starting dose within fast titration phase): } 2 \mathrm{mg} \text { for oral midazolam or } 3 \mathrm{mg} \text { for oral morphine with } \\
\text { incremental steps of } 25 \% \text { of the preceding dose every } 30 \text { min until dyspnoea was alleviated } 50 \% \text { or } \\
\text { more ("effective dose" used in follow-up assessment) }\end{array}$ \\
\hline & Delivery: oral \\
\hline & $\begin{array}{l}\text { Duration of follow-up treatment: } 5 \text { days using the "effective dose" every } 4 \text { hours (except the sleep } \\
\text { hours) }\end{array}$ \\
\hline \multirow[t]{6}{*}{ Outcomes } & $\begin{array}{l}\text { Dyspnoea relief (fast titration phase): } 5 \text {-category scale ( } 0 \% \text { none, } 25 \% \text { slight, } 50 \% \text { moderate, } 75 \% \text { a lot, } \\
100 \% \text { complete) }\end{array}$ \\
\hline & $\begin{array}{l}\text { Dyspnoea intensity for the chronic component of dyspnoea (baseline and follow-up assessment): NRS } \\
0 \text { to } 10\end{array}$ \\
\hline & Proportion of participants with BTD episodes \\
\hline & Number of BTD episodes per day \\
\hline & Results presented in the published paper: \\
\hline & $\begin{array}{l}\text { In the fast titration phase dyspnoea relief of at least } 50 \% \text { was achieved in all participants in both arms } \\
\text { (after starting dose: midazolam } 21 / 32 \text { vs morphine } 11 / 31(P=0.023) \text {, after dosing step } 1: 9 / 32 \text { vs } 11 / 31 \\
(P=0.59) \text {, and after dosing step } 2: 2 / 32 \text { vs } 9 / 31(P=0.022)) ; \text { in the follow-up phase, mean }(95 \% \mathrm{Cl}) \text { base- } \\
\text { line dyspnoea intensity is presented in a table: midazolam } 8.8( \pm 0.3) \text { vs morphine } 8.7( \pm 0.3)(P=0.62) \text {, } \\
\text { but follow-up results on dyspnoea intensity are only presented in figure with box plots (participants re- } \\
\text { ceiving midazolam maintained a significantly lower dyspnoea intensity level in comparison with the } \\
\text { morphine group, during the } 4 \text { days of follow-up) and as median at the second day in text: midazolam } 6 \\
\text { vs morphine } 4.5(P=0.003) \text {; }\end{array}$ \\
\hline
\end{tabular}


number of participants with 1 or more BTD episodes at baseline was 25 in both arms, and the proportion of participants with BTD episodes was significantly different at days 3 to 5 , favouring the midazo-

lam arm (data only presented by a figure);

therapeutic failure (i.e. NRS 8 to 10 by day 5) midazolam 0/31 vs morphine 6/30;

$A E$ ( $n$ during fast titration phase): mild somnolence midazolam 18/32 vs morphine $15 / 31$, mild agitation $2 / 32$ vs $2 / 31$, mild and moderate nausea only morphine $2 / 31$ and $1 / 31$;

$\mathrm{AE}$ ( $\mathrm{n}$ during follow-up): somnolence (time spent sleeping during daytime) $3 \mathrm{~h}$ to $5 \mathrm{~h}$ midazolam 4/31 vs morphine $5 / 30,6.11$ h only morphine $1 / 30$; agitation grade $1 / 2$ only in morphine arm $2 / 1 / 30$; nausea grade 1 only morphine $1 / 30$; constipation grade 2 only morphine 2/30; others midazolam $1 / 31$ (cognitive disturbance) vs morphine $2 / 31$ (cough g1, pruritus g2, xerostomia g1, flushing g1);

dose reduction (because of excessive somnolence): midazolam 1 vs morphine 2;

Oxygen saturation: no change in either group

Additional results received from the authors:

Mean $(95 \% \mathrm{Cl})$ dyspnoea intensity for baseline and day 5 measures (data skewed): 1 . (midazolam) baseline: 8.84 (8.50 to 9.19), day 5: 3.23 (2.51 to 3.94); 2. (morphine) baseline: 8.74 (8.44 to 9.04), day 5: 6.00 (5.31 to 6.69$)$

\section{Notes}

Author conclusion: the data demonstrate the beneficial effect of midazolam versus morphine in the relief of chronic dyspnoea intensity and the number of episodes of breathlessness (breakthrough dyspnoea), while adverse events occurred and were comparable between both arms

\section{Risk of bias}

\begin{tabular}{lll}
\hline Bias & Authors' judgement & Support for judgement \\
\hline $\begin{array}{l}\text { Random sequence genera- } \\
\text { tion (selection bias) }\end{array}$ & Low risk & "random number generator in 1:1 ratio in blocks of six" \\
\hline $\begin{array}{l}\text { Allocation concealment } \\
\text { (selection bias) }\end{array}$ & Low risk & $\begin{array}{l}\text { "Numbered envelopes that were used to implement the randomization were } \\
\text { concealed until interventions were assigned. The researchers had final respon- } \\
\text { sibility for patient enrollment" }\end{array}$ \\
\hline $\begin{array}{l}\text { Blinding (performance } \\
\text { bias and detection bias) }\end{array}$ & High risk & Only single-blind \\
$\begin{array}{l}\text { All outcomes } \\
\begin{array}{l}\text { Incomplete outcome data } \\
\text { (attrition bias) } \\
\text { All outcomes }\end{array}\end{array}$ & Unclear risk & No information on dealing with missing data or presence of it \\
\hline $\begin{array}{l}\text { Selective reporting (re- } \\
\text { porting bias) }\end{array}$ & Low risk & No indication of selective reporting \\
\hline \begin{tabular}{l} 
Other bias \\
\hline
\end{tabular} & Unclear risk & None \\
\hline
\end{tabular}

\section{Shivaram 1989}

$\begin{array}{ll}\text { Methods } & \text { Design: } \mathrm{RCT}, \text { cross-over, placebo-controlled } \\ & \text { Blinding: double }\end{array}$




\begin{tabular}{|c|c|}
\hline \multirow[t]{11}{*}{ Participants } & Disease: COPD \\
\hline & Number (randomised): $\mathrm{N}=12$ \\
\hline & Setting: unclear \\
\hline & Age (years, mean): 64.9 \\
\hline & Sex (male/female): $8 / 0$ \\
\hline & Participant pool: not stated \\
\hline & Randomised: 12; study completed: 8 \\
\hline & Withdrawals/dropouts: 4 (excluded from analysis) \\
\hline & Reason for drop-out: all on placebo ( $3 / 4$ increasing dyspnoea and drowsiness, $1 / 4$ acute exacerbation) \\
\hline & Baseline parameters: FEV1/FVC: all less than $65 \%$ \\
\hline & $\mathrm{SpO}_{2}(\mathrm{mmHg}): 76.0 ; \mathrm{SpCO}_{2}(\mathrm{mmHg}): 38.0$ \\
\hline \multirow[t]{4}{*}{ Interventions } & Drug (dose): alprazolam $0.75 \mathrm{mg} /$ day (0.25 mg 3 times a day) \\
\hline & Control: placebo \\
\hline & Delivery: oral \\
\hline & Duration of treatment: 2 weeks \\
\hline \multirow[t]{4}{*}{ Outcomes } & Dyspnoea (modified Borg scale 0 to 10 ) \\
\hline & $\begin{array}{l}\text { Results* (baseline to after intervention): alprazolam: } 3.6 \text { to } 3.6 \text {; placebo: } 3.6 \text { to } 3.0 \text { (*not explicitly stated } \\
\text { if mean or median, but must be mean because of decimal numbers) }\end{array}$ \\
\hline & Adverse effects: none within the 8 participants \\
\hline & $\mathrm{SpO}_{2}$ and $\mathrm{SpCO}_{2}$ : no significant change \\
\hline
\end{tabular}

\section{Risk of bias}

\section{Bias}

Authors' judgement Support for judgement

Random sequence genera- Unclear risk tion (selection bias)

"Patients were started on a double-blind, randomized crossover regimen"

"The patients then received either placebo or alprazolam $0.25 \mathrm{mg}$ in a double-blind fashion"

Not mentioned how this was done

\begin{tabular}{|c|c|c|}
\hline $\begin{array}{l}\text { Allocation concealment } \\
\text { (selection bias) }\end{array}$ & Unclear risk & Not mentioned how it was done \\
\hline $\begin{array}{l}\text { Blinding (performance } \\
\text { bias and detection bias) } \\
\text { All outcomes }\end{array}$ & Low risk & $\begin{array}{l}\text { "The medication code was known only to the hospital pharmacist." } \\
\text { "Patients were started on a double-blind, randomized crossover regimen" } \\
\text { "The patients then received either placebo or alprazolam } 0.25 \mathrm{mg} \text { in a dou- } \\
\text { ble-blind fashion" }\end{array}$ \\
\hline
\end{tabular}

Benzodiazepines for the relief of breathlessness in advanced malignant and non-malignant diseases in adults (Review) 
Shivaram 1989 (Continued) (attrition bias)

All outcomes
Unclear risk Described the attrition and reasons for it

Excluded from analysis, but stated that they did not differ with regard to spirometric measures

Demographics only from included participants (8/12)

No predicted FEV1 and FVC mentioned

Selective reporting (re- Low risk No indication for selective reporting

porting bias)

Other bias

High risk

Only men (Veterans Affairs Medical Center)

Stege 2010

$\begin{array}{ll}\text { Methods } & \text { Design: RCT, placebo-controlled, cross-over design } \\ & \text { Blinding: double } \\ & \text { Methodological quality: } 16 / 22 \text { (Edwards Method Score) }\end{array}$

Participants

Disease: COPD (stages III to IV)

Number (randomised/analysed): $\mathrm{n}=17 / 14$

Setting: outpatient center of a respiratory medicine department

Age (years, mean, SD): $61.6 \mp 8.0$

Sex (male/female): 10/4

Participant pool: 199

Randomised: 17 ; study completed: 14

Withdrawals/dropouts: 3 (excluded from analysis)

Reason for drop-out: 1/3 on intervention: (exacerbation of COPD), 2/3 on placebo (1 obstructive sleep apnoea-hypopnoea syndrome, 1 withdrew due to burden of the measurements)

Baseline parameters: FEV1/FVC (mean, SD) $32.7 \mp 13, \mathrm{PaCO}_{2}, \mathrm{kPa} 5.4 \mp 0.4, \mathrm{PaO}_{2}, \mathrm{kPa} 9.6 \mp 0.7$

Baseline sleep-related complaints: difficulty maintaining sleep (experienced by 8 participants), a prolonged sleep-onset latency (experienced by 7 participants), extensive daytime sleepiness (experienced by 6 participants), and nocturnal dyspnoea (experienced by 2 participants)

Baseline medication: inhaled corticosteroids $14 / 14$, anticholinergics $13 / 14, \beta 2$-antagonists $9 / 14$, oral steroids $4 / 14$, proton pump inhibitors $4 / 14$, anticoagulants $4 / 14$, other antihypertensives $4 / 14$, theophylline $3 / 14$, diuretics $3 / 14$, acetylcysteine $1 / 14$

Interventions

Drug (dose): temazepam $10 \mathrm{mg} /$ day (30 min before bedtime)

Control: placebo

Delivery: oral

Duration of treatment: 1 week each, with 1-week wash-out time 

0.90 ;

transcutaneous carbon dioxide ( $\left.\mathrm{PtcCO}_{2}\right)$ during sleep: baseline 6.2 (0.6), temazepam 5.9 (1.0), placebo 6.3 (1.4), $\mathrm{P}=0.27$; oxygen saturation $\left(\mathrm{SpO}_{2}\right)$ during sleep: baseline 92 (2), temazepam 92 (3), placebo 92 (2), $P=0.31$;

total sleep time, h (mean (SD)): baseline 5.7 (1.2), temazepam 6.3 (1.0), placebo 5.4 (1.1), P=0.03;

sleep latency (10-point VAS): baseline 4.4 (3.2), temazepam 3.3 (2.8), placebo 4.6 (3.2), P=0.03;

amount of stage 2 sleep, minutes (non-rapid eye movement sleep): baseline 130.8 (54.5), temazepam 168.8 (34.4), placebo 140.0 (44.6), $P=0.03$;

no statistically significant changes for the other secondary outcomes;

Adverse effects: none reported

\author{
Notes
}

\title{
Risk of bias
}

\begin{tabular}{lll}
\hline Bias & Authors' judgement & Support for judgement \\
\hline $\begin{array}{ll}\text { Random sequence genera- } \\
\text { tion (selection bias) }\end{array}$ & Unclear risk & $\begin{array}{l}\text { "Subjects were randomized after the baseline measurements to use } 10 \mathrm{mg} \\
\text { temazepam or placebo once a day orally, both during one week, separated by } \\
\text { a washout-period of one week. (...) Randomization was done by the hospital } \\
\text { pharmacy." }\end{array}$ \\
& Not mentioned of how this was done
\end{tabular}

\begin{tabular}{|c|c|c|}
\hline $\begin{array}{l}\text { Allocation concealment } \\
\text { (selection bias) }\end{array}$ & Unclear risk & $\begin{array}{l}\text { "Subjects were randomized after the baseline measurements to use } 10 \mathrm{mg} \\
\text { temazepam or placebo once a day orally, both during one week, separated by } \\
\text { a washout-period of one week. Randomization was done by the hospital phar- } \\
\text { macy." }\end{array}$ \\
\hline
\end{tabular}

Blinding (performance Low risk

"Subjects were randomized after the baseline measurements to use $10 \mathrm{mg}$ All outcomes temazepam or placebo once a day orally, both during one week, separated by a washout-period of one week. Randomization was done by the hospital pharmacy. Subjects were instructed to take the study medication 30 min before they went to bed. (...) Sleep was manually staged according to standard methods by two qualified sleep technicians blinded to the subject's treatment status."

\begin{tabular}{|c|c|c|}
\hline $\begin{array}{l}\text { Incomplete outcome data } \\
\text { (attrition bias) } \\
\text { All outcomes }\end{array}$ & Unclear risk & $\begin{array}{l}\text { Described the attrition }(3 / 17) \text { and the reasons for it, but did not describe par- } \\
\text { ticipant characteristics of dropouts. No intention-to-treat analysis ( } 14 \text { of } 17 \text { en- } \\
\text { rolled participants analysed) }\end{array}$ \\
\hline
\end{tabular}

Selective reporting (re- Unclear risk The article addresses only respiratory adverse events; it is unclear if other than
porting bias) respiratory events had occurred

\begin{tabular}{ll}
\hline Unclear risk & - Lack of participant characteristics (e.g. no information on comorbidity, func- \\
tional status) & More male than female participants \\
- & No control for specific participant characteristics or medication, no sensitiv- \\
& ity analysis \\
- & The stability of the COPD was not objectively confirmed with spirometry at \\
& the second week, but only assessed on clinical grounds
\end{tabular}




\begin{tabular}{|c|c|}
\hline Methods & $\begin{array}{l}\text { Design: RCT, cross-over, placebo-controlled, multi-arm (3) } \\
\text { Blinding: double } \\
\text { Methodological quality: 15/22 (Edwards Method Score) }\end{array}$ \\
\hline Participants & 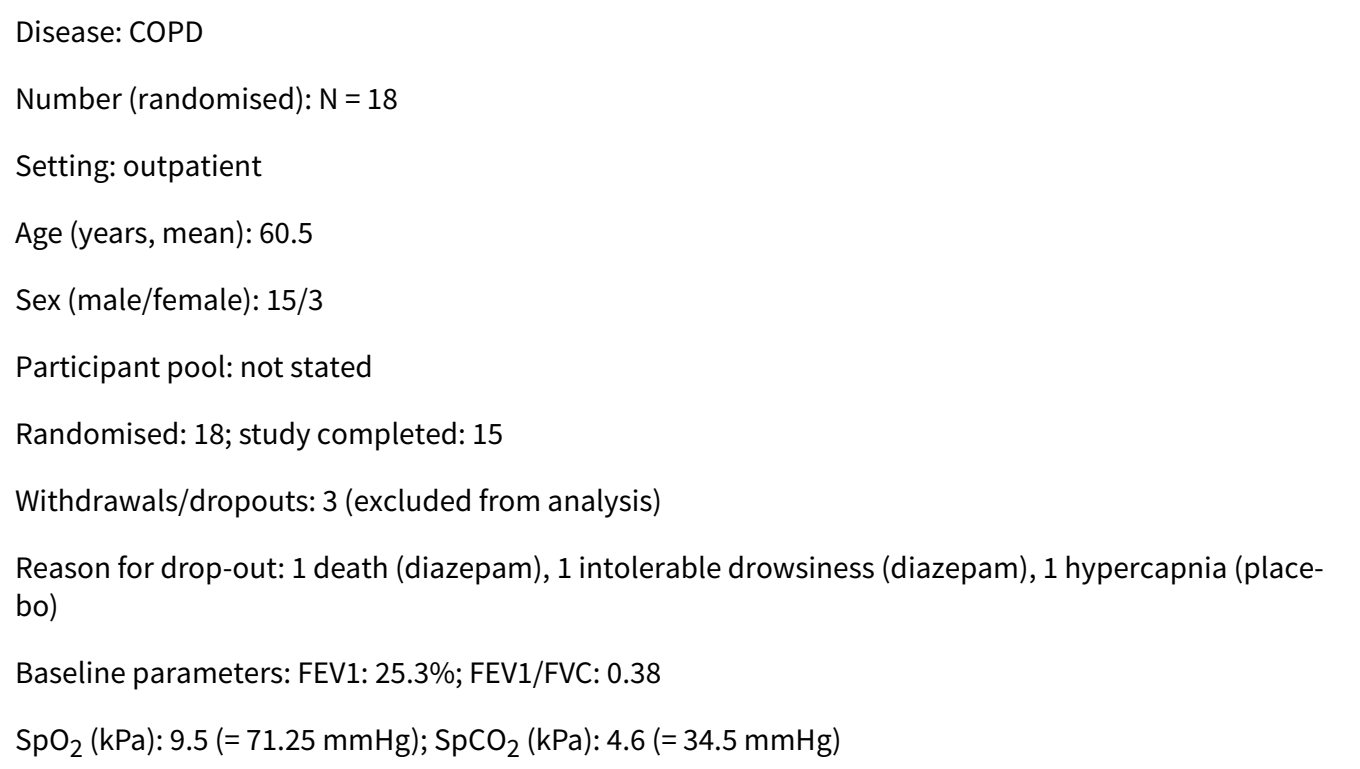 \\
\hline Interventions & $\begin{array}{l}\text { Drug (dose): } 1 . \text { diazepam } 25 \mathrm{mg} / \mathrm{day} \text { ( } 5 \mathrm{mg} 3 \text { times a day plus } 10 \mathrm{mg} \text { at bedtime); } 2 \text {. promethazine } 125 \\
\mathrm{mg} / \text { day ( } 25 \mathrm{mg} 3 \text { times a day plus } 50 \mathrm{mg} \text { at bedtime); 3. placebo } \\
\text { Delivery: oral } \\
\text { Duration of treatment: } 2 \text { weeks }\end{array}$ \\
\hline Outcomes & $\begin{array}{l}\text { Dyspnoea grade ( } 1 \text { to } 5) \text { after each intervention and daily dyspnoea by VAS (0 to } 10) \text { at rest and after ex- } \\
\text { ercise (only by graph) } \\
\text { Results (mean): dyspnoea grade: } 1.3 .46 \text { (diazepam); } 2.3 .29(\mathrm{P}<0.05) \text { (promethazine); } 3.4 .00 \text { (placebo) } \\
\text { Adverse effects ( } 6 \text { - reduce dosage): all drowsiness: 5/6 diazepam; } 1 / 6 \text { promethazine; } 5 / 5 \text { drowsiness in- } \\
\text { cidents (like falling down stairs) with diazepam } \\
\text { Functional test (12-minute walking test in metres): } 1.642(\mathrm{P}<0.05) \text { (diazepam); } 2.707(\mathrm{P}<0.05) \\
\text { (promethazine); } 3.675 \text { (placebo) } \\
\mathrm{SpO}_{2} \text { and } \mathrm{SpCO}_{2} \text { : no significant change } \\
\text { No significant change in anxiety and depression }\end{array}$ \\
\hline
\end{tabular}
cise tolerance. Promethazine reduced breathlessness and improved exercise tolerance without altering lung function.

Review author: however, there is a beneficial effect of diazepam, although not significant 
Woodcock 1981 (Continued)

\section{Risk of bias}

\begin{tabular}{|c|c|c|}
\hline Bias & Authors' judgement & Support for judgement \\
\hline $\begin{array}{l}\text { Random sequence genera- } \\
\text { tion (selection bias) }\end{array}$ & Unclear risk & $\begin{array}{l}\text { "The treatments were given in a randomized order." } \\
\text { Not mentioned how this was done }\end{array}$ \\
\hline $\begin{array}{l}\text { Allocation concealment } \\
\text { (selection bias) }\end{array}$ & Unclear risk & Not mentioned \\
\hline $\begin{array}{l}\text { Blinding (performance } \\
\text { bias and detection bias) } \\
\text { All outcomes }\end{array}$ & Low risk & "Double-blind" procedure was described \\
\hline $\begin{array}{l}\text { Incomplete outcome data } \\
\text { (attrition bias) } \\
\text { All outcomes }\end{array}$ & Low risk & $\begin{array}{l}\text { Although } 3 / 18 \text { participants were lost and excluded from the analysis, they } \\
\text { would underline the presented results rather than bias them }\end{array}$ \\
\hline $\begin{array}{l}\text { Selective reporting (re- } \\
\text { porting bias) }\end{array}$ & Unclear risk & $\begin{array}{l}\text { All main outcomes are presented in detail } \\
\text { The effect of diazepam in the relief of breathlessness is nearly statistically sig- } \\
\text { nificant, but was discussed as "diazepam had no effect on breathlessness" }\end{array}$ \\
\hline Other bias & Unclear risk & $\begin{array}{l}\text { It is not explicitly stated if a wash-out phase was used (on contacting the au- } \\
\text { thor, there was no wash-out) } \\
\text { Results of compliance test are not mentioned } \\
\text { Screening method and numbers are not mentioned }\end{array}$ \\
\hline
\end{tabular}

AEs $=$ adverse effects

BTD = breakthrough dyspnoea

$\mathrm{Cl}=$ confidence interval

COPD = chronic obstructive pulmonary disease

ECOG $=$ Eastern Cooperative Oncology Group

$\mathrm{FEV} 1$ = forced expiratory volume in one second

FVC $=$ forced vital capacity

HADS = Hospital Anxiety and Depression Scale

$\mathrm{Mi}=$ midazolam

$\mathrm{MM}=$ midazolam + morphine

MMSE = Mini-Mental State Exam

Mo $=$ morphine

NRS = numeric rating scale

$\mathrm{RCT}=$ randomised controlled trial

$\mathrm{SD}=$ standard deviation

VAS = visual analogue scale

Characteristics of excluded studies [ordered by study ID]

\begin{tabular}{ll} 
Study & Reason for exclusion \\
\hline Allcroft 2013 & Non-controlled study (phase II) \\
\hline Allen 1984 & Review
\end{tabular}

Anonymous 1980a Review




\begin{tabular}{|c|c|}
\hline Study & Reason for exclusion \\
\hline Anonymous 1980b & Review \\
\hline Appel 1989 & No subjective measurement of breathlessness; different drug (flumazenil) \\
\hline Argyropoulou 1993 & Different drug (buspirone) \\
\hline Bar-Or 1982 & Review \\
\hline Beaupre 1988 & No subjective measurement of breathlessness \\
\hline Borson 1992 & Different drug (nortriptyline) \\
\hline Bottomley 1990 & No subjective measurement of breathlessness; observational design \\
\hline Boyden 2015 & Systematic review \\
\hline Catchlove 1971a & No subjective measurement of breathlessness \\
\hline Catchlove 1971b & No subjective measurement of breathlessness \\
\hline Cherny 2014 & Guideline \\
\hline Clark 1971 & No subjective measurement of breathlessness; case series \\
\hline Clemens 2011 & Non-controlled study (before-after design) \\
\hline Cohn 1992 & No subjective measurement of breathlessness \\
\hline Daubert 2014 & Study protocol; study was cancelled before any participants were enrolled \\
\hline De Sousa 1988 & No subjective measurement of breathlessness; letter/observational design \\
\hline Denaut 1974 & No subjective measurement of breathlessness \\
\hline Dolly 1982 & No subjective measurement of breathlessness; healthy participants \\
\hline Dowson 2004 & Review \\
\hline Ekstrom 2015 & Review \\
\hline Fonsmark 2015 & Guideline \\
\hline Forster 1983 & No subjective measurement of breathlessness; healthy participants \\
\hline Gaddie 1972 & Review \\
\hline Garrett 2015 & Review \\
\hline Geddes 1976 & No subjective measurement of breathlessness \\
\hline Gomutbutra 2013 & Non-controlled, retrospective study \\
\hline Greene 1989 & Non-controlled experimental study (case report) \\
\hline Guilleminault 1993 & No subjective measurement of breathlessness; observational design \\
\hline
\end{tabular}




\begin{tabular}{|c|c|}
\hline Study & Reason for exclusion \\
\hline Guz 1980 & Review \\
\hline Heinonen 1972 & No subjective measurement of breathlessness; sedation for artificial ventilation \\
\hline Hoeijer 1994 & No subjective measurement of breathlessness; different disease (sleep apnoea) \\
\hline Horfarter 2006 & Review \\
\hline Hosaka 1996 & Non-advanced disease stage; a few participants with a different disease (asthma, tuberculosis) \\
\hline Huttemann 1971 & Different drug (laevomepromazine) \\
\hline Johanson 1993 & Review \\
\hline Jokinen 1984 & Different disease (psychosomatic disorder) \\
\hline Jolly 1996 & No subjective measurement of breathlessness; observational design \\
\hline Jones 1985 & Different disease (healthy participants) \\
\hline Kaltsas 2014 & Editorial \\
\hline Kann 1968 & Review \\
\hline Kronenberg 1975 & No subjective measurement of breathlessness; observational design \\
\hline Lakshminarayan 1976 & No subjective measurement of breathlessness; healthy participants \\
\hline Lareau 1999 & No drug intervention (secondary analysis) \\
\hline Laros 1982 & No subjective measurement of breathlessness; case report; no benzodiazepine \\
\hline Lichterfeld 1967 & Benzodiazepine only in combination (oxazepam + orciprenaline) \\
\hline Light 1996 & Different drug (promethazine) \\
\hline Marin 1987 & No drug intervention (retrospective study) \\
\hline Mclver 1994 & Different drug (chlorpromazine) \\
\hline Mitchell-Heggs 1980a & $\begin{array}{l}\text { No subjective measurement of breathlessness; no control group; no standardised or systematic } \\
\text { design }\end{array}$ \\
\hline Mitchell-Heggs 1980b & No drug intervention \\
\hline Mouzi 2014 & No subjective measurement of breathlessness; case report \\
\hline Murciano 1990 & No subjective measurement of breathlessness \\
\hline Murciano 1993 & No subjective measurement of breathlessness \\
\hline Navigante 1997 & Benzodiazepine only in combination (midazolam + morphine) \\
\hline Navigante 2003 & Benzodiazepine only in combination (midazolam + morphine) \\
\hline
\end{tabular}




\begin{tabular}{|c|c|}
\hline Study & Reason for exclusion \\
\hline NCT01687751 & Study failed to recruit any participants \\
\hline Nordt 1997 & Review \\
\hline O'Donnell 1992 & No drug intervention (observational study) \\
\hline O'Donnell 1994 & Review \\
\hline O'Donnell 1998 & Review \\
\hline O'Neill 1985 & Different drug (chlorpromazine) \\
\hline Rao 1973 & No subjective measurement of breathlessness \\
\hline Rapoport 1991 & No subjective measurement of breathlessness; healthy participants \\
\hline Rice 1986 & Review \\
\hline Rice 1987 & Different drug (promethazine) \\
\hline Rodriguez-Roisin 2014 & Editorial \\
\hline Rose 2002 & Review \\
\hline Rudolf 1978 & No subjective measurement of breathlessness \\
\hline Runo 2001 & Review \\
\hline Schultze-Werninghaus 2007 & Review \\
\hline Sen 1983 & No subjective measurement of breathlessness; no control group \\
\hline Singh 1993 & Different drug (promethazine) \\
\hline Smith 2015 & Review \\
\hline Stark 1981a & Different disease (healthy participants) \\
\hline Stark 1981b & Different disease (healthy participants) \\
\hline Stark 1983 & Different drug (dihydrocodeine) \\
\hline Stark 1988 & Review \\
\hline Steens 1993 & No subjective measurement of breathlessness \\
\hline Tenorio 2012 & Non-controlled, retrospective study; congress abstract \\
\hline Timms 1988 & No subjective measurement of breathlessness \\
\hline Vozoris 2013 & Observational design \\
\hline Walsh 1993 & Review \\
\hline Wanrooij 2005 & Review \\
\hline
\end{tabular}




\begin{tabular}{ll}
\hline Study & Reason for exclusion \\
\hline Wiedemann 1995 & Review \\
\hline Wilson 1954 & No subjective measurement of breathlessness; different drug (oxygen, morphine, barbiturate) \\
\hline Woodcock 1981a & Different drug (dihydrocodeine, alcohol, caffeine) \\
\hline Woodcock 1981b & Different drug (oxygen) \\
\hline
\end{tabular}

Characteristics of studies awaiting assessment [ordered by study ID]

\section{Hardy 2016}

\begin{tabular}{|c|c|}
\hline Methods & Design: multicentre, placebo-controlled, cross-over design, blinded (masking used) RCT \\
\hline \multirow[t]{2}{*}{ Participants } & $\begin{array}{l}\text { Inclusion criteria: adults with dyspnoea related to life-limiting disease (malignant and non-ma- } \\
\text { lignant) or its treatment, dyspnoea score }>3 / 10 \text { on at least } 3 \text { occasions during the previous week, } \\
\text { English speaking or have an interpreter available, AKPS scale }>30 \text {, able to operate a nasal spray de- } \\
\text { vice, able to understand all trial requirements and complete a dyspnoea diary, no changes in any } \\
\text { medication likely to affect dyspnoea (e.g. steroids, opioids) within } 48 \text { hours of starting the study }\end{array}$ \\
\hline & Target sample size: $200>$ terminated after interim analysis including 75 participants \\
\hline Interventions & $\begin{array}{l}\text { Intranasal midazolam ( } 3 \text { inhalations (total dose of } 1.5 \mathrm{mg} \text { active drug) vs placebo (citric acid } 7.65 \\
\mathrm{mg} / \mathrm{ml} \text { in normal saline placebo nasal spray) }\end{array}$ \\
\hline \multirow[t]{2}{*}{ Outcomes } & Primary outcome: dyspnoea intensity at 15 minutes compared to baseline \\
\hline & $\begin{array}{l}\text { Secondary outcomes: DID (dyspnoea intensity difference) at } 5,30 \text {, and } 60 \text { mins, sedation (NRS } 0 \\
=\text { not at all drowsy to } 10=\text { extremely drowsy), anxiety (NRS } 0=\text { not at all anxious to } 10=\text { extremely } \\
\text { anxious) }\end{array}$ \\
\hline \multirow[t]{3}{*}{ Notes } & The study has been published just before publication of this review update \\
\hline & $\begin{array}{l}\text { The study is registered at the Australian New Zealand Clinical Trials Registry (ACTRN), trial ID: AC- } \\
\text { TRN12609000506291, Title: Midazolam nasal spray for the treatment of breathlessness in patients } \\
\text { with life-limiting disease }\end{array}$ \\
\hline & $\begin{array}{l}\text { Contact information: Clare Randall, Arohanui Hospice } 1 \text { Heretaunga St Palmerston North 4414, } \\
\text { New Zealand, clare.r@arohanuihospice.org.nz }\end{array}$ \\
\hline
\end{tabular}

Hart 2012

\begin{tabular}{ll}
\hline Methods & Design: randomised, double-blind, double-dummy, placebo-controlled pilot study \\
\hline Participants & 30 people with severe respiratory disease (MRC dyspnoea score 4 or 5) \\
\hline Interventions & $\begin{array}{l}\text { Lorazepam tablets } 0.5 \mathrm{mg} \text { twice daily with dummy nasal spray up to } 4 \text { times daily or intranasal mi- } \\
\text { dazolam (dose } 400 \mathrm{mg}) 2 \text { sprays up to } 4 \text { times daily with placebo tablets }\end{array}$ \\
\hline Outcomes & $\begin{array}{l}\text { Primary outcome measures were designed to evaluate quality of life measures incorporating } \\
\text { change in: }\end{array}$ \\
- Borg score whilst on treatment \\
- St. George's Respiratory Questionnaire (SGRQ) score
\end{tabular}


Hart 2012 (Continued)

- Hospital Anxiety and Depression Scale (HADS) scores

- Nottingham Activities of Daily Living (NADL) score

Notes

The authors conclude in the abstract that intranasal midazolam is no less effective in this setting than oral lorazepam and suggest that intranasal midazolam is another useful tool for managing dyspnoea. However, only conference abstract is available; we contacted two of the authors asking for further details, but did not receive an answer until the review was published

AKPS $=$ Australia-modified Karnofsky Performance Status

DID = dyspnoea intensity difference

MRC $=$ Medical Research Council

NRS = numeric rating scale

$\mathrm{RCT}=$ randomised controlled trial

DATA AND ANALYSES

Comparison 1. Overall

\begin{tabular}{llllll}
\hline Outcome or subgroup title & $\begin{array}{l}\text { No. of } \\
\text { studies }\end{array}$ & $\begin{array}{l}\text { No. of } \\
\text { partici- } \\
\text { pants }\end{array}$ & Statistical method & Effect size \\
\hline 1 Placebo-controlled/cross-over design & 5 & 156 & $\begin{array}{l}\text { Std. Mean Difference (IV, Random, 95\% } \\
\text { Cl) }\end{array}$ & $-0.10[-0.42,0.21]$ \\
\hline 2 Morphine-controlled/parallel design & 2 & 107 & $\begin{array}{l}\text { Std. Mean Difference (IV, Random, 95\% } \\
\text { Cl) }\end{array}$ & $-0.68[-2.21,0.84]$ \\
\hline
\end{tabular}

Analysis 1.1. Comparison 1 Overall, Outcome 1 Placebo-controlled/cross-over design.

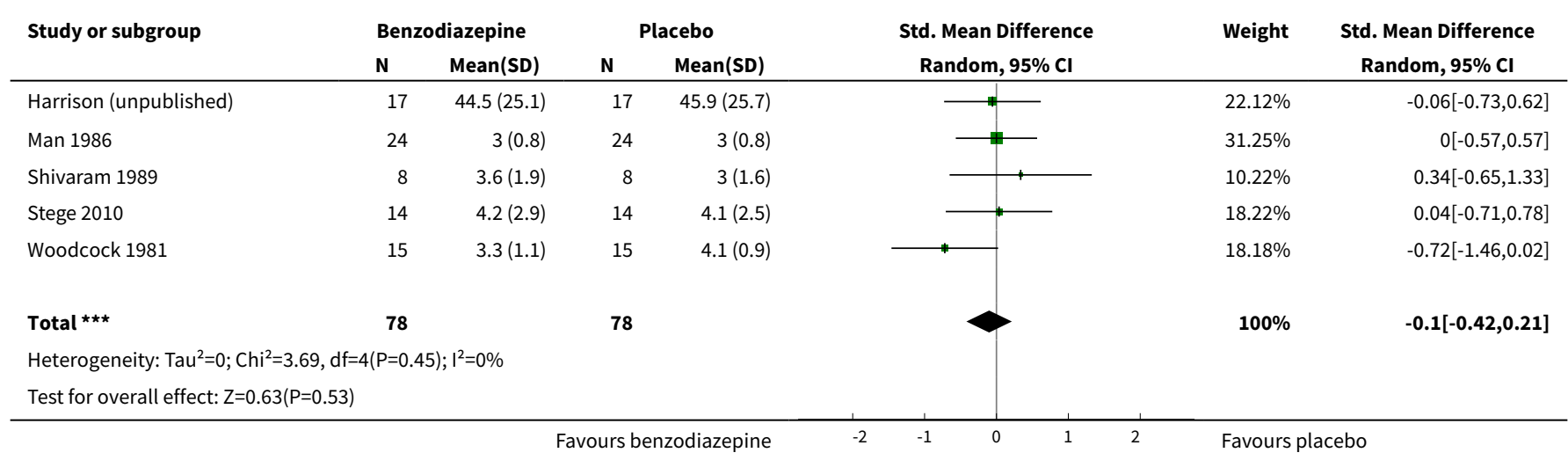


Analysis 1.2. Comparison 1 Overall, Outcome 2 Morphine-controlled/parallel design.

\begin{tabular}{|c|c|c|c|c|c|c|c|}
\hline \multirow[t]{2}{*}{ Study or subgroup } & \multicolumn{2}{|c|}{ Benzodiazepine } & \multicolumn{2}{|c|}{ Morphine } & \multirow{2}{*}{$\begin{array}{c}\text { Std. Mean Difference } \\
\text { Random, } 95 \% \mathrm{Cl}\end{array}$} & \multirow[t]{2}{*}{ Weight } & \multirow{2}{*}{$\begin{array}{c}\text { Std. Mean Difference } \\
\text { Random, } 95 \% \mathrm{Cl}\end{array}$} \\
\hline & $\mathbf{N}$ & $\operatorname{Mean}(\mathrm{SD})$ & $\mathbf{N}$ & $\operatorname{Mean}(\mathrm{SD})$ & & & \\
\hline Navigante 2006 & 23 & $3.1(3.3)$ & 24 & $2.8(2.8)$ & 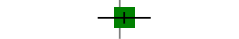 & $50.01 \%$ & $0.1[-0.48,0.67]$ \\
\hline Navigante 2010 & 31 & $3.2(2)$ & 29 & $6(1.8)$ & 十- & $49.99 \%$ & $-1.46[-2.03,-0.89]$ \\
\hline Total $\star \star \star ~$ & 54 & & 53 & & & $100 \%$ & $-0.68[-2.21,0.84]$ \\
\hline \multicolumn{8}{|c|}{ Heterogeneity: $\operatorname{Tau}^{2}=1.13 ; \mathrm{Chi}^{2}=14.17, \mathrm{df}=1(\mathrm{P}=0) ; \mathrm{I}^{2}=92.94 \%$} \\
\hline
\end{tabular}

Comparison 2. Disease

\begin{tabular}{llllll}
\hline Outcome or subgroup title & $\begin{array}{l}\text { No. of } \\
\text { studies }\end{array}$ & $\begin{array}{l}\text { No. of } \\
\text { partici- } \\
\text { pants }\end{array}$ & Statistical method & Effect size \\
\hline 1 COPD & 4 & 122 & Std. Mean Difference (IV, Random, 95\% Cl) & $-0.12[-0.52,0.29]$ \\
\hline 2 Cancer - placebo-controlled & 1 & 34 & Std. Mean Difference (IV, Random, 95\% Cl) & $-0.06[-0.73,0.62]$ \\
\hline 3 Cancer- morphine-controlled & 2 & 107 & Std. Mean Difference (IV, Random, 95\% Cl) & $-0.68[-2.21,0.84]$ \\
\hline
\end{tabular}

Analysis 2.1. Comparison 2 Disease, Outcome 1 COPD.

\begin{tabular}{|c|c|c|c|c|c|c|c|}
\hline \multirow[t]{2}{*}{ Study or subgroup } & \multicolumn{2}{|c|}{ Benzodiazepine } & \multicolumn{2}{|c|}{ Control } & \multirow{2}{*}{$\begin{array}{c}\text { Std. Mean Difference } \\
\text { Random, } 95 \% \mathrm{Cl}\end{array}$} & \multirow[t]{2}{*}{ Weight } & \multirow{2}{*}{$\begin{array}{c}\text { Std. Mean Difference } \\
\text { Random, } 95 \% \mathrm{Cl}\end{array}$} \\
\hline & $\mathbf{N}$ & Mean(SD) & $\mathbf{N}$ & $\operatorname{Mean}(S D)$ & & & \\
\hline Man 1986 & 24 & $3(0.8)$ & 24 & $3(0.8)$ & 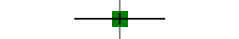 & $36.83 \%$ & $0[-0.57,0.57]$ \\
\hline Shivaram 1989 & 8 & $3.6(1.9)$ & 8 & $3(1.6)$ & $\rightarrow$ & $14.76 \%$ & $0.34[-0.65,1.33]$ \\
\hline Stege 2010 & 14 & $4.2(2.9)$ & 14 & $4.1(2.5)$ & & $24.23 \%$ & $0.04[-0.71,0.78]$ \\
\hline Woodcock 1981 & 15 & $3.3(1.1)$ & 15 & $4.1(0.9)$ & & $24.18 \%$ & $-0.72[-1.46,0.02]$ \\
\hline \multicolumn{8}{|c|}{ Heterogeneity: $\mathrm{Tau}^{2}=0.03 ; \mathrm{Chi}^{2}=3.67, \mathrm{df}=3(\mathrm{P}=0.3) ; \mathrm{I}^{2}=18.16 \%$} \\
\hline \multicolumn{8}{|c|}{ Test for overall effect: $Z=0.56(P=0.57)$} \\
\hline
\end{tabular}

Analysis 2.2. Comparison 2 Disease, Outcome 2 Cancer - placebo-controlled.

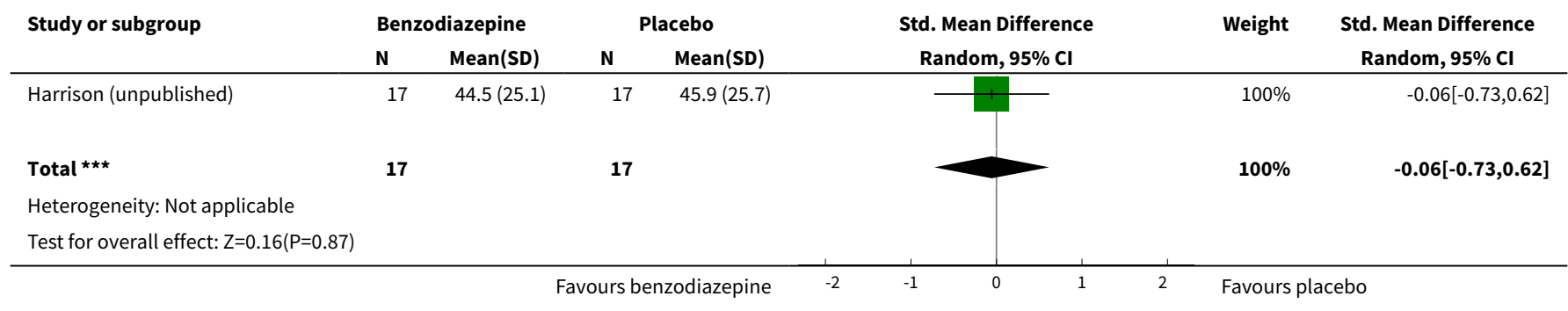


Analysis 2.3. Comparison 2 Disease, Outcome 3 Cancer - morphine-controlled.

\begin{tabular}{|c|c|c|c|c|c|c|c|}
\hline \multirow[t]{2}{*}{ Study or subgroup } & \multicolumn{2}{|c|}{ Benzodiazepine } & \multicolumn{2}{|c|}{ Morphine } & \multirow{2}{*}{$\begin{array}{c}\text { Std. Mean Difference } \\
\text { Random, } 95 \% \mathrm{Cl}\end{array}$} & \multirow[t]{2}{*}{ Weight } & \multirow{2}{*}{$\begin{array}{c}\text { Std. Mean Difference } \\
\text { Random, } 95 \% \mathrm{Cl}\end{array}$} \\
\hline & $\mathbf{N}$ & $\operatorname{Mean}(\mathrm{SD})$ & $\mathbf{N}$ & Mean(SD) & & & \\
\hline Navigante 2006 & 23 & $3.1(3.3)$ & 24 & $2.8(2.8)$ & $-\frac{1}{4}$ & $50.01 \%$ & $0.1[-0.48,0.67]$ \\
\hline Navigante 2010 & 31 & $3.2(2)$ & 29 & $6(1.8)$ & + & $49.99 \%$ & $-1.46[-2.03,-0.89]$ \\
\hline Total ${ }^{\star \star \star}$ & 54 & & 53 & & & $100 \%$ & $-0.68[-2.21,0.84]$ \\
\hline \multicolumn{8}{|c|}{ Heterogeneity: $\mathrm{Tau}^{2}=1.13 ; \mathrm{Chi}^{2}=14.17, \mathrm{df}=1(\mathrm{P}=0) ; \mathrm{I}^{2}=92.94 \%$} \\
\hline \multicolumn{8}{|c|}{ Test for overall effect: $\mathrm{Z}=0.88(\mathrm{P}=0.38)$} \\
\hline
\end{tabular}

\section{Comparison 3. Intervention}

\begin{tabular}{|c|c|c|c|c|}
\hline Outcome or subgroup title & $\begin{array}{l}\text { No. of } \\
\text { studies }\end{array}$ & $\begin{array}{l}\text { No. of } \\
\text { partici- } \\
\text { pants }\end{array}$ & Statistical method & Effect size \\
\hline $\begin{array}{l}1 \text { Benzodiazepines - alprazo- } \\
\text { lam }\end{array}$ & 2 & 64 & Std. Mean Difference (IV, Random, 95\% CI) & $0.08[-0.41,0.57]$ \\
\hline $\begin{array}{l}2 \text { Benzodiazepines - di- } \\
\text { azepam }\end{array}$ & 1 & 30 & Std. Mean Difference (IV, Fixed, 95\% CI) & $-0.72[-1.46,0.02]$ \\
\hline $\begin{array}{l}3 \text { Benzodiazepines - midazo- } \\
\text { lam }\end{array}$ & 2 & 107 & Std. Mean Difference (IV, Random, 95\% CI) & $-0.68[-2.21,0.84]$ \\
\hline $\begin{array}{l}4 \text { Benzodiazepines - } \\
\text { temazepam }\end{array}$ & 1 & 28 & Mean Difference (IV, Fixed, 95\% CI) & $0.10[-1.91,2.11]$ \\
\hline $\begin{array}{l}5 \text { Benzodiazepines - ultra } \\
\text { short-acting }\end{array}$ & 2 & 107 & Std. Mean Difference (IV, Random, 95\% CI) & $-0.68[-2.21,0.84]$ \\
\hline $\begin{array}{l}6 \text { Benzodiazepines - interme- } \\
\text { diate-acting }\end{array}$ & 4 & 126 & Std. Mean Difference (IV, Random, 95\% CI) & $0.04[-0.31,0.38]$ \\
\hline $\begin{array}{l}7 \text { Benzodiazepines - long-act- } \\
\text { ing }\end{array}$ & 1 & 30 & Std. Mean Difference (IV, Fixed, 95\% CI) & $-0.72[-1.46,0.02]$ \\
\hline $\begin{array}{l}8 \text { Benzodiazepines - short } \\
\text { duration of treatment ( } \leqq 24 \\
\text { hours) }\end{array}$ & 2 & 116 & Std. Mean Difference (IV, Fixed, 95\% CI) & $-0.36[-0.74,0.01]$ \\
\hline $\begin{array}{l}9 \text { Benzodiazepines - long du- } \\
\text { ration of treatment (5 to } 14 \\
\text { days) }\end{array}$ & 5 & 156 & Std. Mean Difference (IV, Fixed, 95\% CI) & $-0.10[-0.42,0.21]$ \\
\hline $\begin{array}{l}10 \text { Benzodiazepines - mor- } \\
\text { phine + midazolam-con- } \\
\text { trolled }\end{array}$ & 1 & 46 & Std. Mean Difference (IV, Fixed, 95\% CI) & $0.03[-0.54,0.61]$ \\
\hline $\begin{array}{l}11 \text { Benzodiazepines - } \\
\text { promethazine-controlled }\end{array}$ & 1 & 30 & Std. Mean Difference (IV, Fixed, 95\% CI) & $0.0[-0.72,0.72]$ \\
\hline
\end{tabular}


Analysis 3.1. Comparison 3 Intervention, Outcome 1 Benzodiazepines - alprazolam.

\begin{tabular}{|c|c|c|c|c|c|c|c|}
\hline \multirow[t]{2}{*}{ Study or subgroup } & \multicolumn{2}{|c|}{ Alprazolam } & \multicolumn{2}{|c|}{ Placebo } & \multirow{2}{*}{$\begin{array}{c}\text { Std. Mean Difference } \\
\text { Random, } 95 \% \mathrm{Cl}\end{array}$} & \multirow[t]{2}{*}{ Weight } & \multirow{2}{*}{$\begin{array}{c}\text { Std. Mean Difference } \\
\text { Random, } 95 \% \mathrm{Cl}\end{array}$} \\
\hline & $\mathbf{N}$ & $\operatorname{Mean}(S D)$ & $\mathbf{N}$ & $\operatorname{Mean}(S D)$ & & & \\
\hline Man 1986 & 24 & $3(0.8)$ & 24 & $3(0.8)$ & 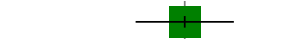 & $75.35 \%$ & $0[-0.57,0.57]$ \\
\hline Shivaram 1989 & 8 & $3.6(1.9)$ & 8 & $3(1.6)$ & I & $24.65 \%$ & $0.34[-0.65,1.33]$ \\
\hline 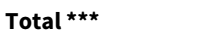 & 32 & & 32 & & & $100 \%$ & $0.08[-0.41,0.57]$ \\
\hline \multicolumn{8}{|c|}{ Heterogeneity: $\operatorname{Tau}^{2}=0 ; \mathrm{Chi}^{2}=0.34, \mathrm{df}=1(\mathrm{P}=0.56) ; \mathrm{I}^{2}=0 \%$} \\
\hline
\end{tabular}

Analysis 3.2. Comparison 3 Intervention, Outcome 2 Benzodiazepines - diazepam.

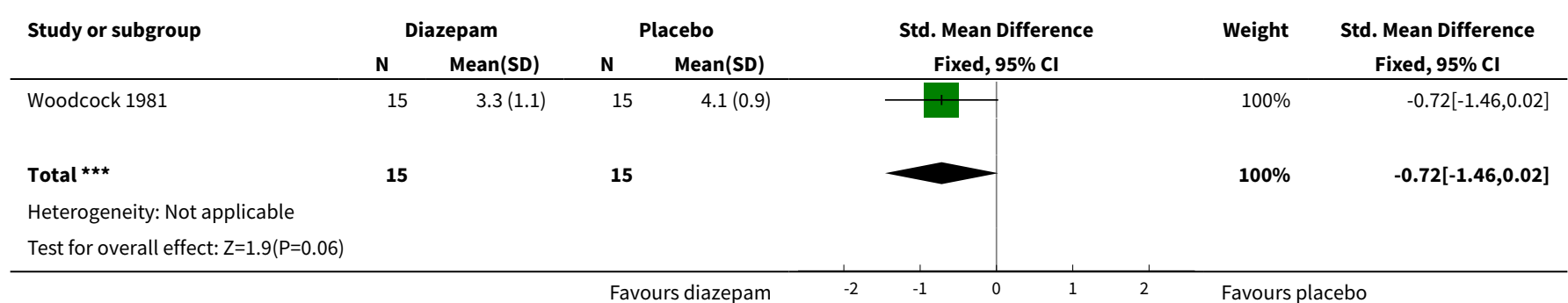

Analysis 3.3. Comparison 3 Intervention, Outcome 3 Benzodiazepines - midazolam.



Analysis 3.4. Comparison 3 Intervention, Outcome 4 Benzodiazepines - temazepam.

\begin{tabular}{|c|c|c|c|c|c|c|c|}
\hline \multirow[t]{2}{*}{ Study or subgroup } & \multicolumn{2}{|c|}{ Temazepam } & \multicolumn{2}{|c|}{ Placebo } & \multirow{2}{*}{$\begin{array}{c}\text { Mean Difference } \\
\text { Fixed, } 95 \% \mathrm{Cl}\end{array}$} & \multirow[t]{2}{*}{ Weight } & \multirow{2}{*}{$\begin{array}{c}\text { Mean Difference } \\
\text { Fixed, } 95 \% \mathrm{Cl}\end{array}$} \\
\hline & $\mathbf{N}$ & Mean(SD) & $\mathbf{N}$ & $\operatorname{Mean}(S D)$ & & & \\
\hline Stege 2010 & 14 & $4.2(2.9)$ & 14 & $4.1(2.5)$ & & $100 \%$ & $0.1[-1.91,2.11]$ \\
\hline 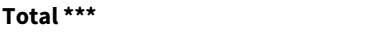 & 14 & & 14 & & & $100 \%$ & $0.1[-1.91,2.11]$ \\
\hline Heterogeneity: Not applicable & & & & & & & \\
\hline Test for overall effect: $Z=0.1(P=0.92)$ & & & & & & & \\
\hline
\end{tabular}


Analysis 3.5. Comparison 3 Intervention, Outcome 5 Benzodiazepines - ultra short-acting.

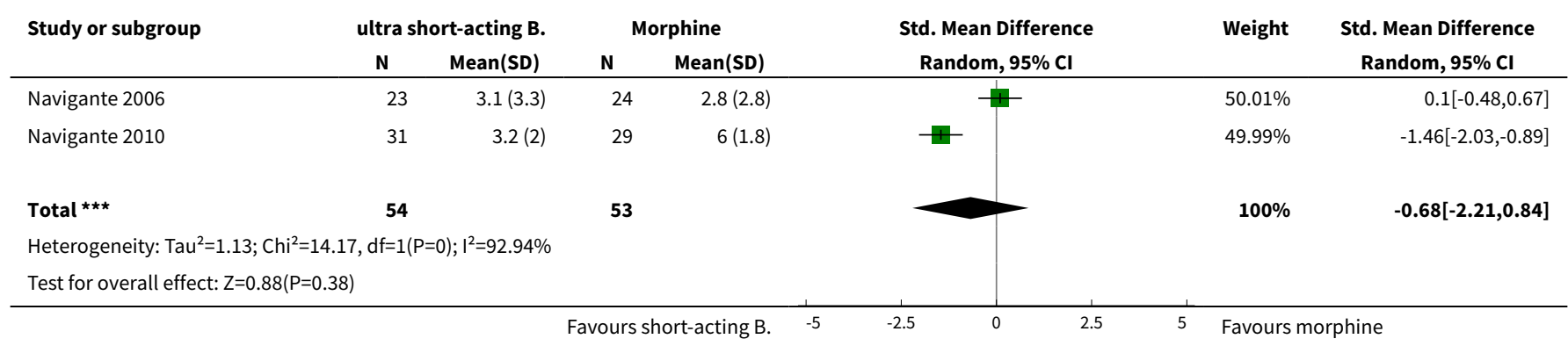

Analysis 3.6. Comparison 3 Intervention, Outcome 6 Benzodiazepines - intermediate-acting.

\begin{tabular}{|c|c|c|c|c|c|c|c|}
\hline \multirow[t]{2}{*}{ Study or subgroup } & \multicolumn{2}{|c|}{$\begin{array}{l}\text { Intermedi- } \\
\text { ate-acting B. }\end{array}$} & \multicolumn{2}{|c|}{ Placebo } & \multirow{2}{*}{$\begin{array}{l}\text { Std. Mean Difference } \\
\text { Random, } 95 \% \mathrm{Cl}\end{array}$} & \multirow[t]{2}{*}{ Weight } & \multirow{2}{*}{$\begin{array}{l}\text { Std. Mean Difference } \\
\text { Random, } 95 \% \mathrm{Cl}\end{array}$} \\
\hline & $\mathbf{N}$ & Mean(SD) & $\mathbf{N}$ & Mean(SD) & & & \\
\hline Harrison (unpublished) & 17 & $44.5(25.1)$ & 17 & $45.9(25.7)$ & 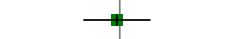 & $27.04 \%$ & $-0.06[-0.73,0.62]$ \\
\hline Man 1986 & 24 & $3(0.8)$ & 24 & $3(0.8)$ & & $38.19 \%$ & $0[-0.57,0.57]$ \\
\hline Shivaram 1989 & 8 & $3.6(1.9)$ & 8 & $3(1.6)$ & & $12.49 \%$ & $0.34[-0.65,1.33]$ \\
\hline Stege 2010 & 14 & $4.2(2.9)$ & 14 & $4.1(2.5)$ & $\longrightarrow$ & $22.27 \%$ & $0.04[-0.71,0.78]$ \\
\hline Total $\star \star \star ~$ & 63 & & 63 & & & $100 \%$ & $0.04[-0.31,0.38]$ \\
\hline \multicolumn{8}{|c|}{ Heterogeneity: $\mathrm{Tau}^{2}=0 ; \mathrm{Chi}^{2}=0.44, \mathrm{df}=3(\mathrm{P}=0.93) ; \mathrm{I}^{2}=0 \%$} \\
\hline \multicolumn{8}{|c|}{ Test for overall effect: $Z=0.2(P=0.84)$} \\
\hline
\end{tabular}

Analysis 3.7. Comparison 3 Intervention, Outcome 7 Benzodiazepines - long-acting.

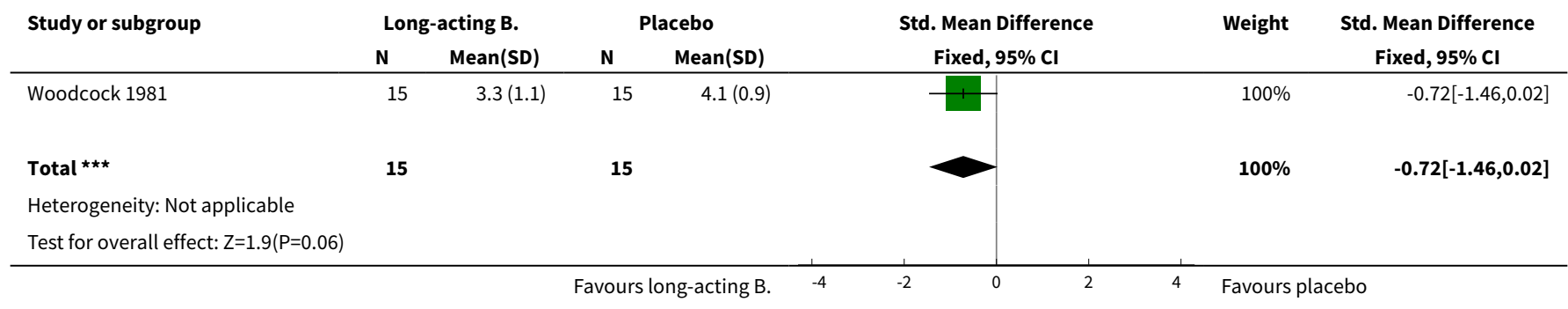

Analysis 3.8. Comparison 3 Intervention, Outcome 8 Benzodiazepines - short duration of treatment ( $\leqq 24$ hours).

\begin{tabular}{|c|c|c|c|c|c|c|c|}
\hline \multirow[t]{2}{*}{ Study or subgroup } & \multicolumn{2}{|c|}{$\begin{array}{l}\text { Benzodiazepine } \\
\leqq 24 \text { hours }\end{array}$} & \multicolumn{2}{|c|}{ Morphine } & \multirow{2}{*}{$\begin{array}{c}\text { Std. Mean Difference } \\
\text { Fixed, } 95 \% \mathrm{Cl} \\
\end{array}$} & \multirow[t]{2}{*}{ Weight } & \multirow{2}{*}{$\begin{array}{c}\text { Std. Mean Difference } \\
\text { Fixed, } 95 \% \mathrm{Cl} \\
\end{array}$} \\
\hline & $\mathbf{N}$ & Mean(SD) & $\mathbf{N}$ & Mean(SD) & & & \\
\hline Navigante 2006 & 26 & $4.1(3.2)$ & 29 & $3.9(2.9)$ & 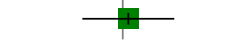 & $49.29 \%$ & $0.06[-0.46,0.59]$ \\
\hline Navigante 2010 & 31 & $4.6(2.5)$ & 30 & $6.4(2.1)$ & 1 & $50.71 \%$ & $-0.78[-1.3,-0.26]$ \\
\hline
\end{tabular}




\begin{tabular}{|c|c|c|c|c|c|c|c|c|}
\hline \multirow[t]{2}{*}{ Study or subgroup } & \multicolumn{2}{|c|}{$\begin{array}{l}\text { Benzodiazepine } \\
\leqq 24 \text { hours }\end{array}$} & \multicolumn{2}{|c|}{ Morphine } & \multirow{2}{*}{\multicolumn{2}{|c|}{$\begin{array}{c}\text { Std. Mean Difference } \\
\text { Fixed, } 95 \% \mathrm{Cl} \\
\end{array}$}} & \multirow[t]{2}{*}{ Weight } & \multirow{2}{*}{$\begin{array}{l}\text { Std. Mean Difference } \\
\text { Fixed, } 95 \% \mathrm{Cl}\end{array}$} \\
\hline & $\mathbf{N}$ & $\operatorname{Mean}(\mathrm{SD})$ & $\mathbf{N}$ & $\operatorname{Mean}(S D)$ & & & & \\
\hline 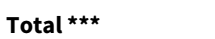 & 57 & & 5 & & & & $100 \%$ & $-0.36[-0.74,0.01]$ \\
\hline \multicolumn{9}{|c|}{ Heterogeneity: $\mathrm{Tau}^{2}=0 ; \mathrm{Chi}^{2}=4.97, \mathrm{df}=1(\mathrm{P}=0.03) ; \mathrm{I}^{2}=79.86 \%$} \\
\hline \multicolumn{9}{|c|}{ Test for overall effect: $Z=1.92(P=0.05)$} \\
\hline
\end{tabular}

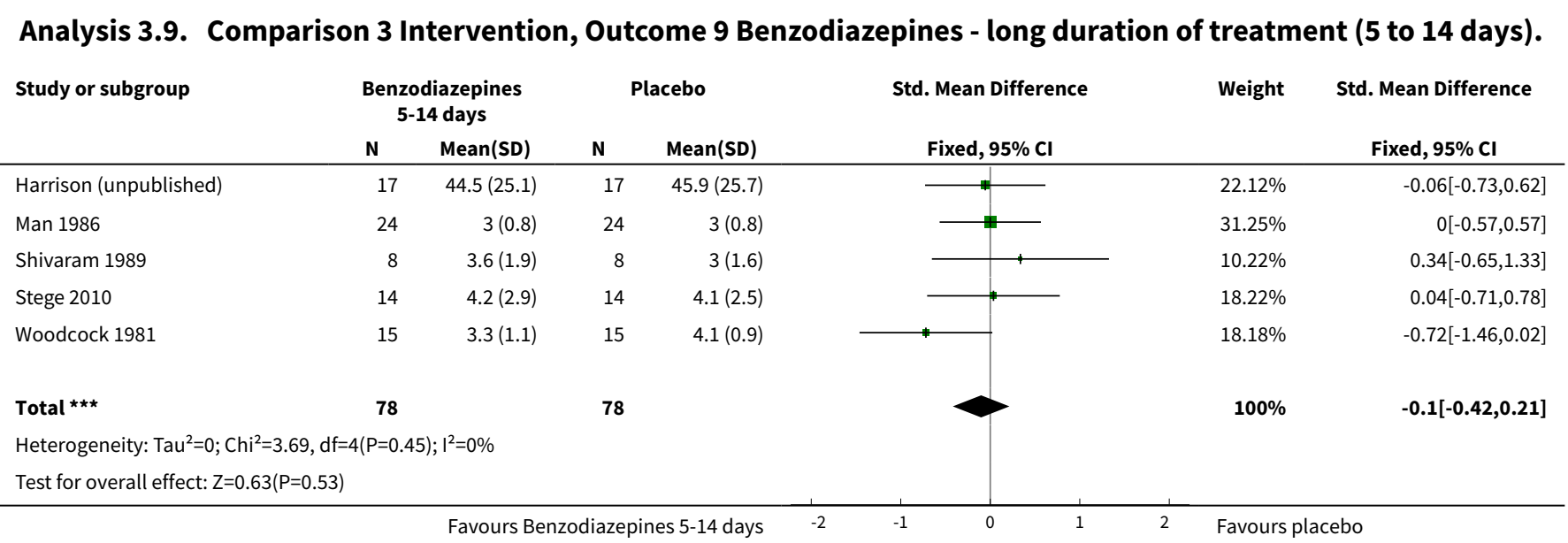

Analysis 3.10. Comparison 3 Intervention, Outcome 10 Benzodiazepines - morphine + midazolam-controlled.



Analysis 3.11. Comparison 3 Intervention, Outcome 11 Benzodiazepines - promethazine-controlled.

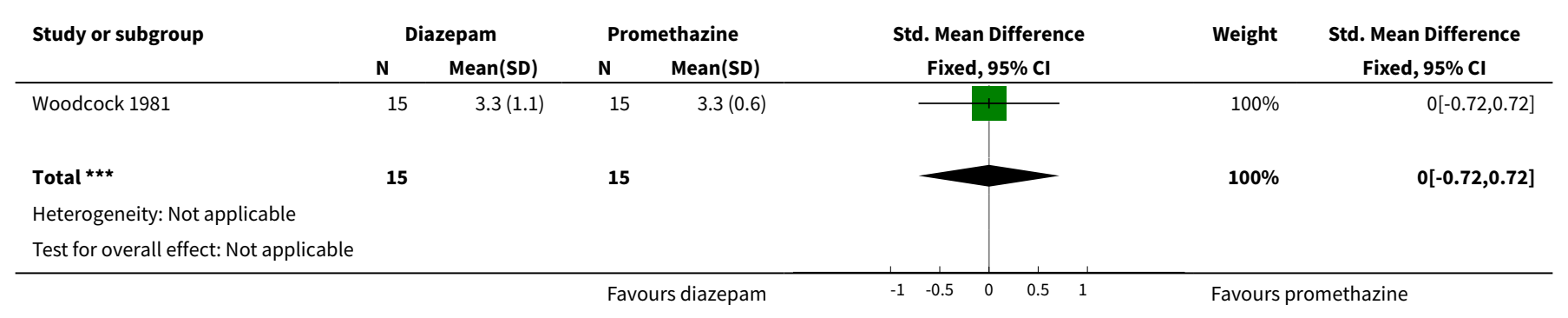


Comparison 4. Primary outcome

\begin{tabular}{|c|c|c|c|c|}
\hline Outcome or subgroup title & $\begin{array}{l}\text { No. of } \\
\text { studies }\end{array}$ & $\begin{array}{l}\text { No. of } \\
\text { partici- } \\
\text { pants }\end{array}$ & Statistical method & Effect size \\
\hline $\begin{array}{l}1 \text { Breathlessness - no relief (placebo-con- } \\
\text { trolled) }\end{array}$ & 2 & 50 & Risk Ratio (M-H, Random, 95\% Cl) & $0.88[0.56,1.39]$ \\
\hline $\begin{array}{l}2 \text { Breathlessness - no relief (mor- } \\
\text { phine-controlled) }\end{array}$ & 1 & 55 & Risk Ratio (M-H, Random, 95\% Cl) & $1.74[0.91,3.32]$ \\
\hline 3 Breathlessness - episodic after 48 hours & 2 & 108 & Risk Ratio (M-H, Random, 95\% Cl) & $0.76[0.53,1.09]$ \\
\hline 4 Breathlessness - episodic after 24 hours & 2 & 116 & Risk Ratio (M-H, Random, 95\% Cl) & $0.97[0.71,1.34]$ \\
\hline
\end{tabular}

Analysis 4.1. Comparison 4 Primary outcome, Outcome 1 Breathlessness - no relief (placebo-controlled).

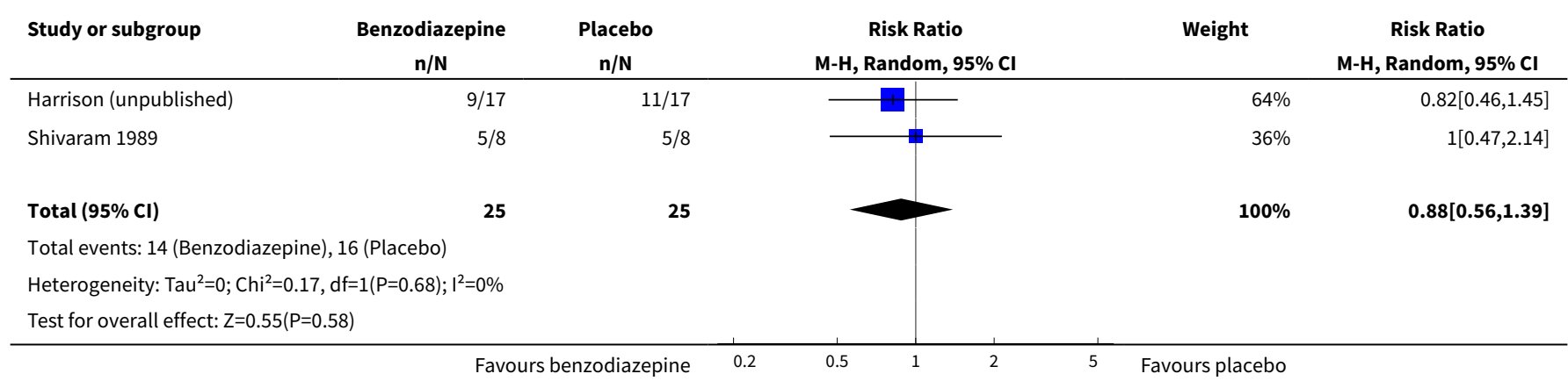

Analysis 4.2. Comparison 4 Primary outcome, Outcome 2 Breathlessness - no relief (morphine-controlled).

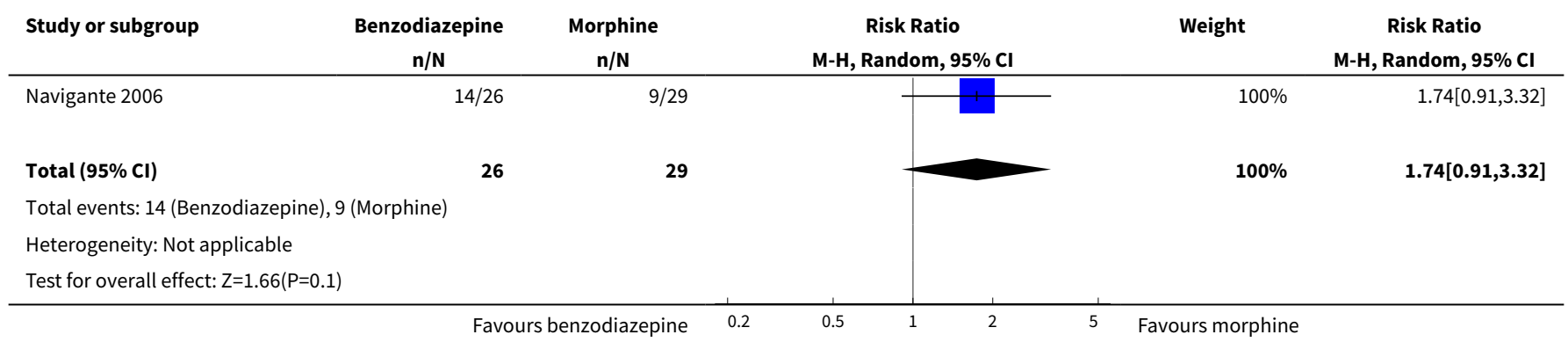

Analysis 4.3. Comparison 4 Primary outcome, Outcome 3 Breathlessness - episodic after 48 hours.

\begin{tabular}{|c|c|c|c|c|c|}
\hline Study or subgroup & $\begin{array}{c}\text { Benzodiazepine } \\
\mathrm{n} / \mathrm{N} \\
\end{array}$ & $\begin{array}{c}\text { Morphine } \\
\mathrm{n} / \mathrm{N} \\
\end{array}$ & $\begin{array}{c}\text { Risk Ratio } \\
\text { M-H, Random, 95\% Cl }\end{array}$ & Weight & $\begin{array}{c}\text { Risk Ratio } \\
\text { M-H, Random, } 95 \% \mathrm{Cl}\end{array}$ \\
\hline Navigante 2006 & $10 / 23$ & $11 / 24$ & 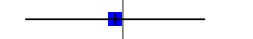 & $31.53 \%$ & $0.95[0.5,1.79]$ \\
\hline
\end{tabular}




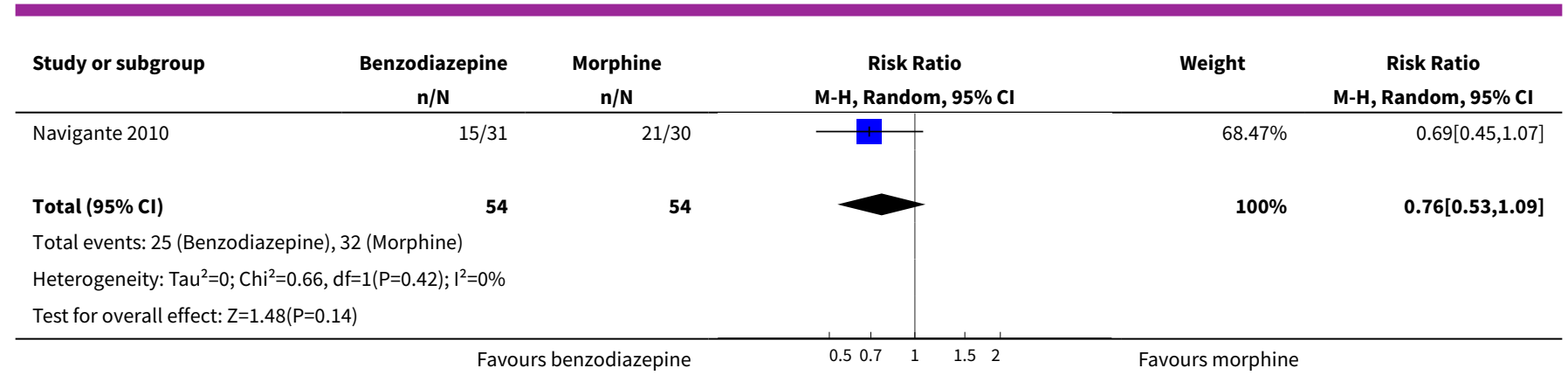

Analysis 4.4. Comparison 4 Primary outcome, Outcome 4 Breathlessness - episodic after 24 hours.

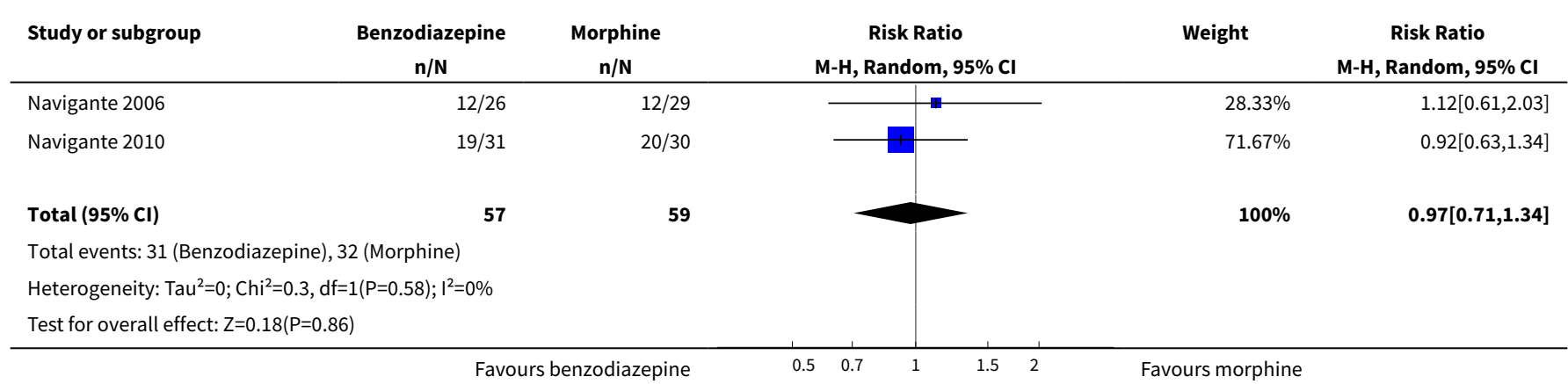

\section{Comparison 5. Secondary outcomes}

\begin{tabular}{|c|c|c|c|c|}
\hline Outcome or subgroup title & $\begin{array}{l}\text { No. of } \\
\text { studies }\end{array}$ & $\begin{array}{l}\text { No. of } \\
\text { partici- } \\
\text { pants }\end{array}$ & Statistical method & Effect size \\
\hline $\begin{array}{l}1 \text { Adverse effects (placebo-con- } \\
\text { trolled) }\end{array}$ & 4 & 66 & Risk Difference (M-H, Random, 95\% Cl) & $0.44[-0.06,0.94]$ \\
\hline $\begin{array}{l}2 \text { Adverse effects (morphine-con- } \\
\text { trolled) }\end{array}$ & 2 & 194 & Risk Difference (M-H, Random, 95\% Cl) & $-0.18[-0.31,-0.04]$ \\
\hline $\begin{array}{l}3 \text { Adverse effects - clinical rele- } \\
\text { vance only (morphine-controlled) }\end{array}$ & 2 & 54 & Risk Difference (M-H, Random, 95\% Cl) & $-0.49[-0.72,-0.25]$ \\
\hline $\begin{array}{l}4 \text { Adverse effects - drowsiness and } \\
\text { somnolence only (placebo-con- } \\
\text { trolled) }\end{array}$ & 3 & 38 & Risk Difference (M-H, Random, 95\% Cl) & $0.74[0.37,1.11]$ \\
\hline $\begin{array}{l}5 \text { Adverse effects - drowsiness and } \\
\text { somnolence only (morphine-con- } \\
\text { trolled) }\end{array}$ & 2 & 122 & Risk Difference (M-H, Random, 95\% Cl) & $-0.07[-0.30,0.16]$ \\
\hline 6 Attrition (placebo-controlled) & 4 & 146 & Risk Difference (M-H, Random, 95\% Cl) & $-0.09[-0.23,0.05]$ \\
\hline 7 Attrition (morphine-controlled) & 2 & 131 & Risk Difference (M-H, Random, 95\% Cl) & $-0.00[-0.08,0.08]$ \\
\hline 8 Deaths (placebo-controlled) & 4 & 120 & Risk Difference (M-H, Random, 95\% Cl) & $-0.01[-0.06,0.05]$ \\
\hline
\end{tabular}




\begin{tabular}{llllll}
\hline Outcome or subgroup title & $\begin{array}{l}\text { No. of } \\
\text { studies }\end{array}$ & $\begin{array}{l}\text { No. of } \\
\text { partici- } \\
\text { pants }\end{array}$ & Statistical method & Effect size \\
\hline 9 Deaths (morphine-controlled) & 2 & 131 & Risk Difference (M-H, Random, 95\% Cl) & $-0.00[-0.06,0.06]$ \\
\hline
\end{tabular}

Analysis 5.1. Comparison 5 Secondary outcomes, Outcome 1 Adverse effects (placebo-controlled).

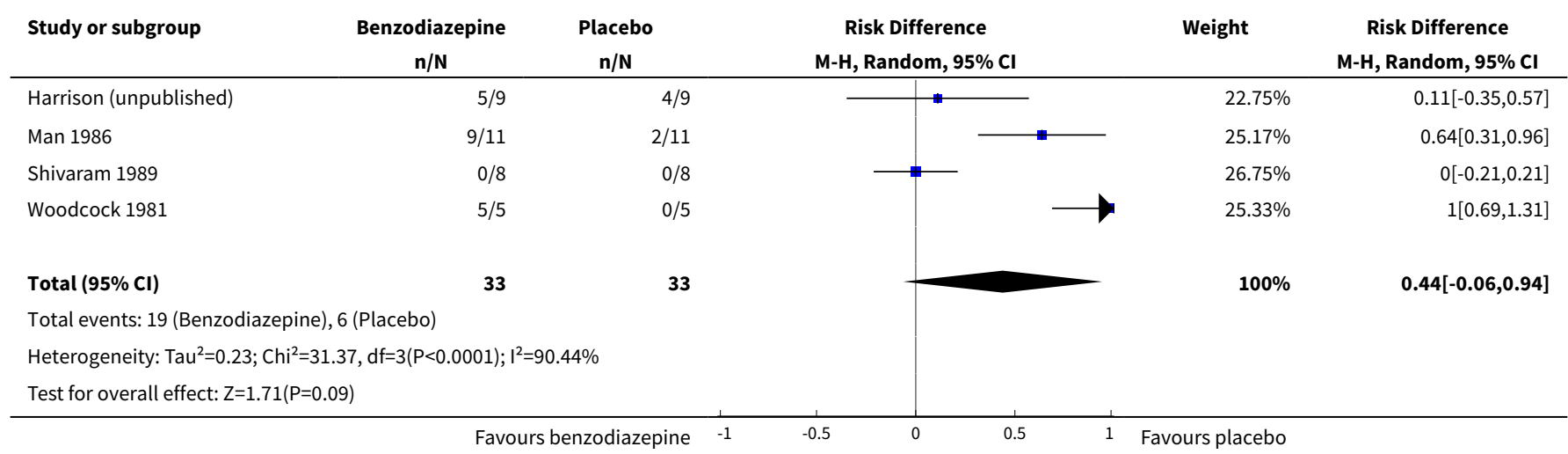

Analysis 5.2. Comparison 5 Secondary outcomes, Outcome 2 Adverse effects (morphine-controlled).

\begin{tabular}{|c|c|c|c|c|c|}
\hline Study or subgroup & $\begin{array}{c}\text { Benzodiazepine } \\
\mathrm{n} / \mathrm{N}\end{array}$ & $\begin{array}{c}\text { Morphine } \\
\mathrm{n} / \mathrm{N}\end{array}$ & $\begin{array}{c}\text { Risk Difference } \\
\text { M-H, Random, 95\% Cl }\end{array}$ & Weight & $\begin{array}{c}\text { Risk Difference } \\
\text { M-H, Random, } 95 \% \mathrm{CI}\end{array}$ \\
\hline Navigante 2006 & $15 / 34$ & $19 / 34$ & $\longrightarrow-$ & $34.38 \%$ & $-0.12[-0.35,0.12]$ \\
\hline Navigante 2010 & $25 / 63$ & $38 / 63$ & - & $65.62 \%$ & $-0.21[-0.38,-0.04]$ \\
\hline Total $(95 \% \mathrm{Cl})$ & 97 & 97 & & $100 \%$ & $-0.18[-0.31,-0.04]$ \\
\hline \multicolumn{6}{|c|}{ Total events: 40 (Benzodiazepine), 57 (Morphine) } \\
\hline \multicolumn{6}{|c|}{ Heterogeneity: $\mathrm{Tau}^{2}=0 ; \mathrm{Chi}^{2}=0.36, \mathrm{df}=1(\mathrm{P}=0.55) ; \mathrm{I}^{2}=0 \%$} \\
\hline \multicolumn{6}{|c|}{ Test for overall effect: $Z=2.49(P=0.01)$} \\
\hline
\end{tabular}

Analysis 5.3. Comparison 5 Secondary outcomes, Outcome 3 Adverse effects - clinical relevance only (morphine-controlled).

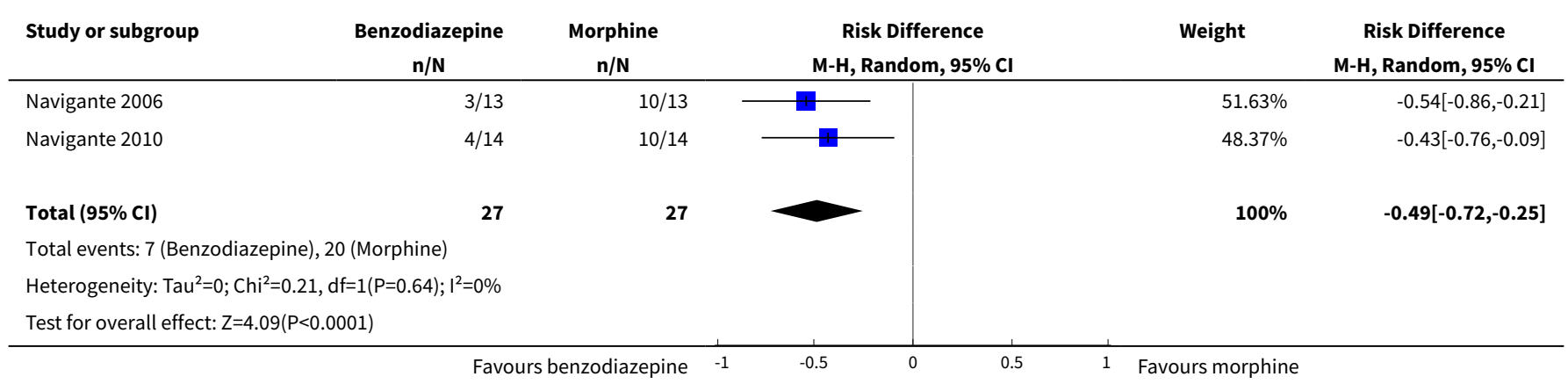


Analysis 5.4. Comparison 5 Secondary outcomes, Outcome 4 Adverse effects - drowsiness and somnolence only (placebo-controlled).

\begin{tabular}{|c|c|c|c|c|c|}
\hline Study or subgroup & $\begin{array}{c}\text { Benzodiazepine } \\
\mathrm{n} / \mathrm{N} \\
\end{array}$ & $\begin{array}{c}\text { Placebo } \\
\mathrm{n} / \mathrm{N}\end{array}$ & $\begin{array}{c}\text { Risk Difference } \\
\text { M-H, Random, } 95 \% \mathrm{Cl}\end{array}$ & Weight & $\begin{array}{c}\text { Risk Difference } \\
\text { M-H, Random, } 95 \% \mathrm{Cl}\end{array}$ \\
\hline Harrison (unpublished) & $4 / 6$ & $2 / 6$ & \begin{tabular}{l|l} 
&
\end{tabular} & $24.93 \%$ & $0.33[-0.2,0.87]$ \\
\hline Man 1986 & $7 / 8$ & $1 / 8$ & & $37.16 \%$ & $0.75[0.43,1.07]$ \\
\hline Woodcock 1981 & $5 / 5$ & $0 / 5$ & & $37.91 \%$ & $1[0.69,1.31]$ \\
\hline Total $(95 \% \mathrm{Cl})$ & 19 & 19 & & $100 \%$ & $0.74[0.37,1.11]$ \\
\hline \multicolumn{6}{|c|}{ Heterogeneity: $\mathrm{Tau}^{2}=0.07 ; \mathrm{Chi}^{2}=5.74, \mathrm{df}=2(\mathrm{P}=0.06) ; \mathrm{I}^{2}=65.14 \%$} \\
\hline \multicolumn{6}{|c|}{ Test for overall effect: $Z=3.94(P<0.0001)$} \\
\hline
\end{tabular}

Analysis 5.5. Comparison 5 Secondary outcomes, Outcome 5 Adverse effects - drowsiness and somnolence only (morphine-controlled).

\begin{tabular}{|c|c|c|c|c|c|}
\hline Study or subgroup & $\begin{array}{c}\text { Benzodiazepine } \\
\mathrm{n} / \mathrm{N}\end{array}$ & $\begin{array}{c}\text { Morphine } \\
\mathrm{n} / \mathrm{N}\end{array}$ & $\begin{array}{c}\text { Risk Difference } \\
\text { M-H, Random, } 95 \% \text { CI }\end{array}$ & Weight & $\begin{array}{c}\text { Risk Difference } \\
\text { M-H, Random, } 95 \% \mathrm{Cl}\end{array}$ \\
\hline Navigante 2006 & $7 / 18$ & $11 / 18$ & 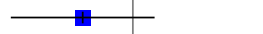 & $37.74 \%$ & $-0.22[-0.54,0.1]$ \\
\hline Navigante 2010 & $22 / 43$ & $21 / 43$ & + & $62.26 \%$ & $0.02[-0.19,0.23]$ \\
\hline Total $(95 \% \mathrm{Cl})$ & 61 & 61 & & $100 \%$ & $-0.07[-0.3,0.16]$ \\
\hline \multicolumn{6}{|c|}{ Total events: 29 (Benzodiazepine), 32 (Morphine) } \\
\hline Test for overall effec & & & & & \\
\hline
\end{tabular}

\section{Analysis 5.6. Comparison 5 Secondary outcomes, Outcome 6 Attrition (placebo-controlled).}

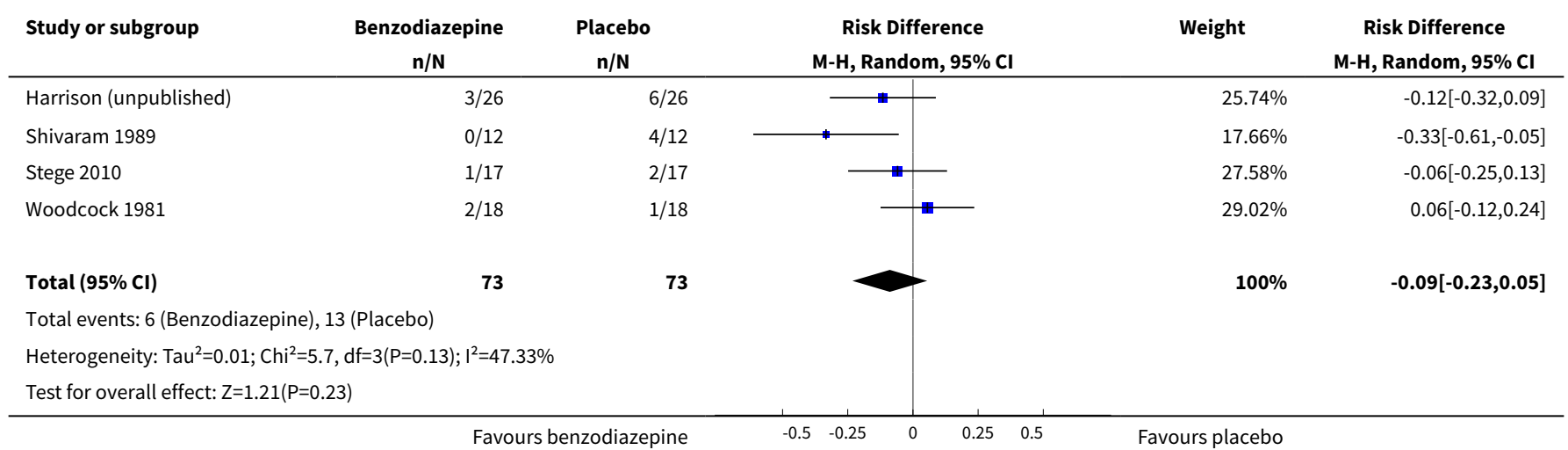


Analysis 5.7. Comparison 5 Secondary outcomes, Outcome 7 Attrition (morphine-controlled).

\begin{tabular}{|c|c|c|c|c|c|}
\hline Study or subgroup & $\begin{array}{c}\text { Benzodiazepine } \\
\mathrm{n} / \mathrm{N}\end{array}$ & $\begin{array}{c}\text { Morphine } \\
\mathrm{n} / \mathrm{N}\end{array}$ & $\begin{array}{c}\text { Risk Difference } \\
\text { M-H, Random, } 95 \% \mathrm{CI}\end{array}$ & Weight & $\begin{array}{c}\text { Risk Difference } \\
\text { M-H, Random, } 95 \% \mathrm{CI}\end{array}$ \\
\hline Navigante 2006 & $10 / 33$ & $11 / 35$ & & $13.46 \%$ & $-0.01[-0.23,0.21]$ \\
\hline Navigante 2010 & $1 / 32$ & $1 / 31$ & & $86.54 \%$ & $-0[-0.09,0.09]$ \\
\hline Total $(95 \% \mathrm{CI})$ & 65 & 66 & & $100 \%$ & $-0[-0.08,0.08]$ \\
\hline \multicolumn{6}{|c|}{ Total events: 11 (Benzodiazepine), 12 (Morphine) } \\
\hline Test for overall effect & & & & & \\
\hline
\end{tabular}

$\begin{array}{lllllll}\text { Favours benzodiazepine } & -0.2 & -0.1 & 0 & 0.1 & 0.2 & \text { Favours morphine }\end{array}$

Analysis 5.8. Comparison 5 Secondary outcomes, Outcome 8 Deaths (placebo-controlled).



Analysis 5.9. Comparison 5 Secondary outcomes, Outcome 9 Deaths (morphine-controlled).

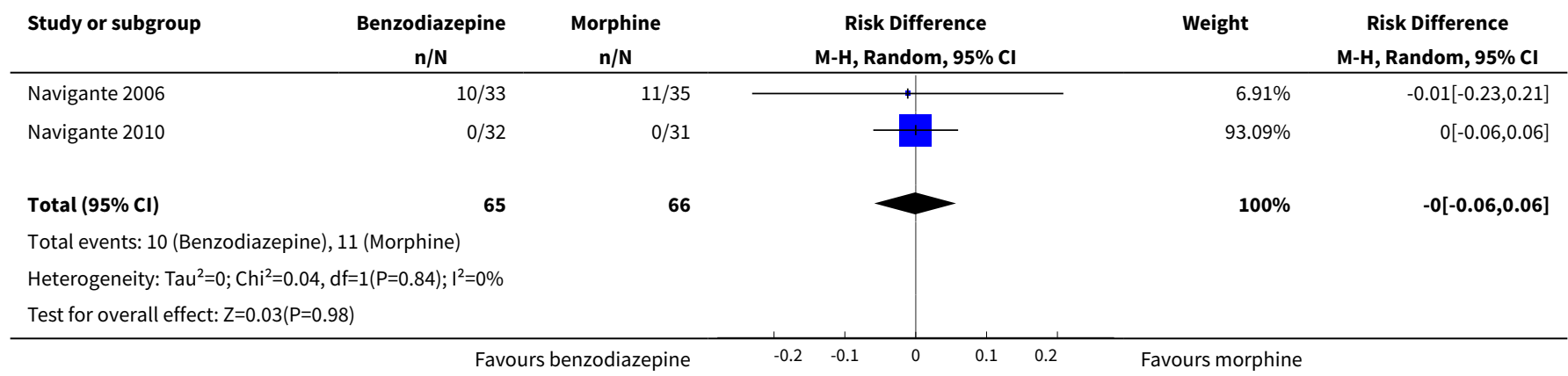

\section{APPENDICES}

\section{Appendix 1. Search strategies used for the original review}

MEDLINE search strategy via OVID

1. exp dyspnea

2. dyspn\$.mp.

Benzodiazepines for the relief of breathlessness in advanced malignant and non-malignant diseases in adults (Review)

Copyright @ 2016 The Cochrane Collaboration. Published by John Wiley \& Sons, Ltd. 
3. breathing adj3 labour\$

4. breathless\$.mp.

5. shortness of breath.mp.

6. breathing difficult\$.mp.

7. 1 or 2 or 3 or 4 or 5 or 6

8. exp benzodiazepines

9. benzodiazepine\$.mp.

10. adinazolam or alprazolam or bentazepam or bromazepam or brotizolam or chlordiazepoxide or cinolazepam or clobazam or clonazepam or clorazepate or clotiazepam or cloxazolam or delorazepam or demoxepam or desmethyldiazepam or diazepam or estazolam or etizolam or etozolam or fludiazepam or flunitrazepam or flurazepam or flutoprazepam or halazepam or haloxazolam or ketazolam or loprazolam or lorazepam or lormetazepam or medazepam or metaclazepam or mexazolam or midazolam or nimetazepam or nitrazepam or nordazepam or oxazepam or oxazolam or pinazepam or prazepam or quazepam or temazepam or tetrazepam or tofisopam or triazolam 11. 8 or 9 or 10

12. 7 AND 11

\section{EMBASE search strategy via OVID}

\section{1. exp DYSPNEA}

2. dyspn\$.mp.

3. breathing adj3 labour\$

4. breathless\$.mp.

5. shortness of breath.mp.

6. breathing difficult\$.mp.

7. 1 or 2 or 3 or 4 or 5 or 6

8. exp Benzodiazepine Derivative

9. benzodiazepine\$.mp.

10. adinazolam or alprazolam or bentazepam or bromazepam or brotizolam or chlordiazepoxide or cinolazepam or clobazam or clonazepam or clorazepate or clotiazepam or cloxazolam or delorazepam or demoxepam or desmethyldiazepam or diazepam or estazolam or etizolam or etozolam or fludiazepam or flunitrazepam or flurazepam or flutoprazepam or halazepam or haloxazolam or ketazolam or loprazolam or lorazepam or lormetazepam or medazepam or metaclazepam or mexazolam or midazolam or nimetazepam or nitrazepam or nordazepam or oxazepam or oxazolam or pinazepam or prazepam or quazepam or temazepam or tetrazepam or tofisopam or triazolam 11.8 or 9 or 10

\section{7 AND 11}

\section{CINAHL search strategy via OVID}

1. MH "dyspnea+"

2. dyspn*

3. breathing N3 labour*

4. breathless ${ }^{\star}$

5. shortness of breath

6. breathing difficult ${ }^{*}$

7. 1 or 2 or 3 or 4 or 5 or 6

8. MH "Anxiety Agents, Benzodiazepine+"

9. benzodiazepine

10. adinazolam or alprazolam or bentazepam or bromazepam or brotizolam or chlordiazepoxide or cinolazepam or clobazam or clonazepam or clorazepate or clotiazepam or cloxazolam or delorazepam or demoxepam or desmethyldiazepam or diazepam or estazolam or etizolam or etozolam or fludiazepam or flunitrazepam or flurazepam or flutoprazepam or halazepam or haloxazolam or ketazolam or loprazolam or lorazepam or lormetazepam or medazepam or metaclazepam or mexazolam or midazolam or nimetazepam or nitrazepam or nordazepam or oxazepam or oxazolam or pinazepam or prazepam or quazepam or temazepam or tetrazepam or tofisopam or triazolam 11.8 or 9 or 10

12. 7 AND 11

\section{PsycINFO search strategy via OVID}

\section{1. exp DYSPNEA}

2. dyspn\$.mp.

3. breathing adj3 labour\$

4. breathless\$.mp.

5. shortness of breath.mp.

6. breathing difficult\$.mp.

7. 1 or 2 or 3 or 4 or 5 or 6

8. exp BENZODIAZEPINES

Benzodiazepines for the relief of breathlessness in advanced malignant and non-malignant diseases in adults (Review) 
9. benzodiazepine\$.mp.

10. adinazolam or alprazolam or bentazepam or bromazepam or brotizolam or chlordiazepoxide or cinolazepam or clobazam or clonazepam or clorazepate or clotiazepam or cloxazolam or delorazepam or demoxepam or desmethyldiazepam or diazepam or estazolam or etizolam or etozolam or fludiazepam or flunitrazepam or flurazepam or flutoprazepam or halazepam or haloxazolam or ketazolam or loprazolam or lorazepam or lormetazepam or medazepam or metaclazepam or mexazolam or midazolam or nimetazepam or nitrazepam or nordazepam or oxazepam or oxazolam or pinazepam or prazepam or quazepam or temazepam or tetrazepam or tofisopam or triazolam 11. 8 or 9 or 10

12. 7 AND 11

\section{CENTRAL search strategy}

\#1 MeSH descriptor Dyspnea explode all trees

\#2 dyspn*

\#3 breathing adj3 labour*

\#4 breathless*

\#5 shortness of breath

\#6 breathing difficult*

\#7 1 or 2 or 3 or 4 or 5 or 6

\#8 exp benzodiazepines

\#9 benzodiazepine ${ }^{*}$

\#10 adinazolam or alprazolam or bentazepam or bromazepam or brotizolam or chlordiazepoxide or cinolazepam or clobazam or clonazepam or clorazepate or clotiazepam or cloxazolam or delorazepam or demoxepam or desmethyldiazepam or diazepam or estazolam or etizolam or etozolam or fludiazepam or flunitrazepam or flurazepam or flutoprazepam or halazepam or haloxazolam or ketazolam or loprazolam or lorazepam or lormetazepam or medazepam or metaclazepam or mexazolam or midazolam or nimetazepam or nitrazepam or nordazepam or oxazepam or oxazolam or pinazepam or prazepam or quazepam or temazepam or tetrazepam or tofisopam or triazolam \#11 8 or 9 or 10

\#12 7 AND 11

\section{PaPaS Register search strategy}

((dyspn* or (breathing AND (laboured or labored)) or breathless* or "shortness of breath" or "breathing difficult*") AND (benzodiazepines or adinazolam or alprazolam or bentazepam or bromazepam or brotizolam or chlordiazepoxide or cinolazepam or clobazam or clonazepam or clorazepate or clotiazepam or cloxazolam or delorazepam or demoxepam or desmethyldiazepam or diazepam or estazolam or etizolam or etozolam or fludiazepam or flunitrazepam or flurazepam or flutoprazepam or halazepam or haloxazolam or ketazolam or loprazolam or lorazepam or lormetazepam or medazepam or metaclazepam or mexazolam or midazolam or nimetazepam or nitrazepam or nordazepam or oxazepam or oxazolam or pinazepam or prazepam or quazepam or temazepam or tetrazepam or tofisopam or triazolam))

\section{Search strategy for Cochrane DSR, ACP Journal Club, DARE, CCTR, CMR, HTA, and NHSEED via OVID}

1. dyspn\$.mp.

2. breathing adj3 labour\$

3. breathless\$.mp.

4. shortness of breath.mp.

5. breathing difficult\$.mp.

6. 1 or 2 or 3 or 4 or 5

7. benzodiazepine\$.mp.

8. adinazolam or alprazolam or bentazepam or bromazepam or brotizolam or chlordiazepoxide or cinolazepam or clobazam or clonazepam or clorazepate or clotiazepam or cloxazolam or delorazepam or demoxepam or desmethyldiazepam or diazepam or estazolam or etizolam or etozolam or fludiazepam or flunitrazepam or flurazepam or flutoprazepam or halazepam or haloxazolam or ketazolam or loprazolam or lorazepam or lormetazepam or medazepam or metaclazepam or mexazolam or midazolam or nimetazepam or nitrazepam or nordazepam or oxazepam or oxazolam or pinazepam or prazepam or quazepam or temazepam or tetrazepam or tofisopam or triazolam 9.7 or 8

10. 6 AND 9

\section{Search strategy for lowa Drug Information System (IDIS) and International Pharmaceutical Abstracts}

((benzodiazepines or tetrazepam or diazepam or oxatepam or lorazepam or lormetazepam or clotiazepam or pinazepam or uldazepam or quazepam or temazepam or metaclazepam nordazepam or fludiazepam or flunitrazepam or halazepam or clonazepam or nitrazepam or zolazepam or flurazepam or flutoprazepam or prazepam or clazepam or meclonazepam or fosazepam or midazolam or medazepam or clotiazepam or doxefazepam or premazepam or camazepam or ritazepam or delorazepam or bentazepam or bromazepam) AND ((abnormality, resp \& dyspnea) or (apnea, unspecified))) 


\section{Appendix 2. Search strategy for the review update 2016}

\section{MEDLINE search strategy via OVID (update)}

1. exp dyspnea/

2. dyspn\$.mp.

3. (breathing adj3 labo?r\$).mp.

4. breathless\$.mp.

5. (short* adj2 breath).mp.

6. breathing difficult\$. mp.

7. or/1-6

8. exp benzodiazepines/

9. benzodiazepine\$.mp.

10. (adinazolam or alprazolam or bentazepam or bromazepam or brotizolam or chlordiazepoxide or cinolazepam or clobazam or clonazepam or clorazepate or clotiazepam or cloxazolam or delorazepam or demoxepam or desmethyldiazepam or diazepam or estazolam or etizolam or etozolam or fludiazepam or flunitrazepam or flurazepam or flutoprazepam or halazepam or haloxazolam or ketazolam or loprazolam or lorazepam or lormetazepam or medazepam or metaclazepam or mexazolam or midazolam or nimetazepam or nitrazepam or nordazepam or oxazepam or oxazolam or pinazepam or prazepam or quazepam or temazepam or tetrazepam or tofisopam or triazolam).mp.

11. or/8-10

12. 7 and 11

13. $\left(200909^{\star}\right.$ or $200910^{\star}$ or $200911^{\star}$ or $200912^{\star}$ or $2010^{\star}$ or $2011^{\star}$ or $2012^{\star}$ or $2013^{\star}$ or $2014^{\star}$ or $2015^{\star}$ or $\left.2016^{\star}\right)$.ed.

14. 12 and 13

\section{EMBASE search via OVID (update)}

1. exp dyspnea/

2. dyspn\$.mp.

3. (breathing adj3 labo?r\$).mp.

4. breathless\$.mp.

5. (short* adj2 breath).mp.

6. breathing difficult\$.mp.

7. or/1-6

8. exp Benzodiazepine Derivative/

9. benzodiazepine\$.mp.

10. (adinazolam or alprazolam or bentazepam or bromazepam or brotizolam or chlordiazepoxide or cinolazepam or clobazam or clonazepam or clorazepate or clotiazepam or cloxazolam or delorazepam or demoxepam or desmethyldiazepam or diazepam or estazolam or etizolam or etozolam or fludiazepam or flunitrazepam or flurazepam or flutoprazepam or halazepam or haloxazolam or ketazolam or loprazolam or lorazepam or lormetazepam or medazepam or metaclazepam or mexazolam or midazolam or nimetazepam or nitrazepam or nordazepam or oxazepam or oxazolam or pinazepam or prazepam or quazepam or temazepam or tetrazepam or tofisopam or triazolam).mp.

11. or/8-10

12. 7 and 11 
13. $\left(200909^{\star}\right.$ or $200910^{\star}$ or $200911^{\star}$ or $200912^{\star}$ or $2010^{\star}$ or $2011^{\star}$ or $2012^{\star}$ or $2013^{\star}$ or 2014 or $2015^{\star}$ or $\left.2016^{\star}\right)$.dd

\section{12 and 13}

\section{CENTRAL search strategy via the Cochrane Library (update)}

\#1 MeSH descriptor: [Dyspnea] explode all trees

\#2 dyspn*:ti,ab,kw (Word variations have been searched)

\#3 (breathing near/3 labo? $\left.{ }^{\star}\right): t i, a b, k w$ (Word variations have been searched)

\#4 breathless*:ti,ab,kw (Word variations have been searched)

\#5 (short* near/2 breath):ti,ab,kw (Word variations have been searched)

\#6 breathing difficult*:ti,ab,kw (Word variations have been searched)

$\# 7$ \#1 or \#2 or \#3 or \#4 or \#5 or \#6

\#8 MeSH descriptor: [Benzodiazepines] explode all trees

\#9 benzodiazepine*:ti,ab,kw (Word variations have been searched)

\#10 (adinazolam or alprazolam or bentazepam or bromazepam or brotizolam or chlordiazepoxide or cinolazepam or clobazam or clonazepam or clorazepate or clotiazepam or cloxazolam or delorazepam or demoxepam or desmethyldiazepam or diazepam or estazolam or etizolam or etozolam or fludiazepam or flunitrazepam or flurazepam or flutoprazepam or halazepam or haloxazolam or ketazolam or loprazolam or lorazepam or lormetazepam or medazepam or metaclazepam or mexazolam or midazolam or nimetazepam or nitrazepam or nordazepam or oxazepam or oxazolam or pinazepam or prazepam or quazepam or temazepam or tetrazepam or tofisopam or triazolam):ti,ab,kw (Word variations have been searched)

\#11 \#8 or \#9 or \#10

\section{WHAT'S NEW}

\begin{tabular}{lll}
\hline Date & Event & Description \\
\hline 21 October 2016 & Review declared as stable & See Published notes. \\
\hline
\end{tabular}

\section{H I S T O R Y}

Protocol first published: Issue 4, 2008

Review first published: Issue 1, 2010

\begin{tabular}{lll}
\hline Date & Event & Description \\
\hline 15 September 2016 & $\begin{array}{l}\text { New citation required but conclusions } \\
\text { have not changed }\end{array}$ & $\begin{array}{l}\text { We included one new study in the update, but the conclusion did } \\
\text { not change. We identified two studies awaiting assessment. }\end{array}$ \\
\hline 29 August 2016 & New search has been performed & $\begin{array}{l}\text { We updated this review to include the results of new search (Au- } \\
\text { gust 2016). We have added new 'Risk of bias' summary tables } \\
\text { and updated contact details. }\end{array}$
\end{tabular}

We have updated contact details.

\section{CONTRIBUTIONSOF AUTHORS}

All review authors contributed to the development of the idea for this review, revised the manuscript, and approved the final version. 
STS: developed and wrote the protocol, developed the search strategies and the data extraction form, searched for studies, obtained copies of the studies, extracted data from studies, entered data into RevMan, carried out analysis and meta-analysis, drafted the review and finalised it after discussion with the other review authors. Responsible for further updates.

$\mathrm{IJH}$ : discussed and approved the protocol, the search strategy, and the data extraction form, discussed the outcomes and analysis with the other review authors, and provided epidemiological and wider systematic review expertise.

SB: discussed and approved the protocol, the search strategy, and the data extraction form, checked extracted information from studies, discussed the outcomes and analysis with the other review authors.

$\mathrm{RH}$ : discussed and approved the protocol, the search strategy, and the data extraction form, discussed the outcomes and analysis with the other review authors, and provided social science expertise.

VW: searched for studies for the update, extracted data from studies for the update, entered data into RevMan for the update, contributed to the meta-analysis for the update, drafted the review update.

CB: supervised the protocol, contributed to the development of the search strategy and the data extraction form, searched the titles, extracted data from studies, supervised the analysis, discussed the outcomes and analysis with the other review authors, and provided wider systematic review expertise.

\section{DECLARATIONS OF INTEREST}

STS: none known. STS is a specialist in palliative care and works as a physician caring for patients with life-limiting diseases.

$\mathrm{IJH}$ : none known. IJH is a specialist in palliative care and works as a researcher and physician caring for patients with life-limiting diseases.

SB: none known. SB worked as a specialist in palliative care and and now supports patients with chronic illness.

$\mathrm{RH}$ : none known. $\mathrm{RH}$ is a reader in palliative care and works as a researcher in palliative care with focus on HIV/AIDS, Sub-Saharan Africa and Global Health.

VW received reimbursement of travel costs from Teva Pharmaceutical Industries Ltd. for the 8th World Research Congress of the European Association of Palliative Care (Lleida, Spain, 2014) outside the submitted work. VW is a health economist with experience in research in palliative care (2011-2015) and works as a research associate at an institute of quality and efficiency in health care (since 2015).

CB: none known. CB is a specialist in palliative care and works as a physician caring for patients with life-limiting diseases.

\section{SOURCES OF SUPPORT}

\section{Internal sources}

- Department of Palliative Care, Policy and Rehabilitation, King's College London, UK.

- Institute of Palliative Care, Germany.

- Department of Palliative Medicine, University Hospital of Cologne, Germany.

\section{External sources}

- The Werner Jackstaedt Foundation, Germany.

- The Federal Ministry of Education and Research (BMBF; 01KG1509), Germany.

Research grant for the conduction of the review update (2015)

\section{DIFFERENCES BETWEEN PROTOCOL AND REVIEW}

For the previous version of the review, we changed the title slightly by inserting 'advanced' in front of 'malignant'. This resulted in no changes to the included and excluded studies.

\section{NOTES}

A new search within two years is not likely to identify any potentially relevant studies likely to change the conclusions. Therefore, this review has now been stabilised following discussion with the authors and editors. If appropriate, we will update the review if new evidence likely to change the conclusions is published, or if standards change substantially which necessitate major revisions. 


\section{N D EX TERMS}

\section{Medical Subject Headings (MeSH)}

Benzodiazepines [adverse effects] [ ${ }^{\star}$ therapeutic use]; Dyspnea [ ${ }^{\star}$ drug therapy] [etiology]; Lung Neoplasms [ ${ }^{\star}$ complications]; Pulmonary Disease, Chronic Obstructive [*complications]; Randomized Controlled Trials as Topic

\section{MeSH check words}

Adult; Humans 